\title{
AN INVESTIGATION INTO THE GRADATION VARIABILITY OF AGGREGATES USED IN BASES
}

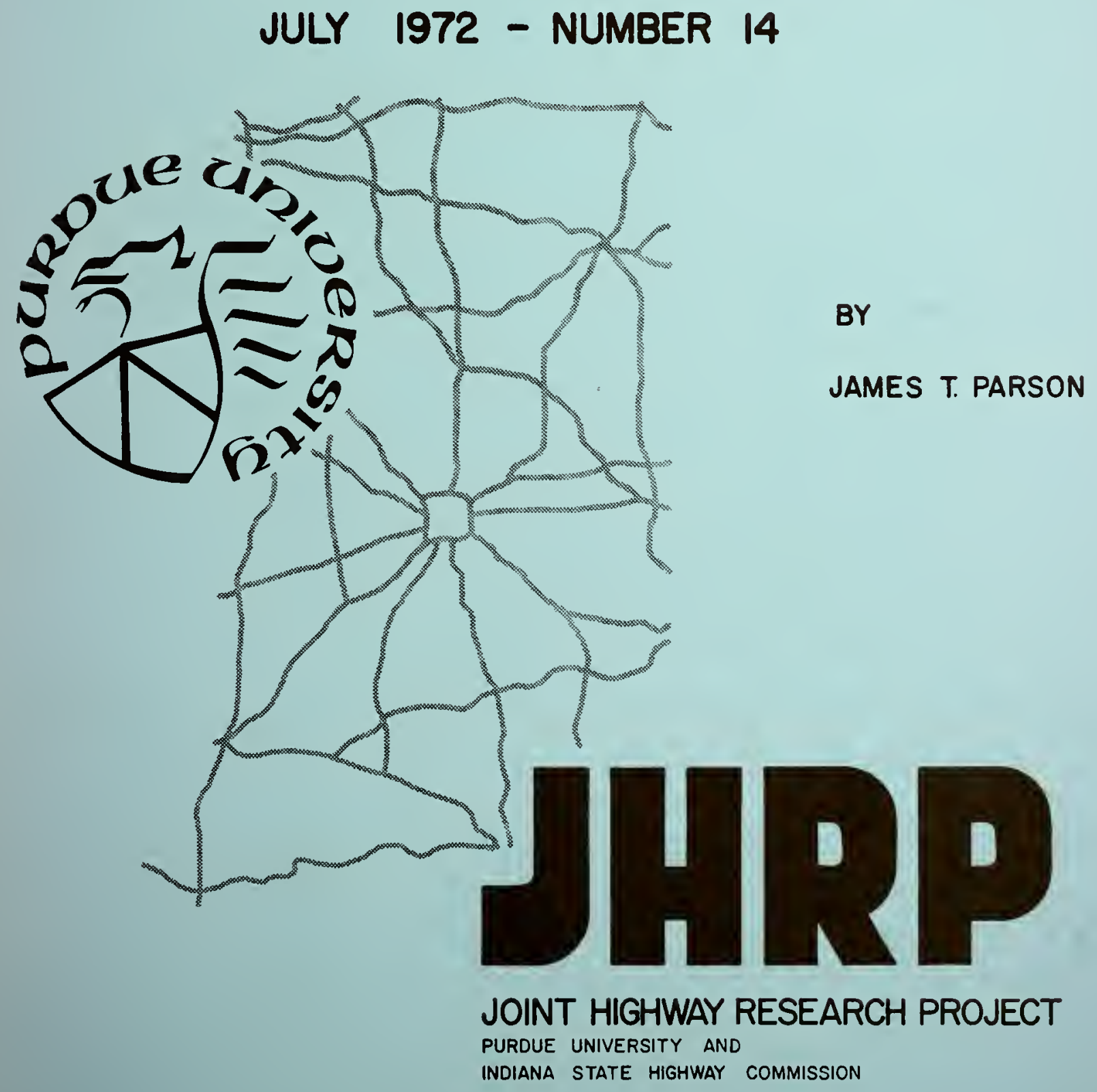





\section{Final Report}

AN INVESTIGATION INTO THE GRADATION VARIABILITY OF

AGGREGATES USED IN BASES

TO: J.F. Mclaughlin, Director Joint Highway Research Porject

FROM: H. L. Michael, Associate Director Joint Highway Research Project
July 26,1972

Project: $\quad$ C $-36-45 \mathrm{~L}$

File: $6-18-11$

Attached is a Final Report entitled "An Investigation into the Gradation Variability of Aggregates Used in Bases" by Mr. James T. Parson. This research is an HPR project and was conducted under the supervision of Professors E. J. Yoder and C. B. Monk. The primary purpose of this project was to determine changes in gradation that result in handling base course materials from the stockpile through the pug mill and to the job site. Variation between several sampling points was determined. The results indicate that, for the particular construction job siviled, sampling from the belt could be used as an indication of the final compacted samples on the road for the upper sieve ranges. However, in the lower sieve sizes, variation was noted from the belt samples to the job site samples.

This Final Report is submitted for acceptance as fulfillment of the objectives of this research.

Respectfully submitted,

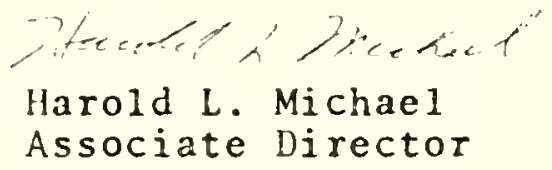

HLM:ms

cc: W. L. Dolch

R. H. Harre 11

R. L. Eskew

W. H. Goetz

W. L. Grecco

M. J. Gutzwiller

G. K. Hallock
M. L. Hayes

C. W. Love 11

G. W. Marks

R. D. Miles

J. W. Miller
C. F. Scholet

M. B. Scott

J. A. Spooner

N. W. Steinkamp

H. R. J. Walsh

E. J. Yoder 
Digitized by the Internet Archive in 2011 with funding from

LYRASIS members and Sloan Foundation; Indiana Department of Transportation 


\title{
Final Report \\ AN INVESTIGATION INTO THE GRADATION VARIABILITY OF AGGREGATES USED IN BASES
}

\author{
by \\ James T. Parson \\ Graduate Assistant in Research \\ Joint Highway Research Project \\ Project No.: C-36-45L \\ File No.: 6-18-11 \\ Prepared as Part of an Investigation \\ Conducted by \\ Joint Highway Research Project \\ Engineering Experiment Station \\ Purdue University \\ In cooperation with the \\ Indiana State Highway Commission \\ and the \\ U.S. Department of Transportation \\ Federal Highway Administration
}

The contents of this report reflect the views of the author who is responsible for the facts and the accuracy of the data presented herein. The contents do not necessarily reflect the official views or policies of the Federal Mighway Administration. This report does not constitute a standard, specification, or regulation.

Purdue University

Lafayette, Indiana

July 26, 1972 


\section{ACKNOWLEDGMENTS}

This writer would like to express his sincere appreciation to Professors C. B. Monk and E. J. Yoder for their aid and advice during the research and presentation of this thesis.

This writer would also like to acknowledge the financial aid given by Purdue through the Joint llighway Research Project. 
TABLE OF CONTENTS

Page

LIST OF TABLES........................ v v

LIST OF EIGURES............................ vii

ABSTRACT ................................

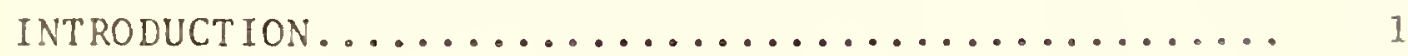

REVIEW OF LITERATURE.................... 3

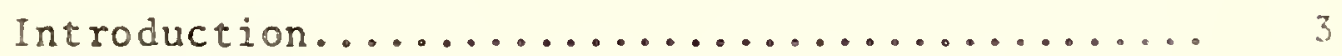

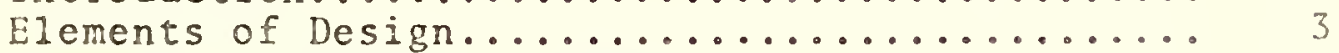

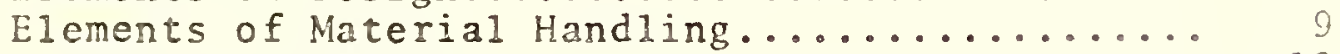

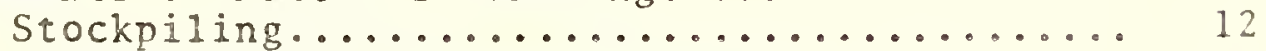

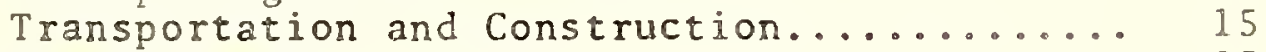

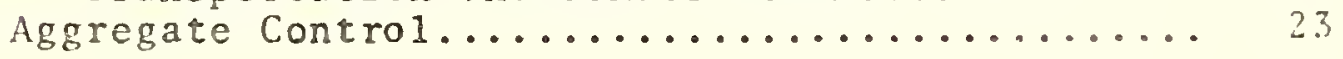

FIELD SAMPLING PLAN...................... 25

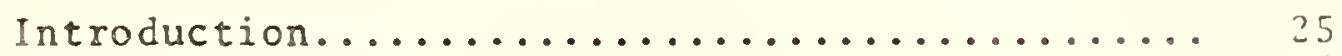

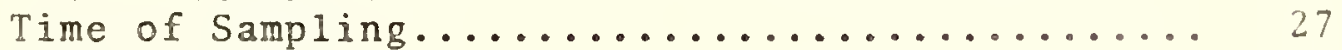

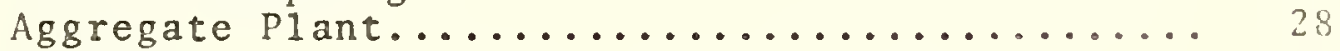

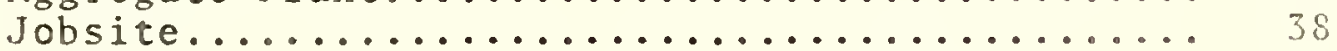

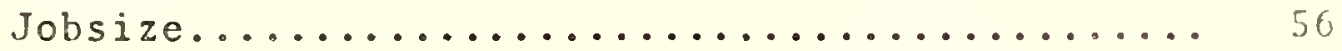

STATISTICAL ANALYSIS OF LABORATORY PROCEDURES...... 57

RESULTS AND DISCUSSION OF RESULTS..............

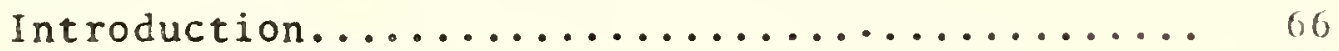

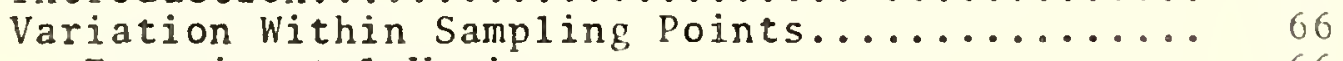

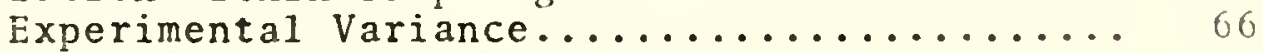

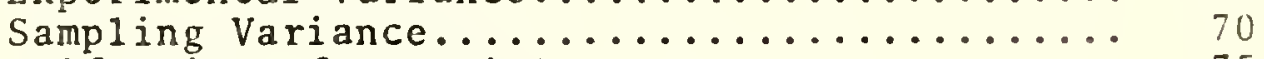

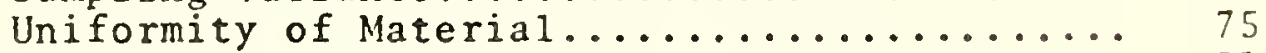

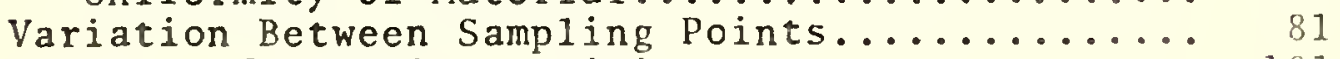

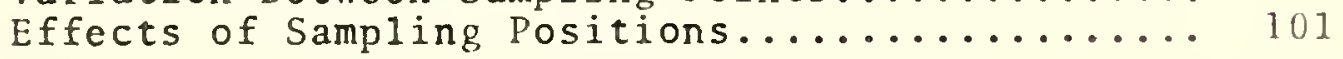

SUMMARY OF CONCLUSIONS................... 105

RECOMMENDATIONS FOR FUTURE RESEARCH............. 107

BI BLI OGRAPHY .......................... I09

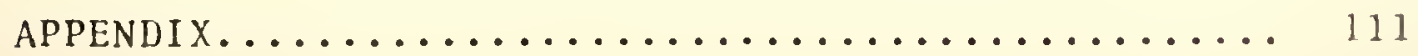


LIST OF TABLES

Table

1 Results of Stockpile Sampling............ 14

2 Gradation of Series 5 Aggregate

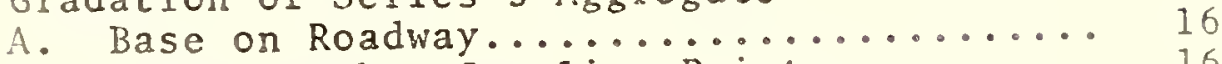

$B$. Base At other Sampling points............ 16

3 Ranges Observed in Laboratory Sieve

Analysis Data for Subbase Material......... 19

$4 \quad t$-Test for Paired Observations, T88-70

Sample Splitter Split vs. T11-60 and

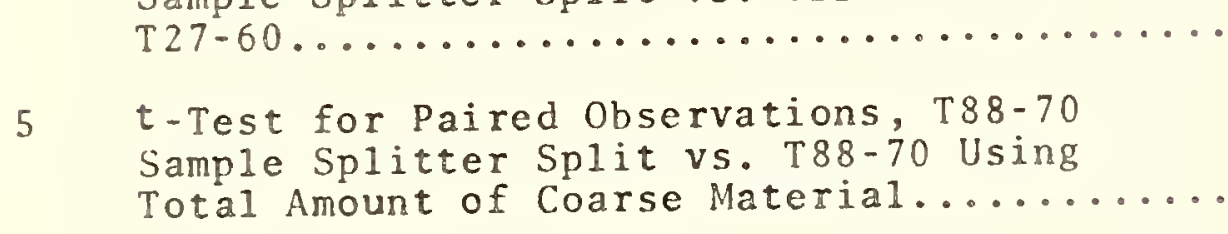

6 t-Test for Paired Observations, T88-70

Sample Splitter Split vs. T88-70 Gilson

Split Followed by Sample Splitter Split....

$7 \quad t$-Test for Paired Observations, T88-70

Sample Splitter vs. T88-70 Sample

Splitter Using Al1 Fine Material Minus

150 Grams for Hygroscopic Moisture.........

8 Summary of Foster-Burr Homogeneity of

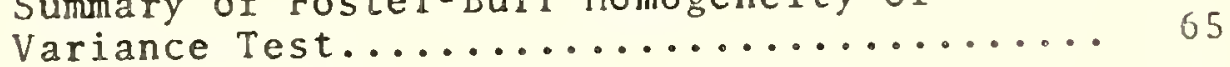

9 Experimental Variance, T88-70 (Sample

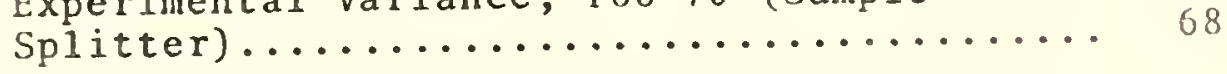

10 Experimental Variance, T88-70 (Initial

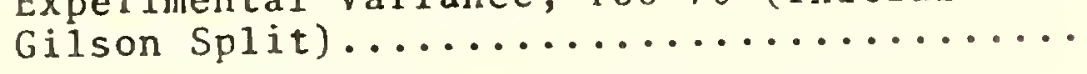

11 Experimental Variance, T88-70 (A11 Fines

Minus 150 Grams)....................69

12 Experimental Variance, $\mathrm{T} 11-60$ and $\mathrm{T} 27-60 \ldots 69$

13 Experimental Variance, A11 Methods Combined. 71 


\section{LIST OF TABLES (Continued)}

Table

$\underline{\text { Page }}$

14 Experimental and Sampling Variance, Pugmill. 74

15 Experimental and Sampling Variance, Before

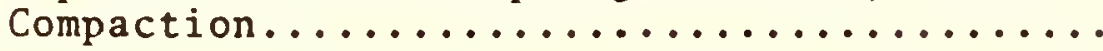

16 Experimental and Sampling Variance, After Compaction...................... 74

17 Variance Analysis Pugmill Feeder Belt and Pugmill Output................... 76

18 Variance Analysis Before Compaction and After Compaction................... 77

19 Comparison of Variances at Sampling Points.. ?9

20 Coefficients of Variation ( $\%$........... 80

21 Kolmogorov-Smirnov Test for Normality

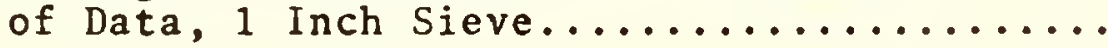

22 Kolmogorov-Smirnov Test for Normality of Data, $3 / 4$ Inch Sieve............... 85

23 Kolmogorov-Smirnov Test for Normality of Data, $1 / 2$ Inch Sieve.............. 86

24 Kolmogorov-Smirnov Test for Normality

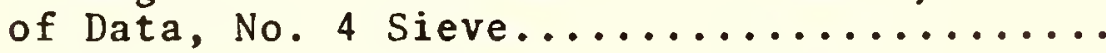

25 Kolmogorov-Smirnov Test for Normality of Data, No. 8 Sieve................. 88

26 Kolmogorov-Smirnov Test for Normality

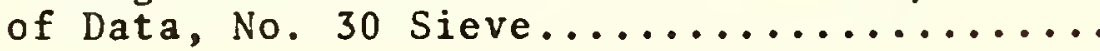

27 Kolmogorov-Smirnov Test for Normality

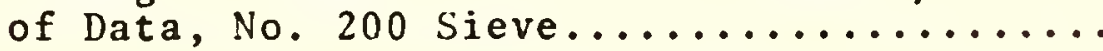

28 Analysis of Variance for One Way Design to Determine Significant Variation Between

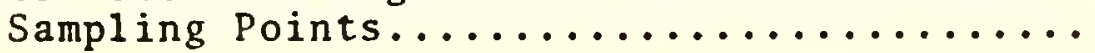

29 Newman-Keuls Sequential Range Test, $3 / 4$ Inch Sieve

A. Means of Percent Passing............ 92

B. Difference Between Means............. 93 


\section{LIST OF TABLES (Continued)}

Table

Page

30 Newman-Keuls Sequential Range Test, No.

8 Sieve

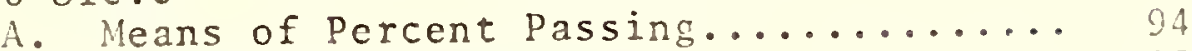

P. Difference Retween Means............ 95

31 Newman-Keuls Sequential Range Test, No. 30 Sieve

A. Means of Percent Passing............................ 96

B. Difference Between Means............. 97

32 Newman-Keuls Sequential Range Test, No. 200 Sieve

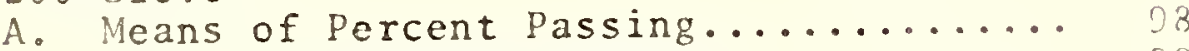

B. Difference Between Means............ 99

33 Means of Percent Passing for Position

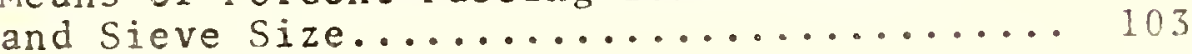




\section{LIST OF FIGURES}

Figure

Page

Physical States of Soil Aggregate

Mixtures.......................

2 Effect of Soil Content and Soil

Plasticity on Bearing Ratios.............

Permeability of Graded Sand and Gravel....

4 Effects of Grain Size Distribution on

Preventing Subgrade Intrusion During

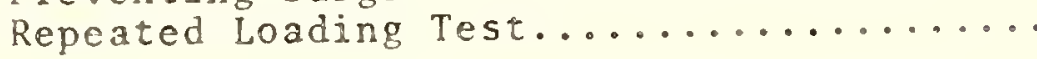

Effects of Grain Size Distribution on

Preventing Subgrade Intrusion During

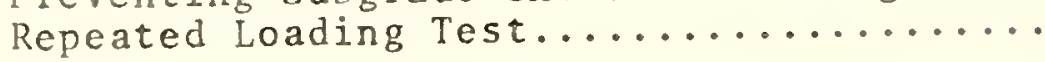

Frequency Histogram of Percent Compaction

of Subbase Material for Three Projects....

Effects of Compaction in a Steel wheel



Gradation Limits for No. 53 Pugmill

Mixed Aggregate.................... 26

Isolating Belt Sample............. 30

Obtaining Isolated Sample From Belt.......

Sweeping Belt to Obtain All of Sample....

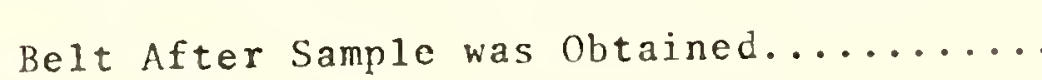

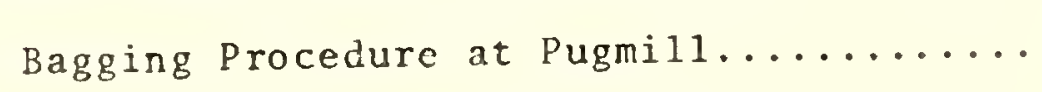

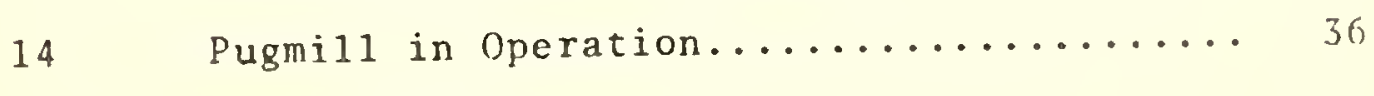

15 Free-Fall Sampling.............. 37

16 Identification of Sample Bearing Truck... 39

17 Truck Identification at Jobsite........ 40 


\section{LIST OF FIGURES (Continued)}

Figure

18

19

20

21

22

23

24

25

26

27

28

29

30

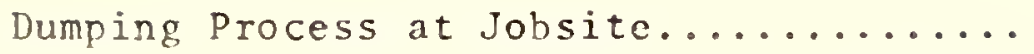

$\underline{\text { Page }}$

Rectangular Sample Size............ 43

Sample Location.................... 44

Cleaned Sample Hole................ 45

Material Split Into Four Quarters....... 46

Coned and Quartered Material Piles........

Material Split by Removing Opposite

Quarters.

Sample and Replicate With Opposite

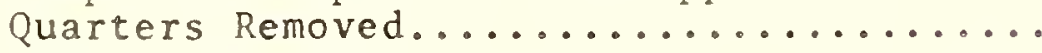

Bagging Procedure at Jobsite.......... 50

Insuring No Material is Lost During

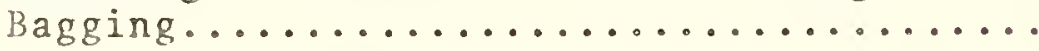

Samples After Bagging Procedure at Jobsite is Complete.

Vibratory Compactor in Operation....... 54

Samples Ready for Transportation to Temporary Storage.

Appendix

Figure 


\section{ABSTRACT}

Parson, James T., M.S.C.E., Purduc University, June, 1972. An Investigation into the Gradation Variability of Aggregates Used in Bases. Major Professors: C. B. Monk, F. J.Yoder.

Construction procedures and equipment in the highway industry have demonstrated rapid advancement during recent years. Time of job completion is a fraction of that experienced in the past. To evaluate the quality of the final product during construction and still not affect the construction process is a tremendous task. This research study was conducted to establish guidelines in this task for better. and more efficient quality control by investigating change in aggregate gradation between the producer's plant and the insitu compacted bighway base. The aggregate studied was Indiana Specification No. 53 pugmill mixed crushed limestone aggregate. The aggregate was tested at different points in the material handling stream. Furthermore, intermediate testing points which indicate the final compacted product were investigated.

The data was analyzed for the purpose of determining uniformity within sampling points and gradation variability within sampling points was found to exist and was contributed to segregation of the stockpile from which the material was initial1y obtained. 
Variation between sampling points was studied by obtaining samples at four points: pugmill feeder belt, pugmill output, on the roadway before compaction, and after compaction. The variability between the producer's plant and the jobsite was found to be statistically critical for the lower sieve sizes. By ranking the means for each sieve size and each position, variability in the middle sieve sizes was evident, but only observable and not critical.

Even though a change in gradation was statistically critical in the lower sieve sizes between the producer's plant and the jobiste, practically speaking this change in gradation was small. Because of this observation, as well as the ease of obtaining samples, belt sampling was proposed as a possible alternative to final compaction sampling and it is recommended as a production control point.

Samples obtained from the pugmill bin output were coarser by approximately two percent. These coarser values were attributed to sampling technique and not to segregation. Because of the difficulties in obtaining samples from this point, coupled with the coarser gradation, pugmill bin output sampling was not recommended.

Samples obtained before compaction indicated a sampling position equally good and possibly superior to the after compaction sampling position. For the aggregates tested, 
the gradation of the before compaction material was not distinguishable from the after compaction material. Furthermore, the deviation of the means for the before compaction samples were less than the after compaction samples. These points coupled with the ease of obtaining before compaction samples is the basis for the recommendation for before compaction sampling as a control point. 
INTRODUCTION

Because of the advancement during recent years in highway construction procedures and equipment, quality control. of the construction process has been challenged to marure to evaluate the innovations. The aggregate proces sing industry has developed noticeable strides in keeping pace with construction innovations for handling material. Presently five to seven thousand tons per day is not an uncommon quantity of crushed stone used for highway basc construction for a given job. To inspect such a large quantity of material and not hamper the construction process is a momentous task for highway departments.

This research study was set up to meet the following objectives.

1. To test aggregate gradation of specified lots in the aggregate processing method between the producer's plant and the insitu compacted base.

2. To evaluate the points at which segregation or breakdown of the aggregate noticeably occurs in the processing stream between the producer source and the insitu compacted base. 
3. To determine testing points for producers and contractors which could improve aggregate quality control and better insure a product that meets defined design standards.

4. To supplement existing knowledge of the aggregate handling process dealing with transportation, spreading, and compacting.

The site selected for this study was a section of Indiana State Road 37 north of Dolitic, Indiana. This project was selected after discussions with the engineers of the Indiana State Highway Commission. The Indiana State highway designation for this project is "Project No. F-92". 
REVIEW OF LITERATURE

\section{Introduction}

The proper use of aggregates in bases of highways is of major importance in highway performance. In both concrete and asphalt pavements, aggregates in the base are used to distribute the traffic load of the pavement; and thus, aid in providing shearing resistance and some stiffness to the pavement. Aggregates play a major role in rigid pavements in controling common problems such as; control of pumping, frost-heave, urainage, and volume change of the subgrade.

\section{Elements of Design}

One factor which influences stability of a soil aggregate mixture is gradation of the mix. Burmister (4) reached the conclusion that the greatest density occurs with the greatest range of particle sizes ordered for the least voids. Figure 1 shows three physical states of soil aggregate mixtures. The first case is well-graded with no fine material. This condition has a variable density, is pervious, and is non-frost susceptible. Strength of the base is gained from grain to grain contact. The second condition has sufficient fines to fill the voids. The strength is still gained from grain to grain contact, but increased resistance against deformation is also obtained. 

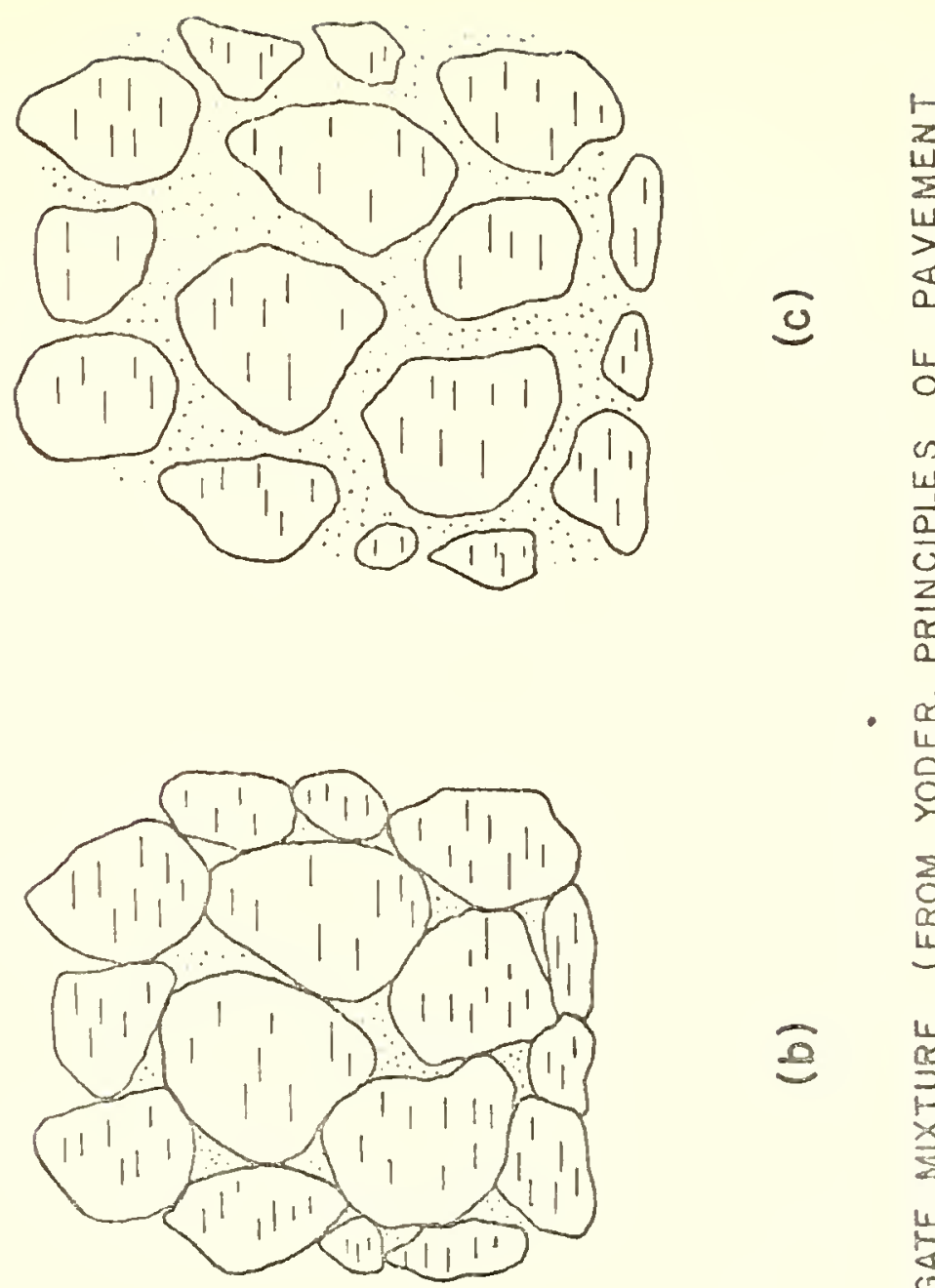

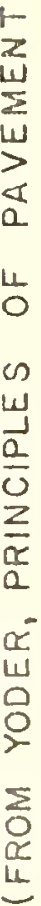

$2 \frac{w}{\frac{x}{5}}$

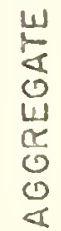

응
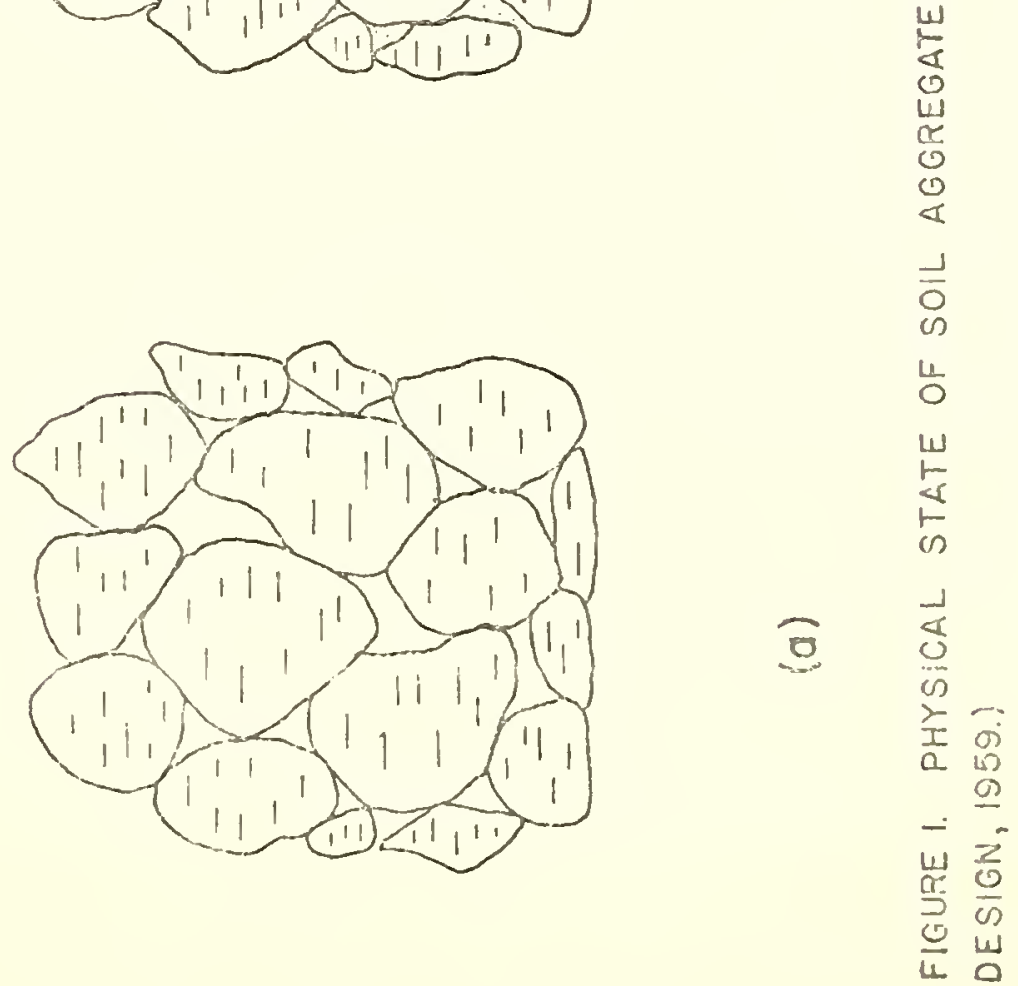
This second material has a high density, a low permeability, and is thus probably highly frost susceptible. In the third condition, grain to grain contact is destroyed. The coarse aggregate seem to float in the mass of fine material. This material would have a decreased density, be nearly impervious, and frost-susceptible. Any adverse water condition would certainly have an adverse effect upon the stability of the third condition. Specifications must be designed for the best combination of these three physical states. plasticity of a binder has a definite effect upon the stability of a base. The greatest stability is obtained by using non-plastic binder material because too great a plastic index could easily cause a pronounced loss in stability (16) especially if grain to grain contact is destroyed. The relationships among the plastic limit, liquid limit, CBR and quantity of soil (material passing the number 40 mesh sieve) in a mix is shown in Figure 2. One can see that, from the standpoint of CBR, an optimum amount of material passing the number 40 mesh sieve exists. This optimum amount can be determined by the equation:

$$
P=100(d / D)^{N}
$$

where:

$$
\begin{aligned}
& \mathrm{d}=\text { sieve size } \\
& \mathrm{p}=\text { percent by weight finer than the sieve } \\
& \mathrm{D}= \\
& \mathrm{N}=\text { maximum size of aggregate } \\
& \quad \text { density). }
\end{aligned}
$$




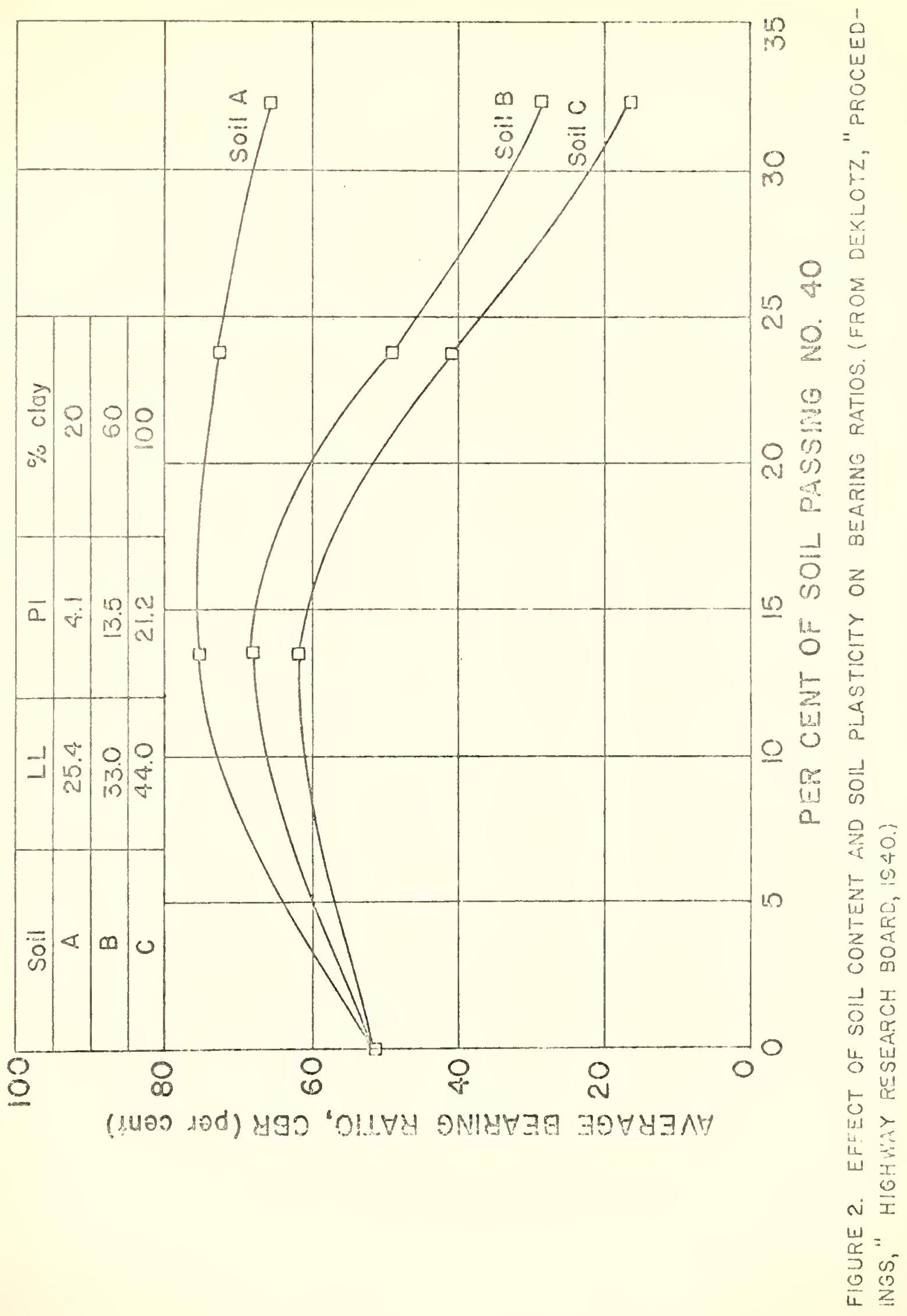


Figure 2 illustrates that the strength of a base as measured by the CBR test is affected by the plasticity and amount of fines.

Permeability of a base is principally dependent upon grain size, shape and arrangement of particles, type of material, and density $(14,15)$. Permeability is expressed by the coefficient of permeability, $k$ :

$$
k=v / i
$$

where:

$$
\begin{aligned}
v= & \text { discharge velocity } \\
k= & \text { coefficient of permeability with units of } \\
& \text { velocity } \\
i= & \text { hydraulic gradient }=\mathrm{h} / \mathrm{l} ; \mathrm{h} \text { being the hydraulic } \\
& \text { head, } \ell \text { being the length of the sample. }
\end{aligned}
$$

The coefficient $k$ is dependent upon the properties of the permeable mass. Granular materials are the most pervious when few fines are present. Figure 3 shows the coefficient of permeability as a function of the percent of fines. One may note that permeability decreases as the percent of fine material increases, but at the same time, as the percent of fine material increases, so does the density. Permeability is especially important in design of bases and subbases in northern climates where drainage of the base is extremely critical.

The ability of a base to carry out its intended functions is dependent upon a combination of all the 


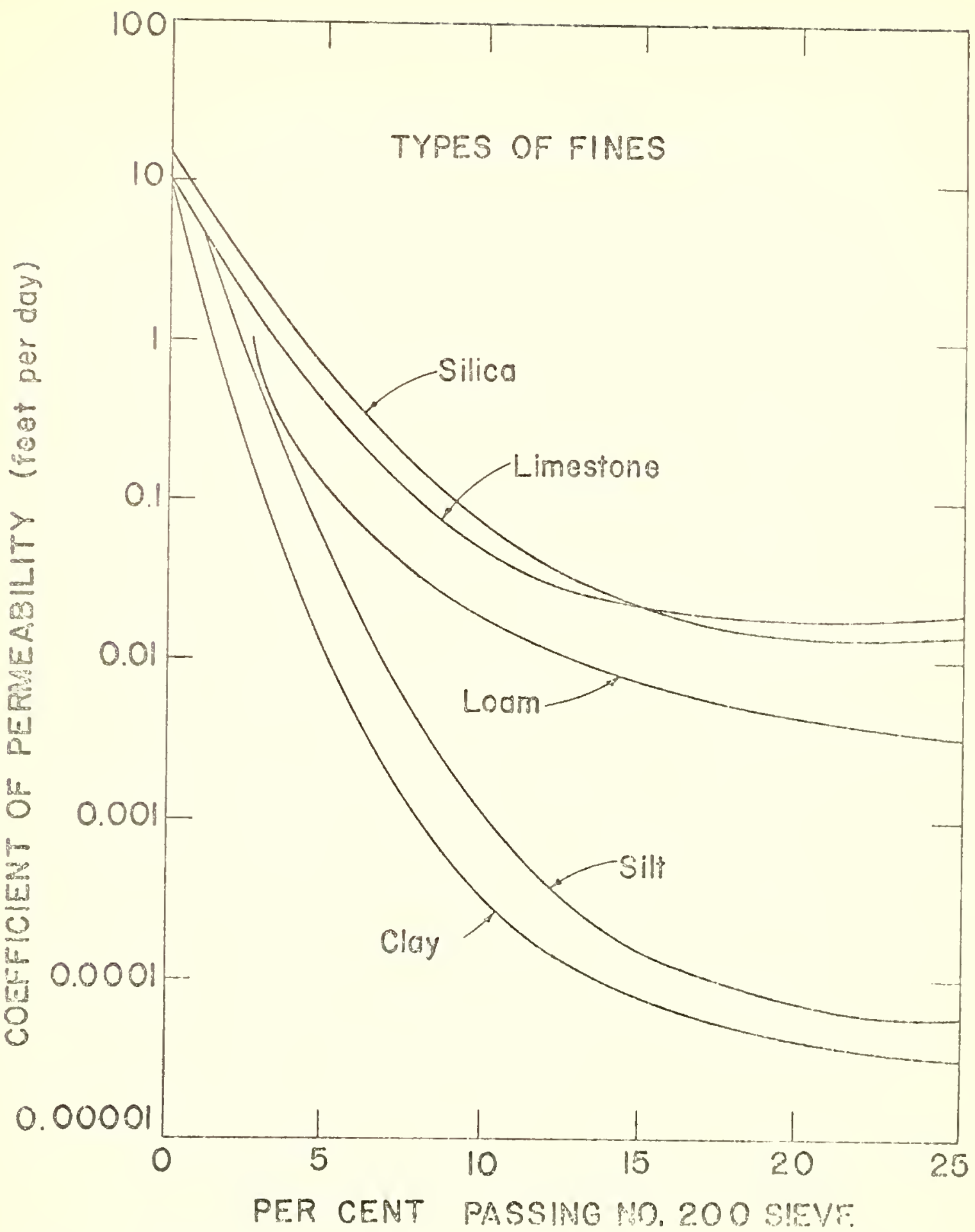

FIGURE 3. PERMEABILITY OF GRADED SAND AND GRAVEL. (FROM BARBER AND SAWYER, "PROCEEDINGS," HIGHWAY RESEARCH BOARD, 195?.) 
aforementioned physical design characteristics. Maximizing one may minimize another. Easily noted is the part that the common denominator of the physical characteristics is gradation since it effects density, permeability, plasticity, and, thus, in general the overall ability of a base to perform as designed.

Another important factor is that after repeated loadings, intrusion of the subgrade material into the base material can affect the stability of the base. The graph in Figure 4 illustrates the weight of the subgrade material that intruded into both a gravel and sand base course under repeated loadings (16) in the laboratory. The subgrade consisted of a silty clay, compacted to 95 percent modified AASHO and the samples. were subjected to a verticle pressure of 25 psi. One may easily note that as the number of loads increased the amount of subgrade material which intruded into the base increased. The curves of Figure 5 illustrate the relationship between cumulative deflection and repeated loadings (18) of the same materials. As the amount of subgrade material that intruded into the base increased, the cumulative deflection also increased.

\section{Elements of Material Handling}

After a base is designed for a set of defined conditions and the material is manufactured to meet a specified gradation, the handling of the aggregate material between initial fabrication and initial use at the jobsite must be 


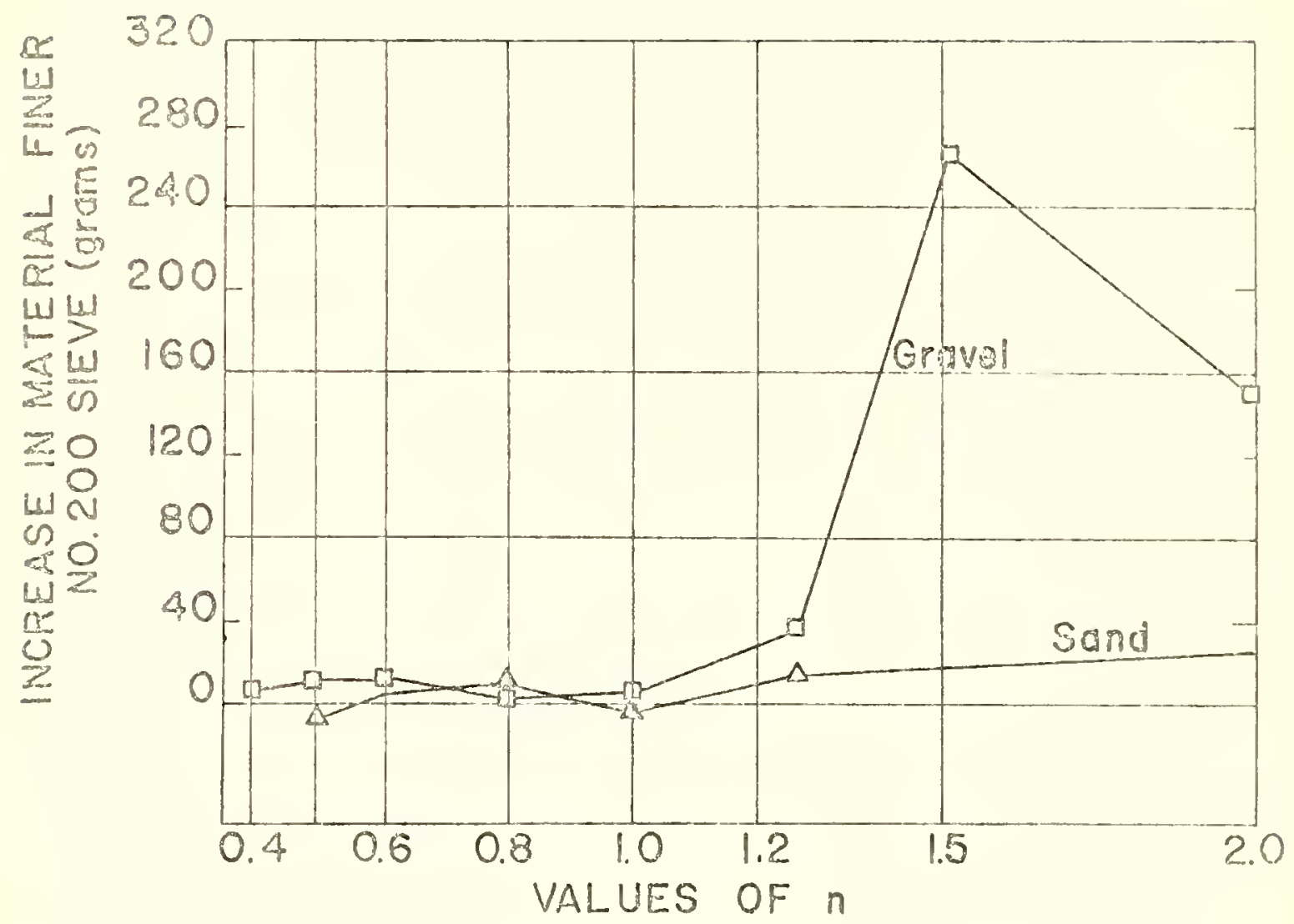

Maparials gradod according to $p=\left(\frac{d}{D}\right)^{n}(100)$

FIGURE 4. EFFECTS OF GRAIN SIZE DISTRIBUTION ON PREVENTING SUBGRADE INTRUSION DURING REPEATED LOADING TEST. (FROM CHAMBERLIN AND YODER, "PROCEEDINGS," HIGHWAY RESEARCH BOARD, 1958.) 


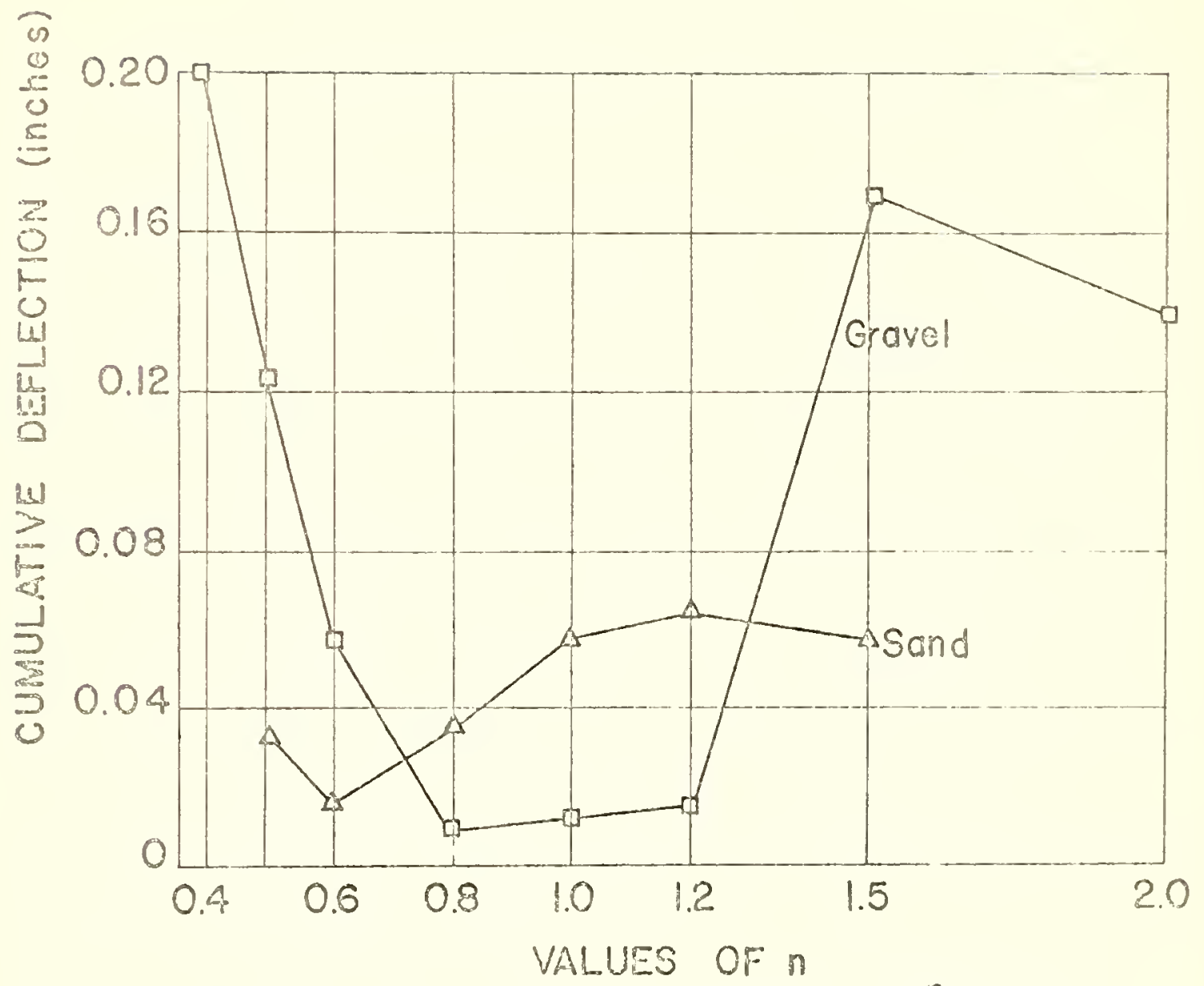

Materials graded according to $p=\left(\frac{d}{D}\right)^{n}(100)$

FIGURE 5. EFFECTS OF GRAIN SIZE DISTRIBUTION ON PREVENTING SUBGRADE INTRUSION DURING RF.PEATED LOADING TEST. (FROM CHAMBERLIN AND YOdER, "PROCEEDINGS," HIGHVAY RESEARCH BOARD, 1958.) 
carefully controlled to prevent segregation. Past studies $(10,12,8)$ give an indication to the seriousness of the problems dealing with aggregate stockpiling at the producer's plant and transportation and construction to and at the jobsite.

Stockpiling

The Manual for Aggregate Inspectors published by the Indiana State Highway Commission, Division of Materials and Tests (9) does not define a specific stockpiling method to be used in Indiana for material destined for State highway use. The only requirements placed upon the producer's stockpile are: 1) that it be geographically placed so that materials of different gradation do not intermix and 2) no heavy equipment may be used on top of the material stockpile. Because of the many stockpiling methods and types of equipment used for stockpiling, this phase of material handling can result in aggregate segregation.

Miller Warden and Associates in their report entitled "Effect of Different Methods of Stockpiling Aggregate Interim Report" (10), investigated stockpiling of aggregate material in depth. A total of eleven different stockpiles were studied; the material had been formed and placed by a different method in each case. The stockpiles were statistically sampled and then compared by their respective "Segregation Index". The Segregation Index is defined as the ratio between the overall variance and the within-batch 
variance. The within batch variance is defined as the combination of inherent, sampling, and testing variances. The overall variance is defined as the within-batch variation plus the variance due to segregation. A segregation index of "l" would indicate no segregation at al 1 and the difference between 1 and the Segregation Index denotes the relative amounts of stockpile segregation. Typical results of the Miller Warden study are given in Tabie 1. The flat-mixed pile formed by the use of a crane bucket was the only one that resulted in an insignificant amount of segregation. The method most commonly used in the state of Indiana for material to be used on state highways is truck dumping. This is an economical method of forming stockpiles, but is also a mediocre technique which tends to segregate the aggregate material.

In a study by Majidzadeh and Brahma (8) of Ohio State University, the Miller Warden findings (10) were strongly reinforced. Majidzadeh and Brahma concerned themselves with the entire aggregate handling process: initial material fabrication, producers stockpile, truck transportation and jobsite stockpile. They concluded that stockpile segregation was not only a serious problem, but the most serious in their study of aggregates handing. They surmised this was due to the tendency for heavier aggregate particles to segregate by gravity action. 
Table 1. Results of Stockpile Sampling*

\begin{tabular}{|c|c|c|c|c|}
\hline $\begin{array}{l}\text { Stockpile } \\
\text { Number }\end{array}$ & $\begin{array}{l}\text { Type of pile } \\
\text { Constructed }\end{array}$ & $\mathrm{N}$ & $\begin{array}{l}\text { Method of } \\
\text { Construction }\end{array}$ & $\begin{array}{l}\text { Segregation } \\
\text { Index }\end{array}$ \\
\hline 1 & F1at-mixed & 46 & Crane bucket & 1.348 \\
\hline 2 & Double-cone & 66 & Crane bucket & $16.476^{c}$ \\
\hline 3 & Flat-layered & 52 & Crane bucket & $1.956^{\mathrm{C}}$ \\
\hline 4 & Single:cone & 65 & Crane bucket & $16.858^{C}$ \\
\hline 5 & Coned tent & 64 & $\begin{array}{l}\text { Portable } \\
\text { conveyor }\end{array}$ & $8.100^{c}$ \\
\hline 6 & Flat-1ayered & 50 & $\begin{array}{l}\text { Front end } \\
\text { loader }\end{array}$ & $4.052^{c}$ \\
\hline 7 & Single cone & 58 & Crane bucket & $13.359^{C}$ \\
\hline 8 & $\begin{array}{l}\text { Tiered } \\
\text { (bermed) }\end{array}$ & 75 & Crane bucket & $7.371^{c}$ \\
\hline 9 & Truck dumped & 73 & Dump trucks & $2.299^{C}$ \\
\hline 10 & Ramped & 74 & $\begin{array}{l}\text { Rubber-tired } \\
\text { dozer }\end{array}$ & $1.591^{\mathrm{C}}$ \\
\hline 11 & Flat-mixed & 66 & $\begin{array}{l}\text { Rubber-tired } \\
\text { dozer }\end{array}$ & $2.096^{c}$ \\
\hline
\end{tabular}

*From: Miller Warden and Associates, "Effects of Different Methods of Stockpile Sampling", Proceedings, Highway Research Board, 1964.

${ }^{\mathrm{C}}$ Significant difference. 
Transportation and Construction

Any additional segregation due to transportation and construction of aggregate material compounds the material handling problem. In another study by Miller Warden and Associates, "Evaluation of Construction Control Procedures Interim Report", (12) and in "Statistical Analysis of Aggregate Size Distribution" by Majidzadeh and Braham (8), aggregate segregation is shown to increase as the material approaches the jobsite.

Majidzaden and Brahma were concerned with material to be used in concrete and bituminous mix plants. Miller Warden and Associates also mainly concerned themselves with aggregates for concrete and bituminous mix plants but they also mentioned highway base material. In the one case in which the report dealt with base material there was variation between the base material at the plant, in the trucks before transportation, and before compaction. These results are qualified in that only one plant processing case was considered. This case was fine material being added to stockpiled coarse material on a conveyor belt, pugmil1-mixed with water added in the pugmill, and trucktransported to the jobsite immediately (12). The specified gradation along with the tabulated values for overall variation are shown in Table $2(\mathrm{~A})$. The overall variation shows the limits within which 95 percent of the test results on a single test portion from the in situ non-compacted stated would be expected to fall. Comparison between the 
Table 2. Gradation of Series 5 Aggregate A. Base on Roadway

\begin{tabular}{|c|c|c|c|}
\hline $\begin{array}{l}\text { Sieve } \\
\text { Size }\end{array}$ & Limits & Variation, & Variation, \\
\hline $11 / 2$ in. & 100 & $\ldots$ & $\ldots$ \\
\hline 1 in. & $80-95$ & $72-90$ & $\ldots$ \\
\hline $3 / 4$ in. & $\ldots$ & $72-90$ & $74-88$ \\
\hline $1 / 2$ in. & $60-75$ & $\cdots$ & $\cdots$ \\
\hline $3 / 8$ in. & $\cdots$ & 42.68 & $44-66$ \\
\hline No. 4 & $40-55$ & $25-48$ & $27-46$ \\
\hline No. 8 & $\cdots$ & $17-34$ & $18-35$ \\
\hline No. 10 & $28-43$ & $\cdots$ & $\cdots$ \\
\hline No. 200 & $\ldots$ & $5-8$ & $5-8$ \\
\hline
\end{tabular}

(From Miller-Warden Associates, "Evaluation of Construction Control Procedures", 1967.

B. Base At Other Sampling Points

\begin{tabular}{llll}
\hline $\begin{array}{l}\text { Sieve } \\
\text { Size }\end{array}$ & $\begin{array}{l}\text { Feeder } \\
\text { Belt }\end{array}$ & $\begin{array}{l}\text { Loaded } \\
\text { Trucks }\end{array}$ & $\begin{array}{l}\text { In-Place } \\
\text { Base }\end{array}$ \\
\hline $3 / 4$ in. & $78-89$ & $82-95$ & $72-90$ \\
$3 / 8$ in. & $50-66$ & $56-80$ & $42-68$ \\
No. 4 & $32-46$ & $38-61$ & $25-48$ \\
No. 8 & $22-33$ & $27-43$ & $17-34$
\end{tabular}

(From Miller-Warden Associates, "Evaluation of Construction Control Procedures", 1967). 
gradation of samples taken from the feeder belt before the material was pugmill mixed with moisture added, in the trucks immediately after being loaded, and on the roadway in situ before compaction is shown in Table $2(B)$. Taking samples from loaded trucks contributes to a large withinbatch variance. If one considers the variation between the loaded truck sample and the feeder belt sample to be nominal, he becomes aware that segregation and breakdown is also occurring somewhere between the producers plant and the in situ non-compacted base.

Material to be used in the base course initiates an aggregate handing conflict with the material for concrete and bituminous mix plants. Base course material is pugmill mixed with water added in the pugmill. Material for concrete and bituminous mix plants by pass the pugmill operation. This conflict between mix plants and highway base material handling to the jobsite is not totally relevant. Due to the addition of water for the base material in the pugmill, the fine particles attach themselves to coarse particles, and, as a result, the material behaves as coarse material, material similar to that transported to mix plant, during transportation. Previously noted was that Majidzadeh and Brahma found that segregation increased as the material progressed in the handling stream. Miller Warden and Associates results parallel this conclusion for both mix plants and highway base material. 
The construction operations of spreading and compacting can also have a detrimental effect on aggregate gradation. The effect of the spreading operation will only be mentioned since it has been previously discussed in relation to the Miller Warden and Associates result. The type of spreader could have an effect upon segregation. Two primary spreaders in present use are: 1) the Jersey Spreader with a spread width capability of approximately 12 feet in which material is trapped in a spreader box and spread with almost a road grader type of action, 2) the CMI spreader with a spread width capability in excess of 32 feet in which material is trapped in a spreader box and spread with an auger type of operation. The Miller Warden and Associates report studied only the Jersey spreader type action. The CMI spreader is becoming increasingly dominant in Indiana. Material that is segregated after spreading can possibly result in defective compaction. Studies by Williamson and Yoder (17) indicated that the percent of compaction of base material on three Indiana highways they studied were below specifications of (100 percent standard AASHO) by about ten percent (see Figure 6). One possible reason given for this lack of compaction is that the contractor did not obtain a uniform compactive effort upon the material. Gradation samples were taken of the compacted material and substantial deviations from the specifications were obtained (see Table 3 ). Base specifications in Indiana do not allow over $60 \%$ passing the No. 4 sieve and $10 \%$ passing 
Table 3. Ranges Observed in Laboratory Sieve Analysis Data for Subbase Materials

\begin{tabular}{lccc}
\hline Sieve & \multicolumn{4}{c}{ Project } \\
\cline { 2 - 3 } & $\begin{array}{c}\text { B-1 } \\
(8)\end{array}$ & $\begin{array}{c}B-2 \\
(\%)\end{array}$ & $(\%)$ \\
No. 4 & $58-82$ & $53-78$ & $63-79$ \\
No. 40 & $9-23$ & $11-33$ & $14.7-30$ \\
No. 200 & $4-14$ & $2.8-8.5$ & $3.3-7.5$
\end{tabular}

* Note: Data in Table represent per cent of total material passing a given sieve

(From Williamson $\&$ Yoder, An Investigaton of Compaction Variability for Selected Highway Projects in Indiana, 1967). 


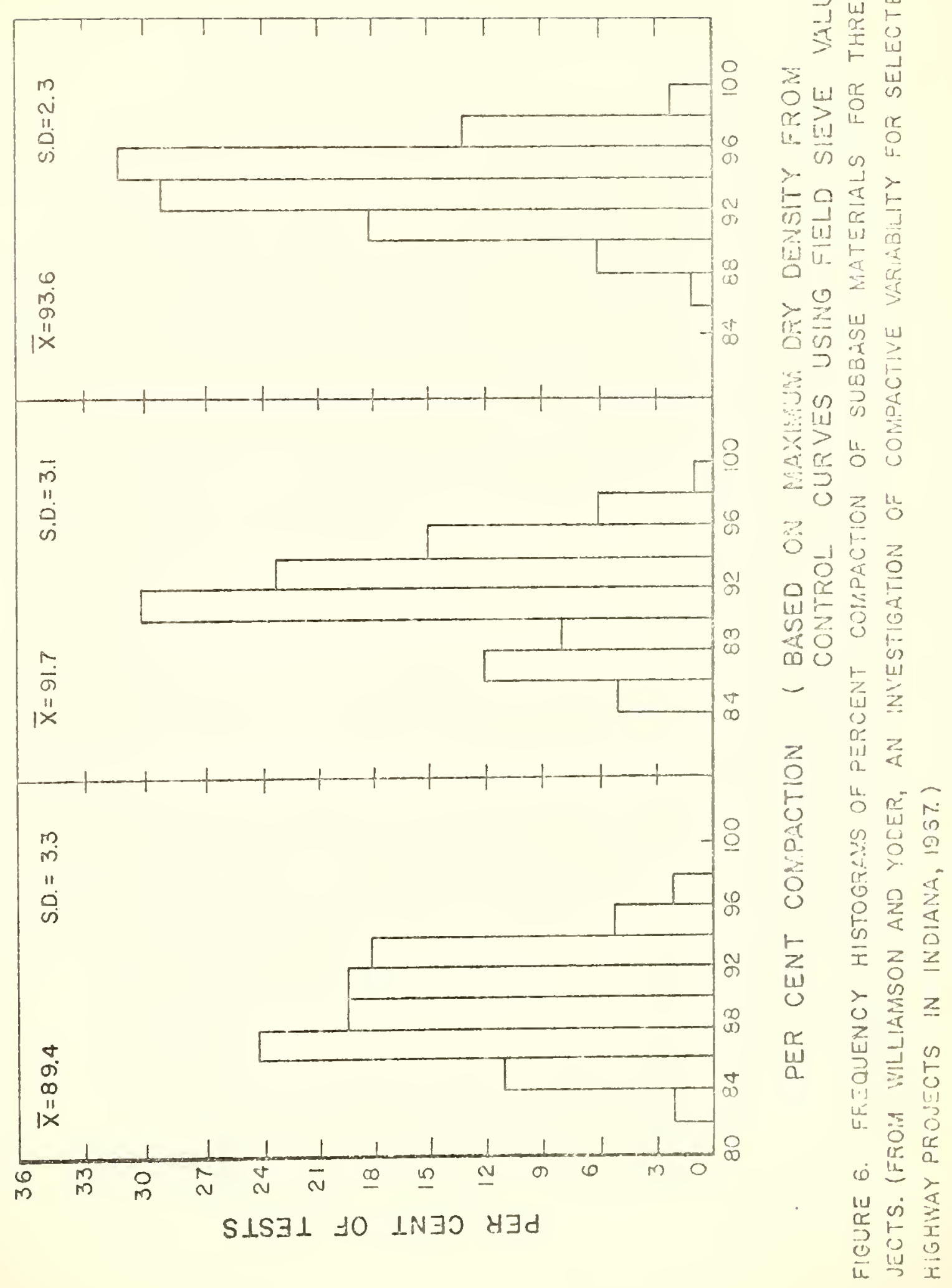


the No. 200 sieve. Since all the projects investigated by Williamson and Yoder were constructed by different contractors, the hypothesis that aggregate gradation may be a handicap in obtaining desired compaction was developed (17). In short, the material was not of the same quality as that material used for the compaction analysis established in the laboratory.

Possible detrimental effects can also be due to aggregate degradation. A harsh graded aggregate will undergo a much greater amount of degradation than a uniformly graded aggregate consisting of a range of particle sizes. During construction, aggregate degradation can result in an increase in the amount of fine particles which leads to densification of the base as they filter into the voids. Studies (1) indicate that degradation is dominate in the top layer; therefore, the height of a layer during compaction may contribute to a non-uniform compactive effort. If a layer is of excessive height, the required average density may be obtained only by overcompacting; thus causing degradation on the surface. The greatest amount of degradation during construction occurs with the first pass of the roller (Figure 7). Even though degradation does not take place during construction due to the compactors weight, it may occur over a period of time under traffic if proper gradation does not exist and resulting air voids are too large (11). 


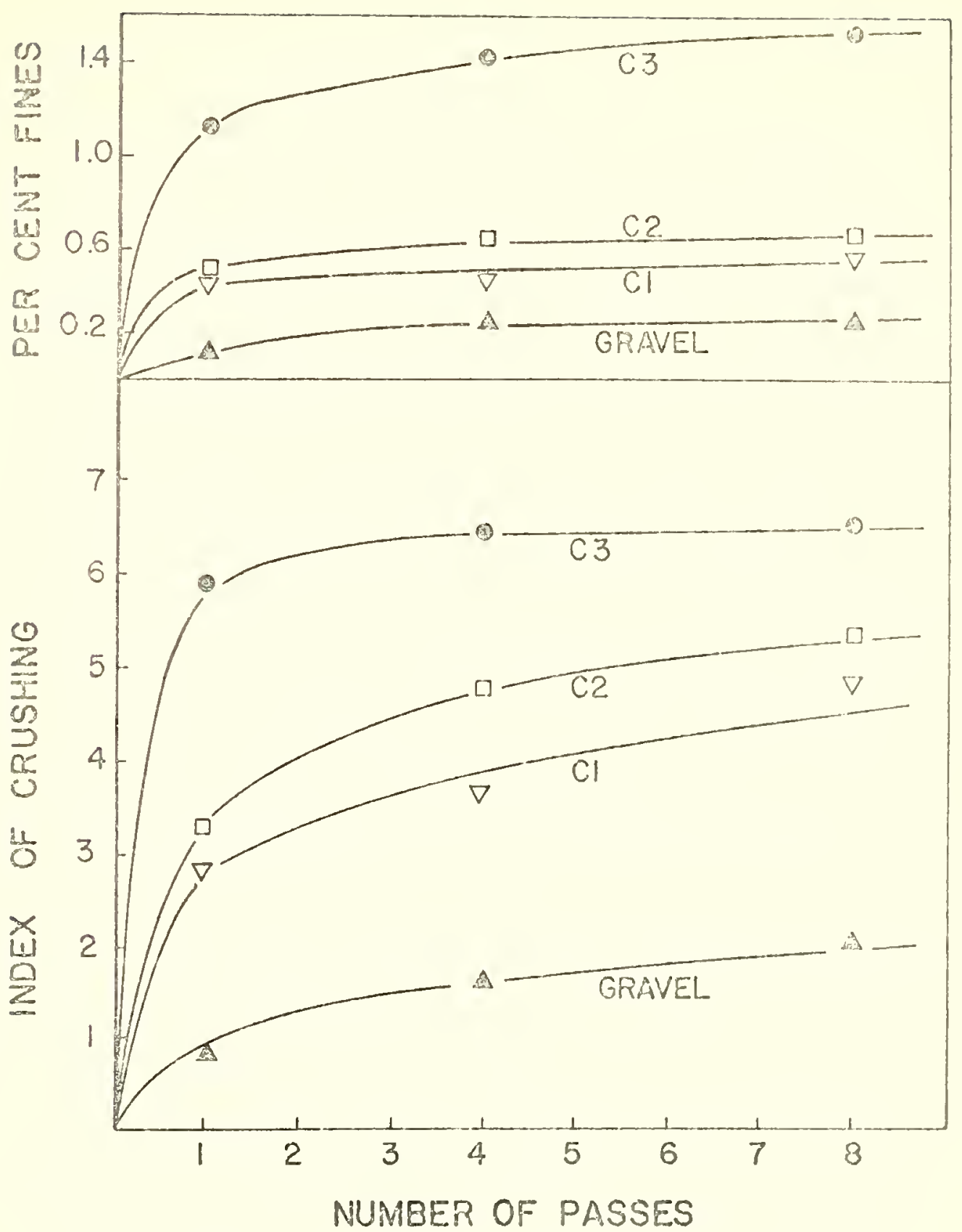

FIGURE 7. EFFECTS OF COMPACTION IN STEEL WHEEL ROLLER TEST. (FROM AUGHENBAUGH, JOHISON, YODER,DEGRADATION OF BASE COUFRL: AGGREGATES DUPING COMPACTION). 


\section{Aggregate Control}

The noted deviations from specifications by Williamson and Yoder in Indiana, Miller-Warden and Associates in North Carolina, and Majidzadeh and Brahma in Ohio indicate that the construction controls presently being used are not sufficient to deal with aggregate gradation. The apparent acceptance of aggregates which do not in fact meet specifications is probably a fault of both acceptance testing and process control. Acceptance testing deals with estimating the parameters of a complete lot by sampling only a limited portion and accepting or rejecting a lot of material upon this sample. Process control deals with controlling the production of a product so it will be able to meet specifications and minimize the risk of rejection. $\Lambda$ statistical approach lends itself to satisfying both conditions.

When a statistical approach is not used, the chance of a biased decision is possible due to the fact that the inspector has taken a greater number of samples from one point in a defined process than from another. As an example, present Indiana procedures require one test at the source per 1000 tons of material produced and one test per half mile of compacted roadway (9). As a result fewer tests are required on the compacted roadway than at the source. This procedure assumes segregations non-existent between the aggregate producer and the insitu compacted base. Segregation, however, can occur due to transportation, 
spreading, and compacting since these are the major handing processes other than initial stockpiling. 


\section{FIELD SAMPLING PLAN}

\section{Introduction}

The purpose of the field sampling plan was to design a method that would produce unbiased random samples at defined sampling points between the producer's plant and the insitu compacted base. The material sampled was Indiana Specification No. 53 pugmill mixed crushed stone aggregate. The gradation limits for this material are noted in Figure 8 .

The handling of the aggregate material prior to the pugmill operation depends upon the producer's processing plant arrangement. The material can be fed directly to the pugmill or be put into temporary storage in stockpiles or storage bins prior to feeding it to the pugmill. The material in this study had previously been placed in a stockpile and the pugmill was belt-fed from it.

After the pugmill operation, the handling processes are more standardized. Material is dumped directly from the pugmill into waiting trucks and transported to the job site where it is dumped into the feeder box of a material spreader and finally it is compacted. The type of spreader and compactor may vary;however, the CMI spreader and a vibratory compactor are becoming increasingly dominant. 


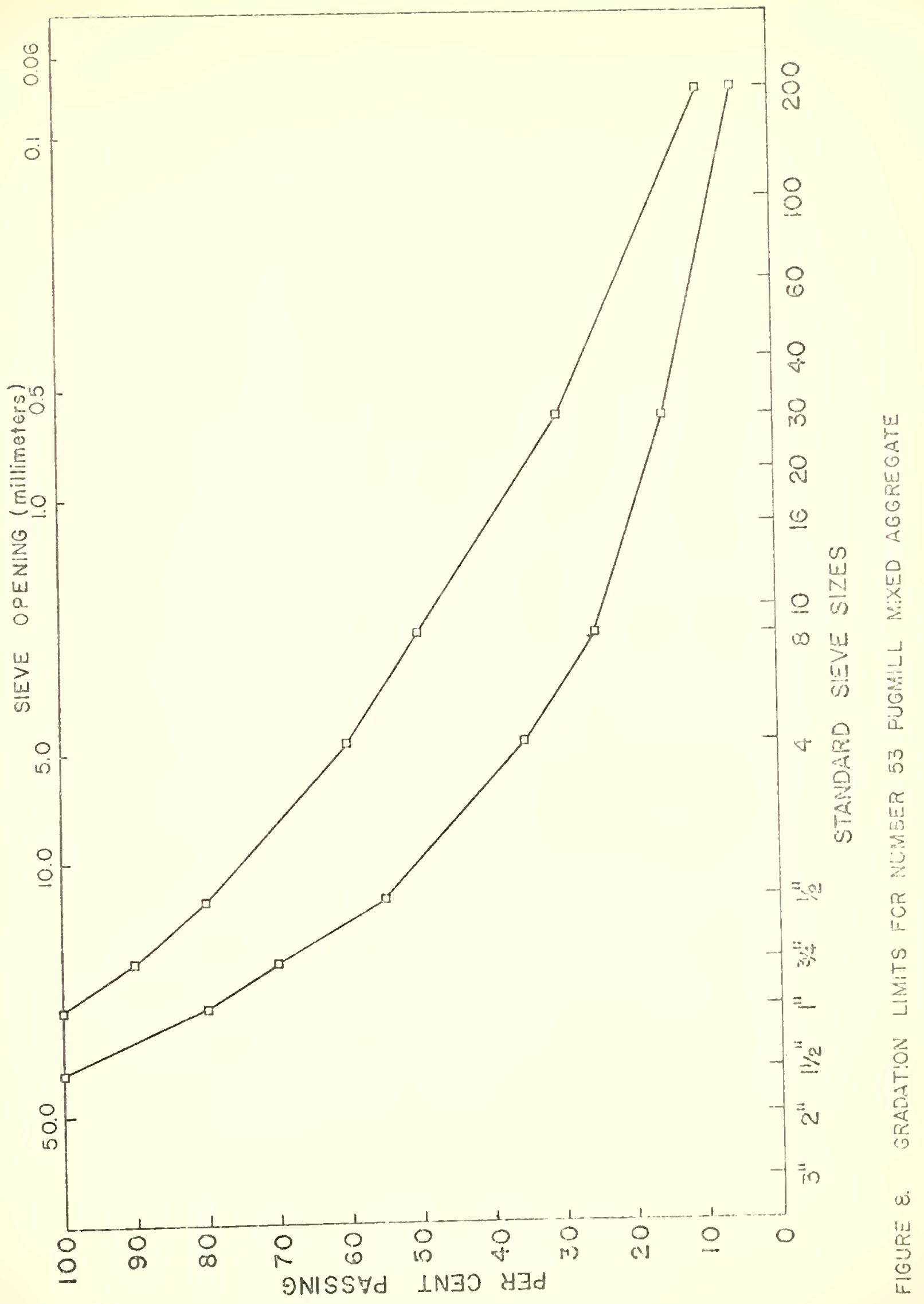


The material handling process at the subject location lent itself to three primary sampling points: pugmill, before compaction, and after compaction. Also sampled in this research study was a fourth point, the feeder belt for the pugmill. A special effort was made to sample the same material at each sampling position.

A total of fifty samples were obtained at each sampling position. A replicate sample was taken for each of the fifty samples at the pugmill, before compaction, and after compaction. No replicate sample was taken from the pugmill feeder belt because of time restrictions which would result in a delay of operations for the contractor.

A completely randomized sampling procedure was used to establish the sampling schedule at each of the sampling points.

\section{Time of Sampling}

Since the same material was to be sampled at each sampling point, and since the largest sampling time at any plant would control the possible frequency of samples, preliminary tests were performed to determine the time requirements for sampling at each point. A time requirement of forty-five minutes at the jobsite was found to control and, therefore, dictated a minimum of at least forty-five minutes between any two consecutive samples. An estimate of the quantity of material for the entire job was slightly in excess of fifty thousand tons. Furthermore, an estimate 
of five thousand tons per day for a full work day was obtained from the contractor. Considering these estimates five samples per day plus replicates for each point of sampling, other than the pugmill feeder belt, was considered most feasible. With these necessary restrictions (five samples per day and forty-five minutes between samples) the sampling interval was established at sixty-three minutes. In other words, in the first sixty-three minutes, one sample was taken at the aggregate plant and this same material was then selectively followed and sampled at each of the other sampling points. The time of sampling at the aggregate plant within the sixty-three minute interval was randomly chosen by a computer generation of a random number between one and sixty-three for each of the fifty samples. Before the second sixty-three minute interval a wait of forty-five minutes was allowed.

With this method of choosing a sample, the important assumption that the process is continuous had to be made. Even though this assumption may not be correct in a pure mathematical and statistical sense, the material handling from the stockpile into the trucks does approach a continuous process, and thus, this assumption is believed to be acceptable.

\section{Aggregate Plant}

As previously stated, samples at the aggregate plant were obtained from both the pugmill feeder belt and from 
the pugmill itself. The batch of material from wich the sample was obtained varied between thirty-five and forty tons. This batch size was established because two truck loads of material were required to keep the CMI spreader sufficiently filled; each truck carried between fifteen and twenty tons of material.

Even though just a single sample was taken from the feeder belt to the pugmill, the sample was a good average of the material within two trucks. This developed because the amount of material that was retained within the pugmill and the amount of material on the feeder belt approached the tonnage of one truck load or one-half of a batch of material.

Figures 9 through 13 depict the process of obtaining samples from the belt. The helt ran from a tunnel in which was located a feeder which opened into the base of the material stockpile. The material sampled on the belt was approximately eighteen inches in length. After the length of the sample was estimated and sample boundaries marked by the individual taking the sample, the sample was isolated by clearing a space on each side of it (Figure 9). The sample was then shoveled into a bucket placed near the individual (Figure 10). When only a slight amount of material was remaining on the belt, the sample was swept into the shovel with a swish broom to insure obtaining all of the fine particles (Figure 11). Figure 12 shows the helt after the sample was obtained. After the material had been gathered, it was bagged. The sample was not bagged as it 


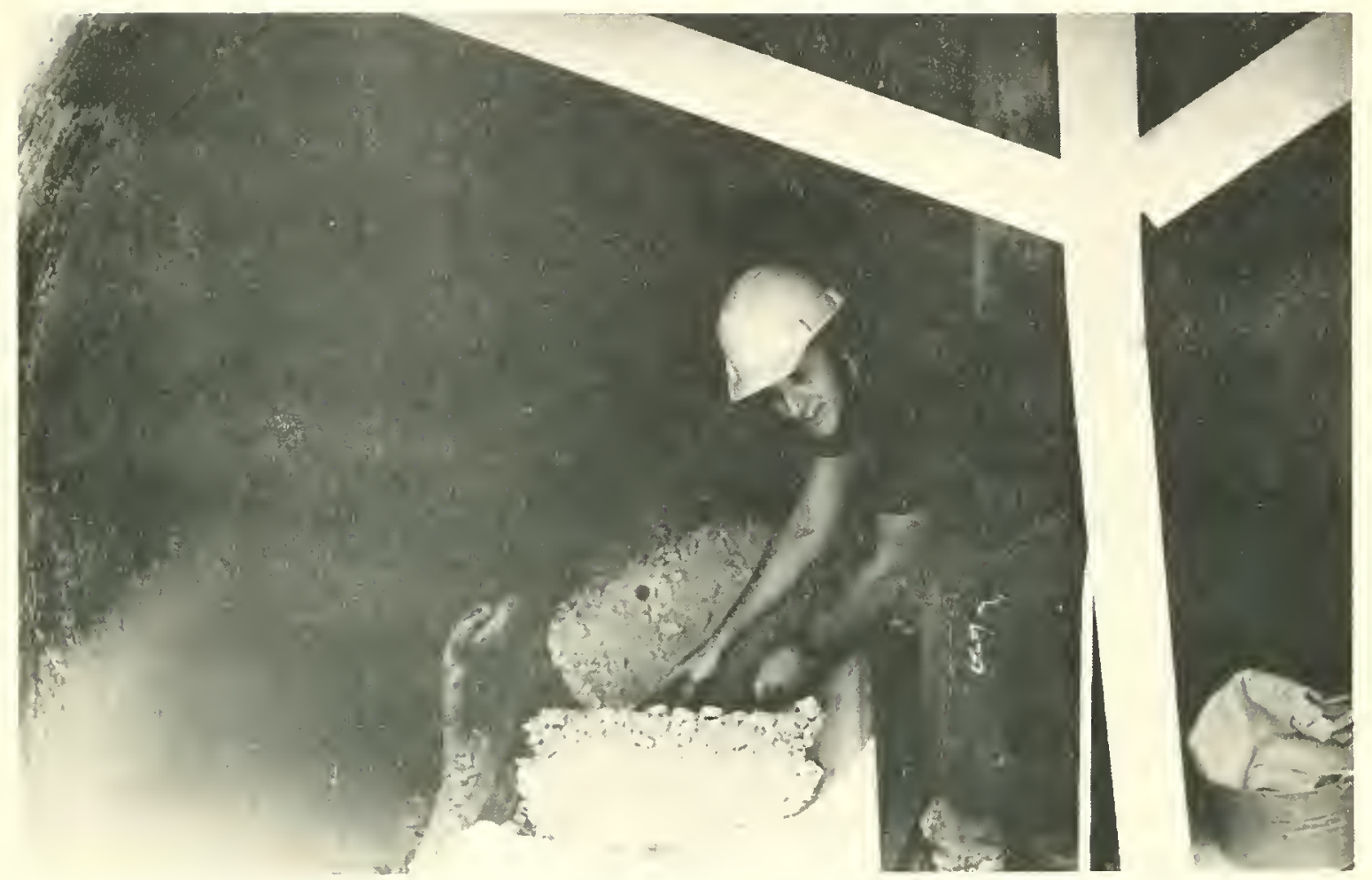

FIGURE 9. ISOLATING BELT SAMPLE. 


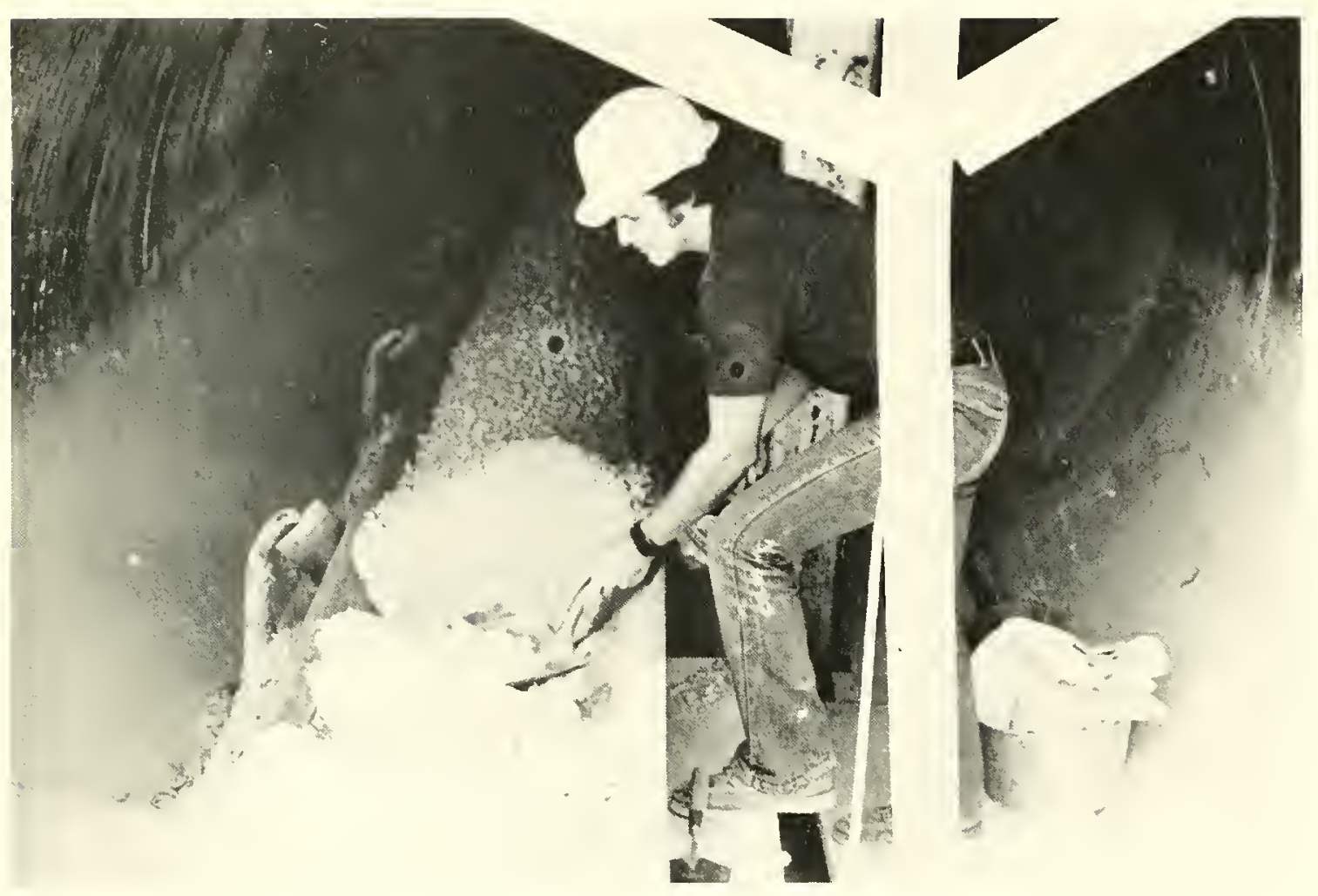

FIGURE 10. OBTAINING ISOLATED SAMPLE FROM BELT. 


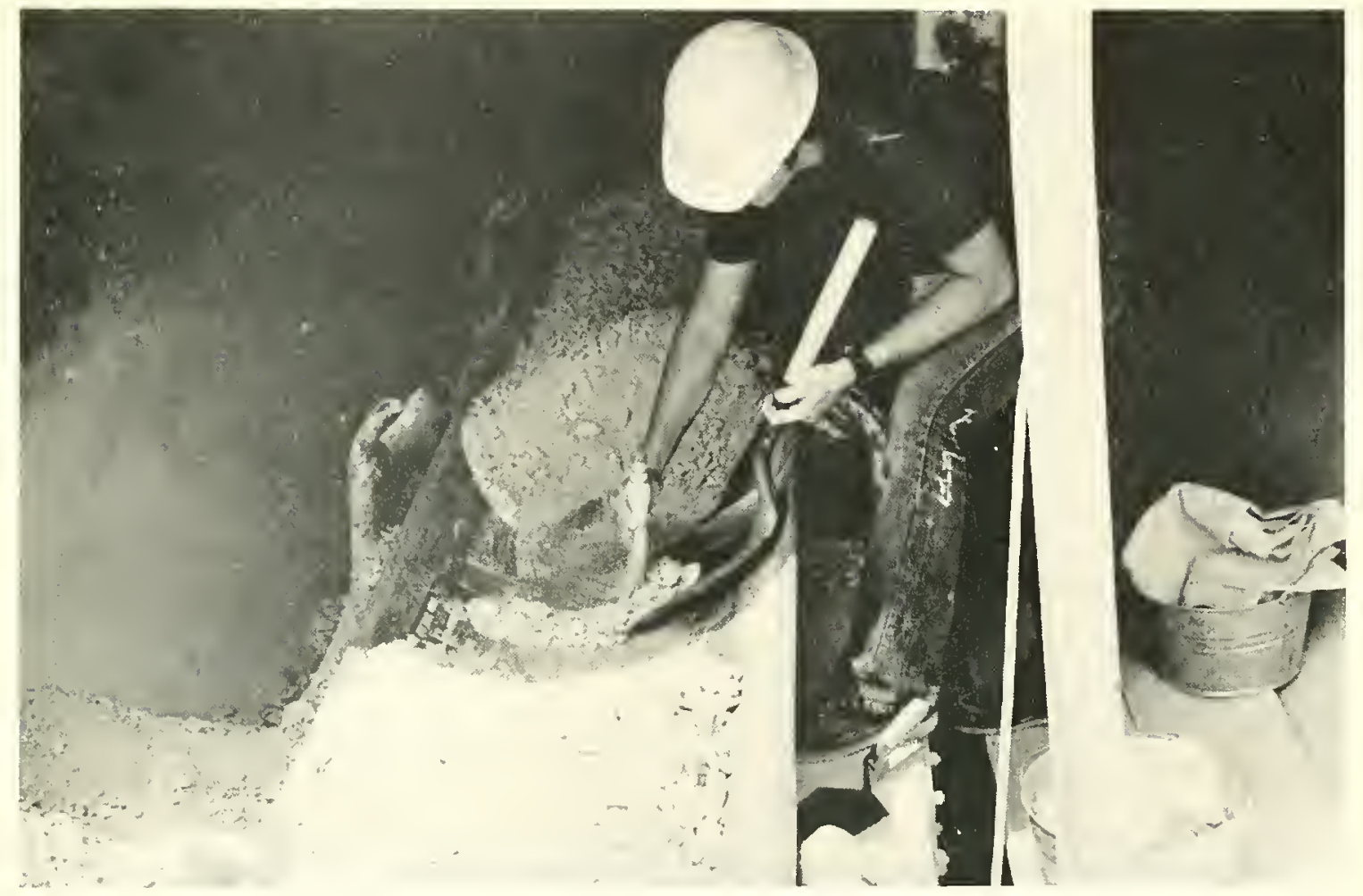

FIGURE 11. SWEEPING BELT TO OBTAIN ENTIRE SAMPLE. 


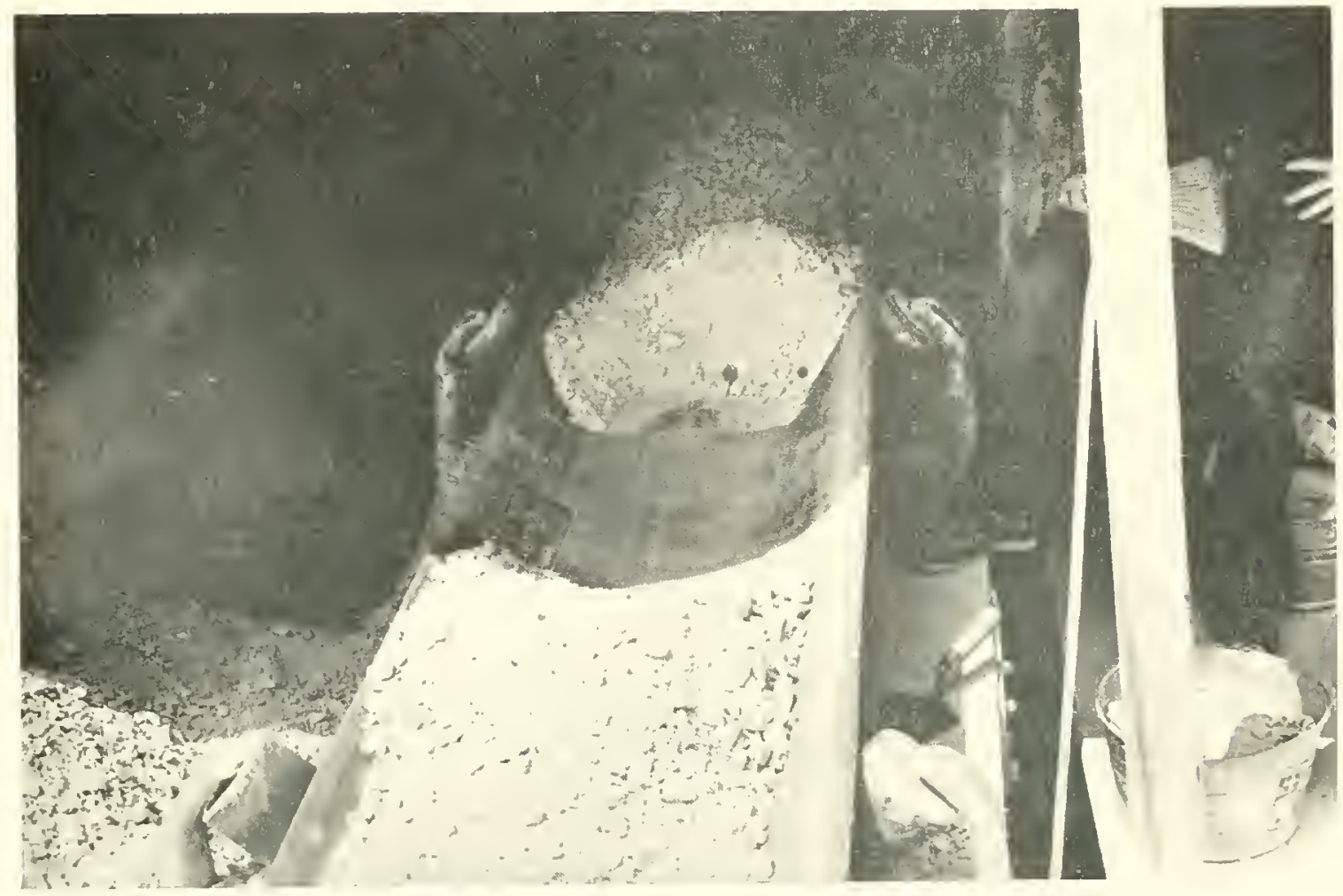

FIGURE 12. BELT AFTER SAMPLE WAS OBTAINED. 


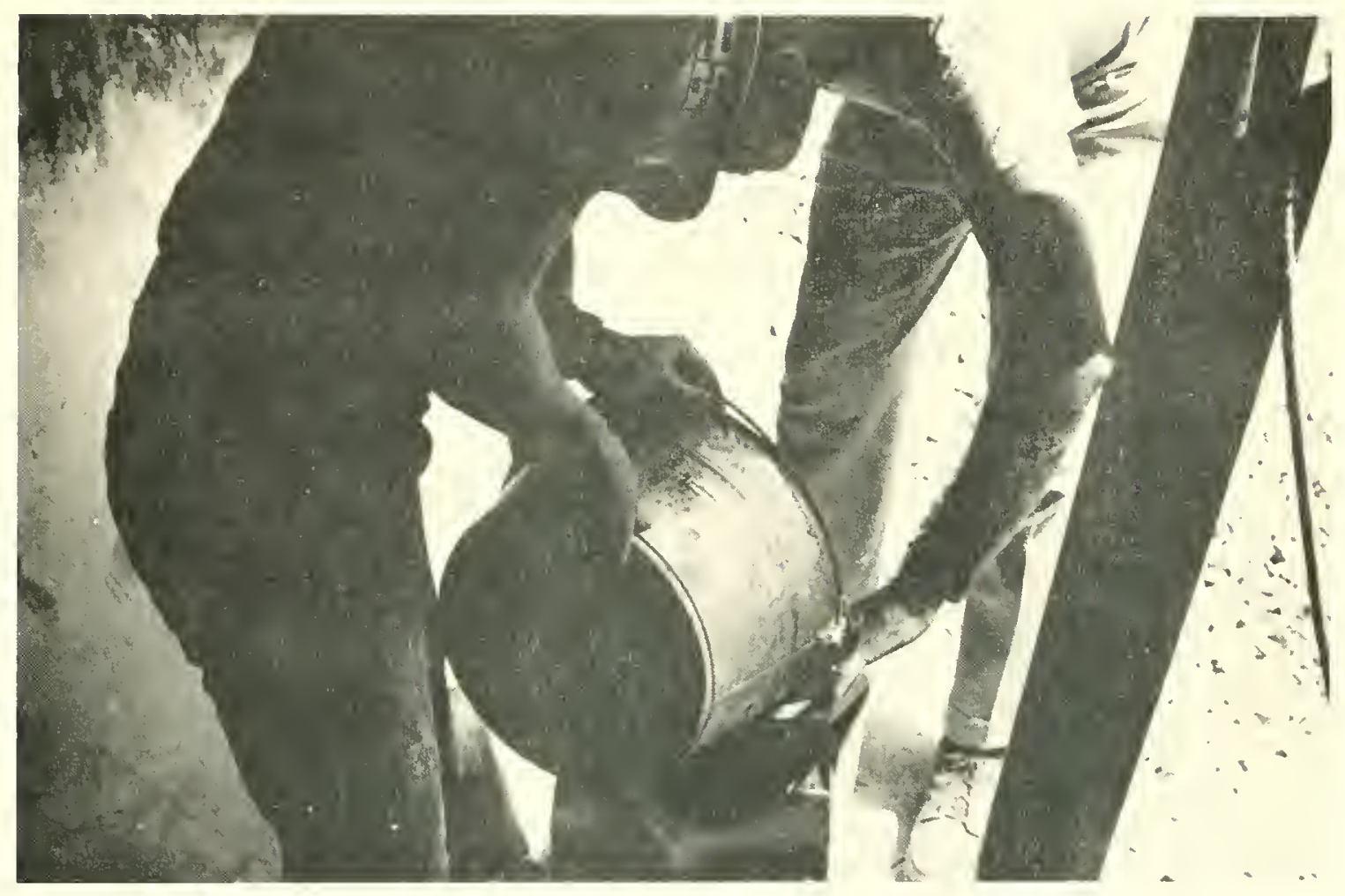

FIGURE 13. BAGGING PROCESS AT PUGMILL. 
was taken because only two people worked at the aggregate plant and the other worker had to be prepared to obtain a sample from the pugmill immediately after the sample was taken on the belt.

The pugmill in operation is shown in Figure 14. Obtaining a representative sample at this point was a difficult task. If a truck load of material was first dumped and then sampled, the problems of stockpile sampling would prevail. In order to obtain a sample of material as it flowed from the pugmi11, a sampling device was designed (see Appendix for discussion of device). The sampling device was not used because it rested on the side boards of the trucks and many of the trucks for this project had non-uniform side boards.

The method finally used for pugmill sampling was to place a worker in a truck bed and let him catch a freefalling sample with a bucket which was of an appropriate sample size (Figure 15). After a few trials, the sampler was able to move the bucket under the complete stream without overflowing the bucket. This method is believed to give a more representative sample than could be obtained from a filled truck bed.

One handicap to this sampling method is that a truck must be sampled before a large quantity of material has been dumped into its bed. Since there was very good correlation between the sample and its replicate at this point, reproducibility of this sampling technique is indicated. 


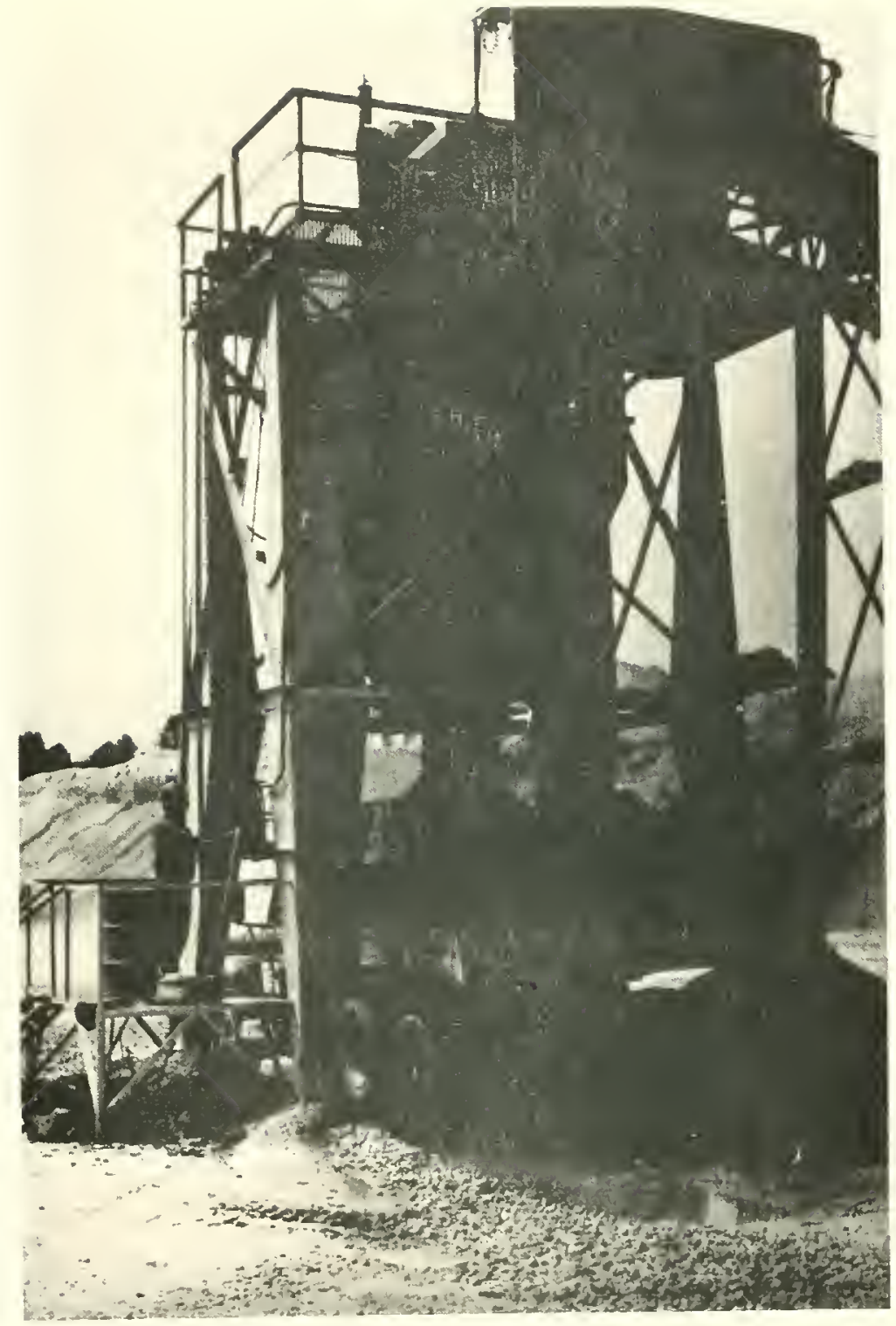

FIGURE 14. PUGMILL IN OPERATION. 


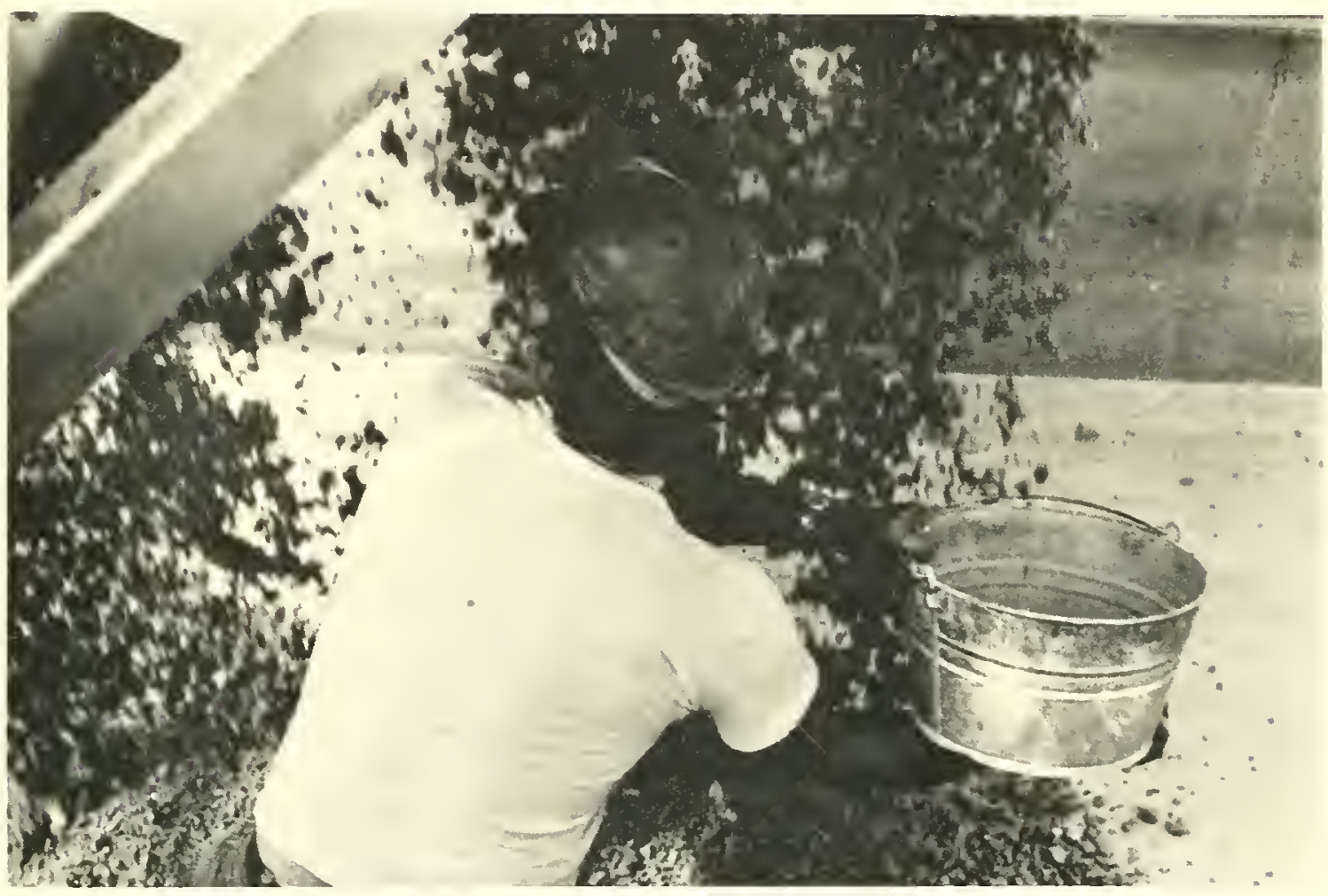

FIGURE 15. FREE FALL SAMPLING OF PUGMILL OUTPUT. 
The replicate sample was taken in the same method from second truck which hauled the remaining part of the batch of material.

Before a truck carrying sampled material left the aggregate plant, it was flagged with a piece of highway ribbon (Figure 16). By knowing when the truck was sampled and the haul time to the jobsite, the flagged trucks could be easily identified by the jobsite personnel.

\section{Jobsite}

As previously noted, the sampling points on the jobsite were before and after compaction. Samples were not taken from the spreader box due to the time delay this would cause in the construction operation.

Knowing the time a certain batch of material should arrive on the jobsite made spotting the trucks carrying material to be sampled very easy (Figure 17). The trucks were followed until they were ready to dump (Figure 18). previous observations had revealed that the material to be sampled would begin to be placed on the roadway approximately four feet in front of the auger of the spreader. This point was marked and the station number recorded.

Sampling procedures before and after compaction were very similar. Because of previous conferences with the contractors' representatives, state officials, and observations, an estimate of the length of spread covered by one batch had been established as twenty-five feet for 


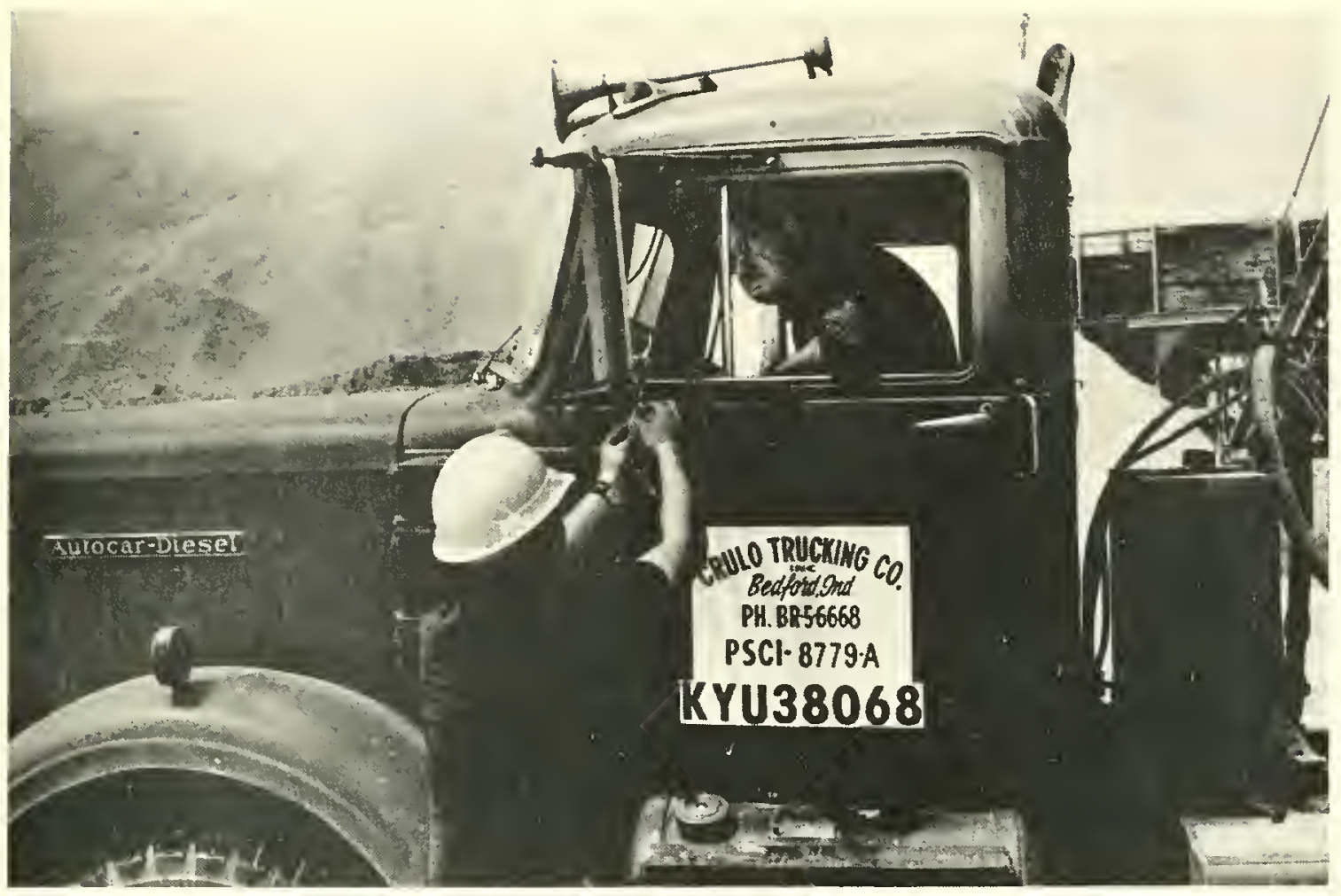

FIGURE 16. IDENTIFICATION OF SAMPLE BEARING TRUCK. 


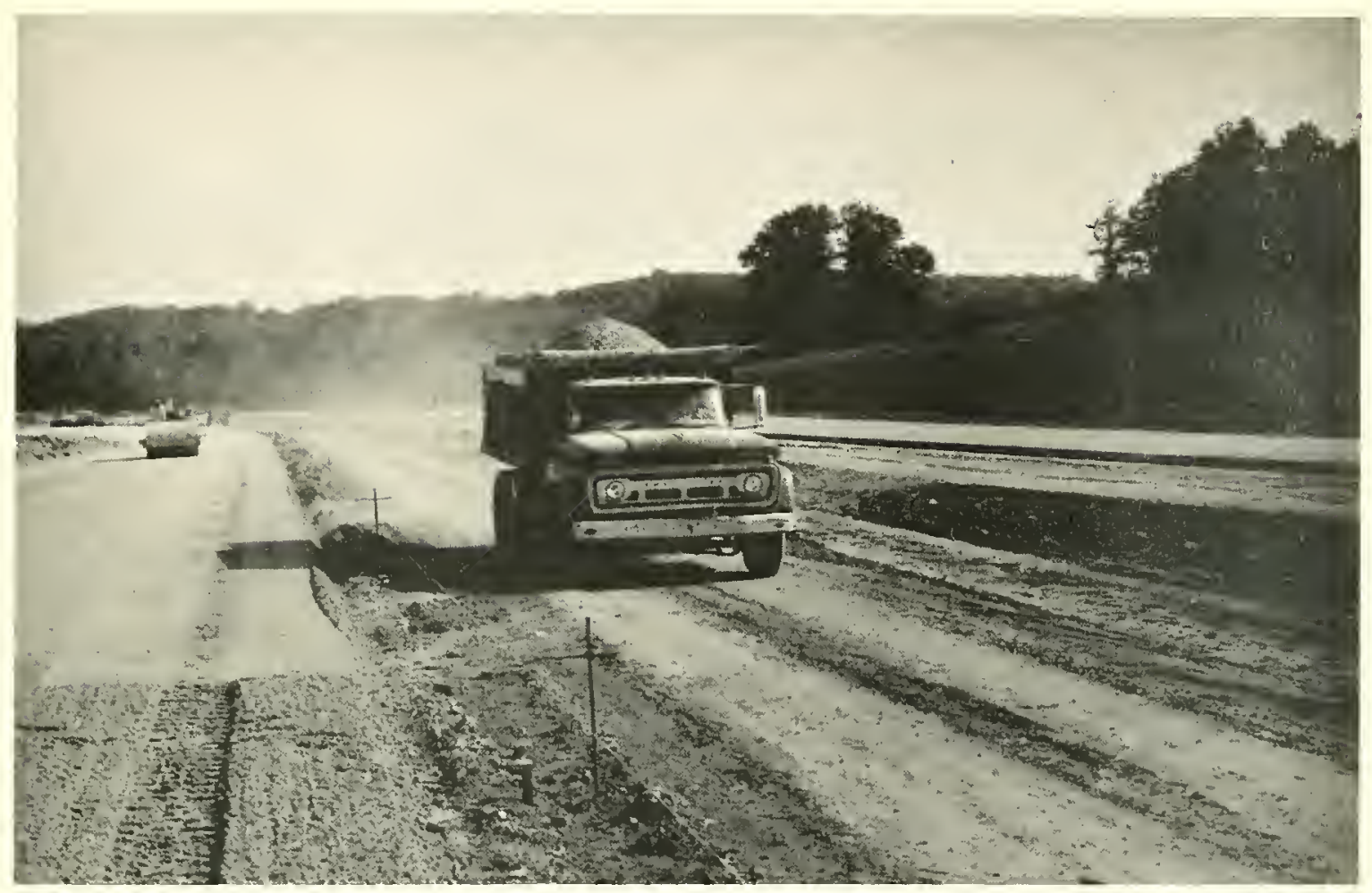

FIGURE 17. TRUCK IDENTIFICATION AT JOBSITE 


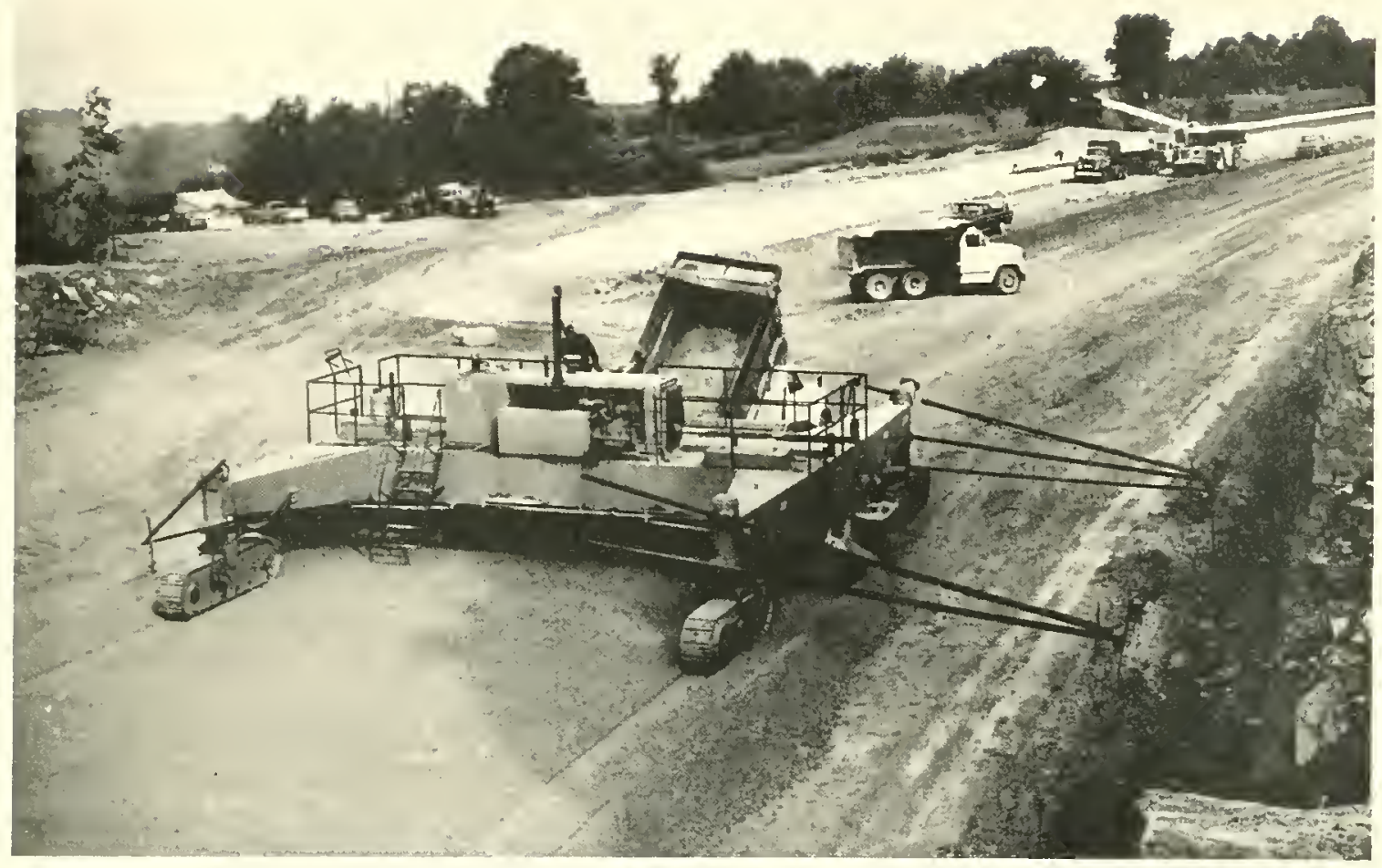

FIGURE 18. DUMPING PROCESS AT JOBSITE. 
the thirty-two feet wide roadway. By using a table of random numbers, both a length between zero and twenty-five and a width between zero and thirty-two were chosen. Measuring always from the left side of the road and the point previously marked for the sample batch, and using the random numbers selected for the length and width for the batch, the sampling point was chosen. If the sampling point was less than $11 / 2$ feet from any boundary of the batch, it was moved away from that boundary until it was at a distance of $11 / 2$ feet from the boundary. The purpose of this move was that a three foot square hole was to be used for sampling and only material sampled previously at other points was desired for inclusion (Figure 19).

As already mentioned, replicate samples were taken at each point. A replicate sample center was located directly four feet behind the randomly selected sample center (random length minus four); however, if the randomly selected sample occurred less than $51 / 2$ feet from the beginning of the batch of the material, the replicate center was located four feet in front of the randomly selected sample (random length plus four) (Figure 20).

Figures 20 through 28 show the road sampling process before compaction. One hole center was randomly chosen within the batch of material and the replicate center was chosen directly behind it. lach hole was estimated for a $3^{\prime} \times 3^{\prime}$ square (Figure 20). Each hole was dug separately and the material piled in a cone for quartering. Material 


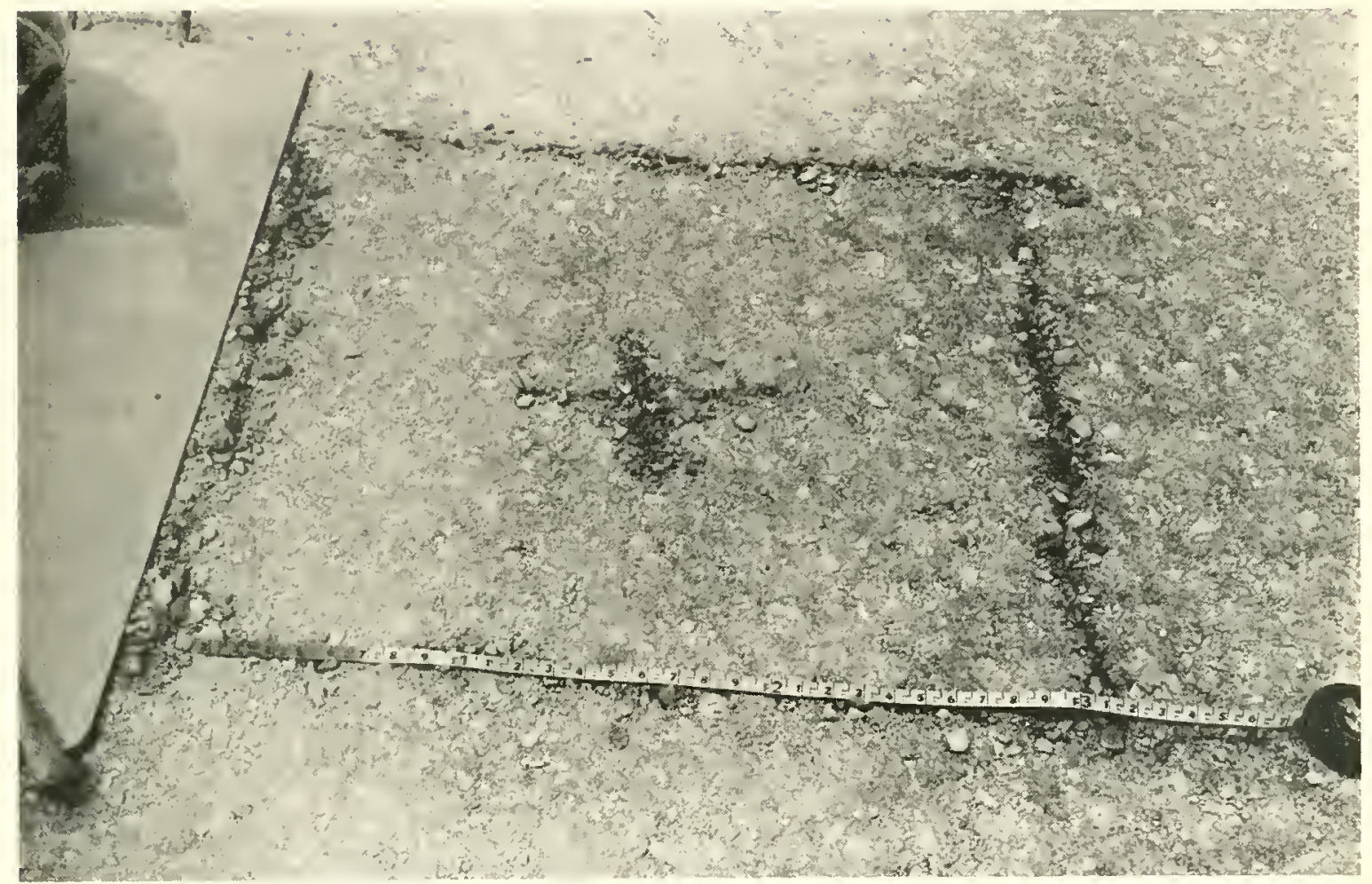

FIGURE 19. LAYOUT OF JOBSITE SAMPLE. 


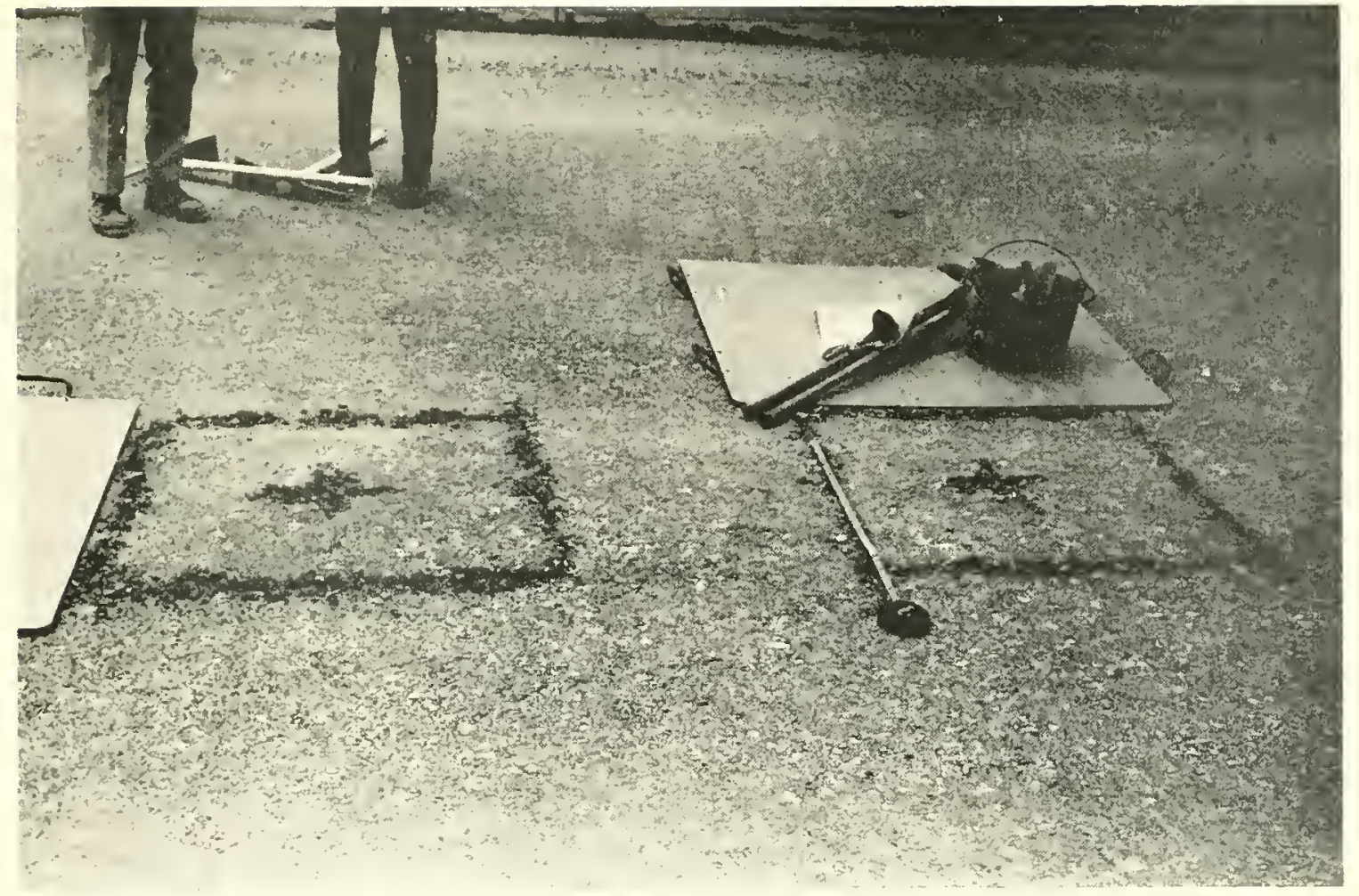

FIGURE 20. SAMPLE LOCATION. 


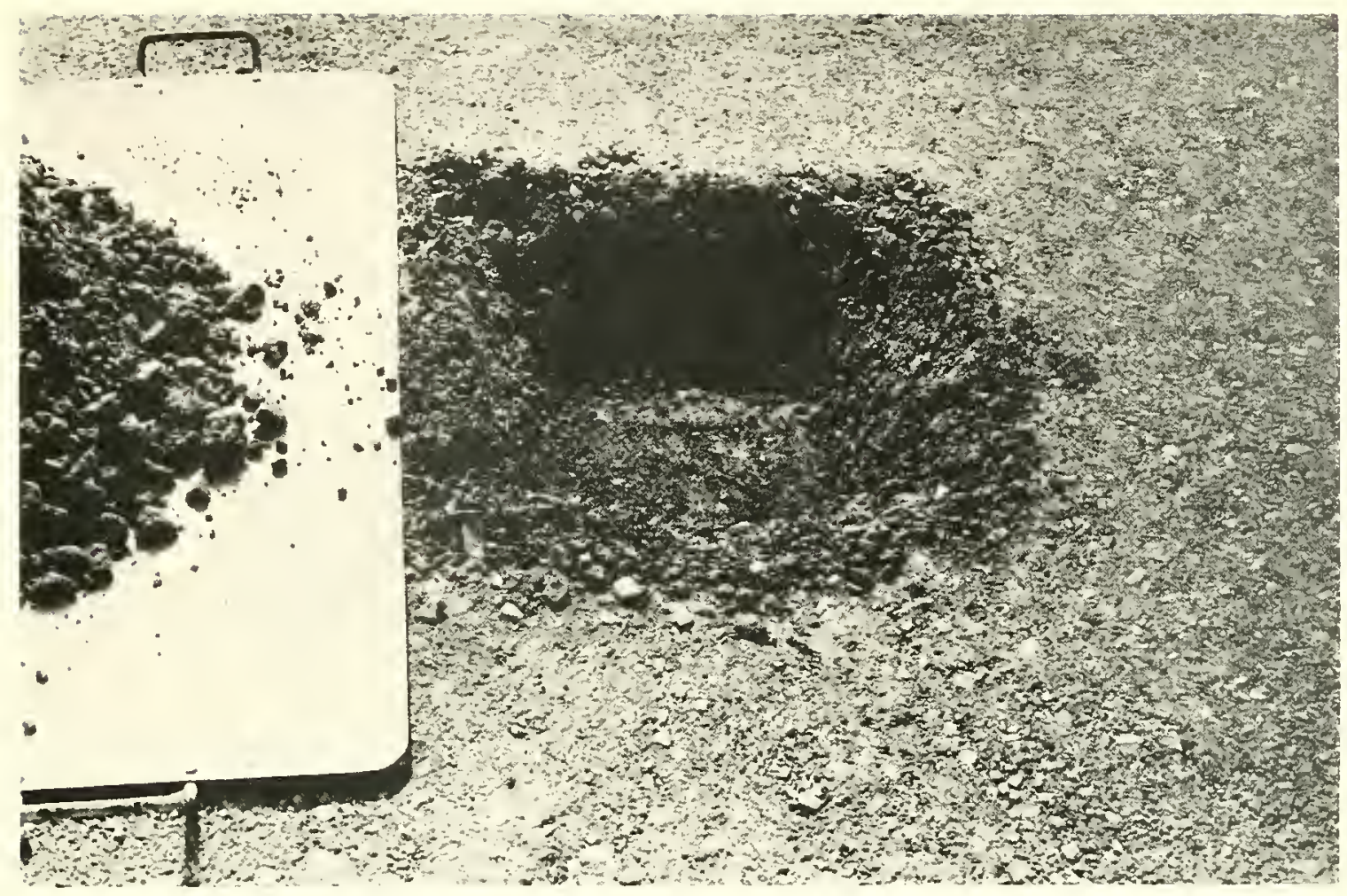

FIGURE 21. CLEANED SAMPLE HOLE. 


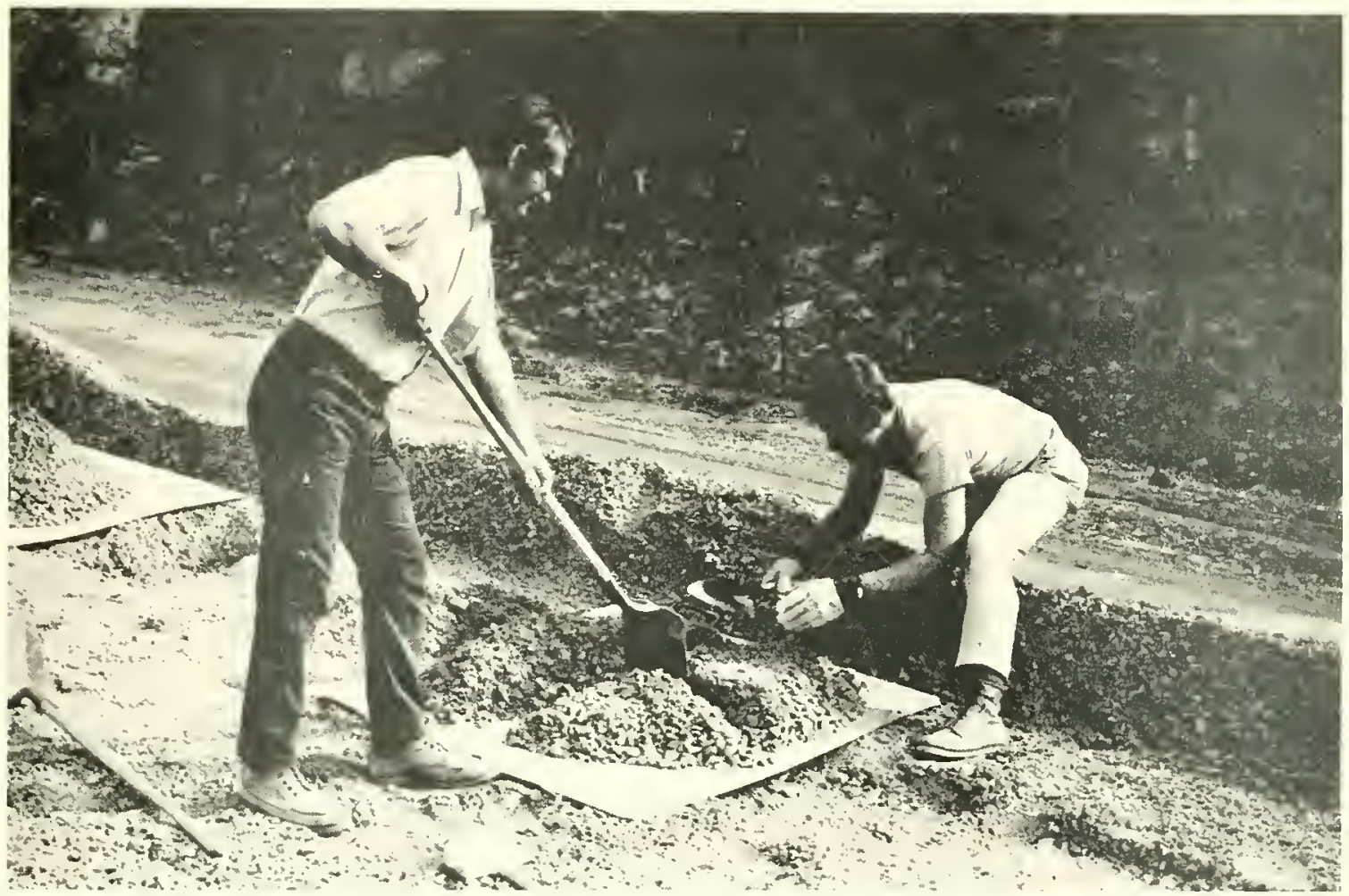

FIQURE 22. MATERIALS BEING SPLIT INTO FOUR SAMPLES. 


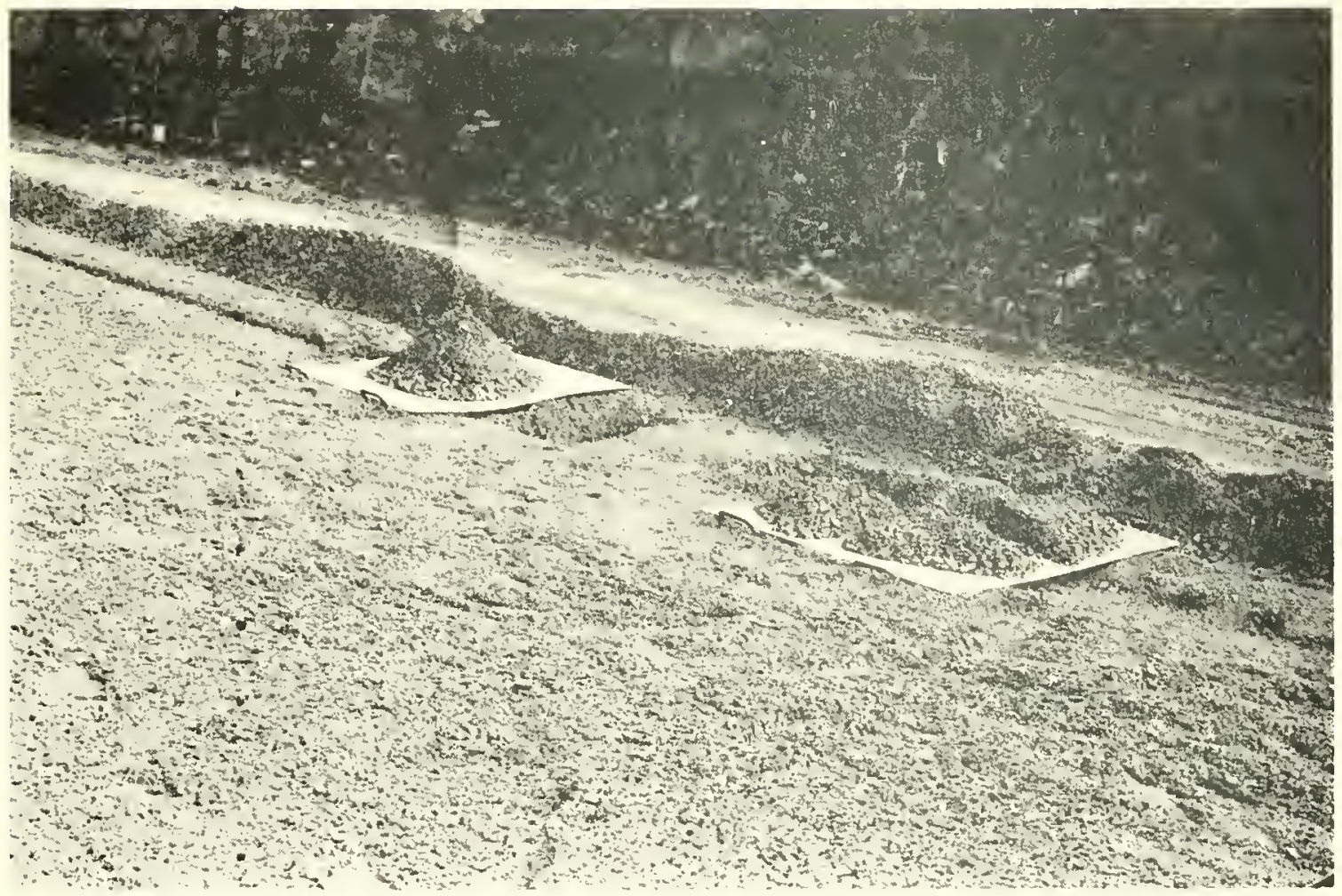

FIGURE 23. CONED AND QUARTERED MATERIAL PILES 


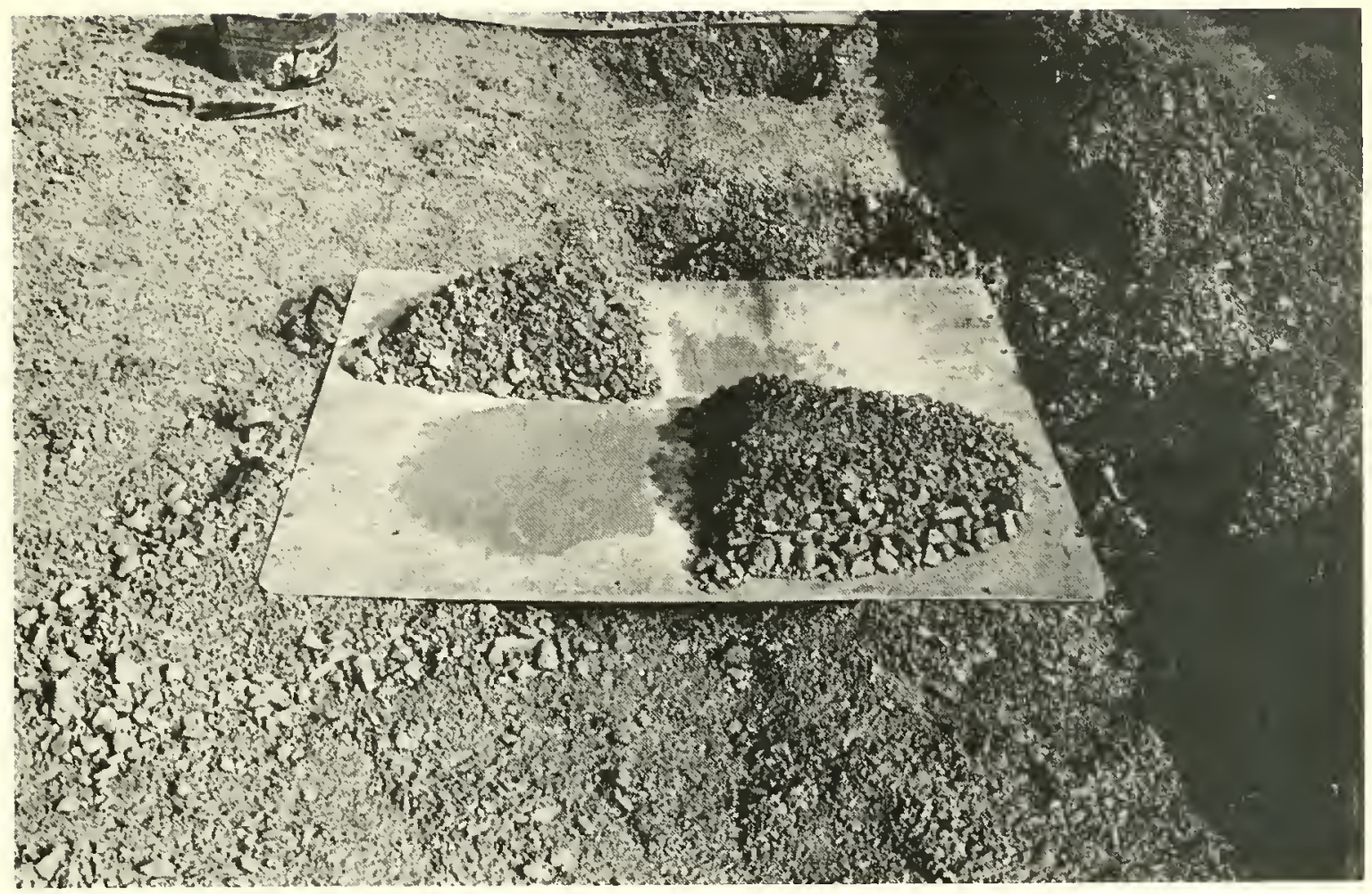

FIGURE 24. MATERIAL SPLIT BY REMOVING OPPOSITE QUARTERS 




FIGURE 25. SAMPLE AND REPLICATE WITH TWO QUARTERS REMOVED. 


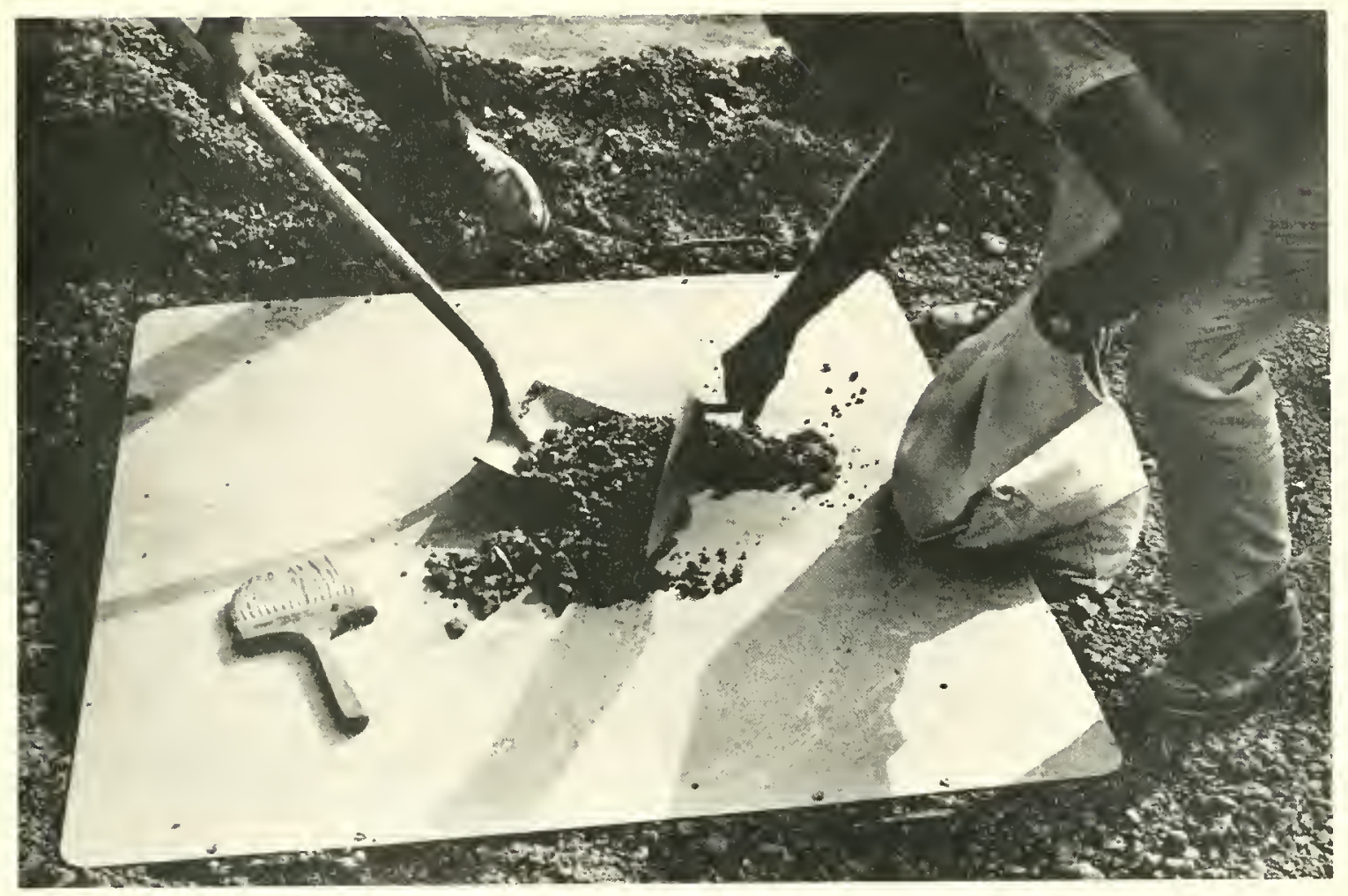

FIGURE 26. BAGGING PROCEDURE AT JOBSITE. 


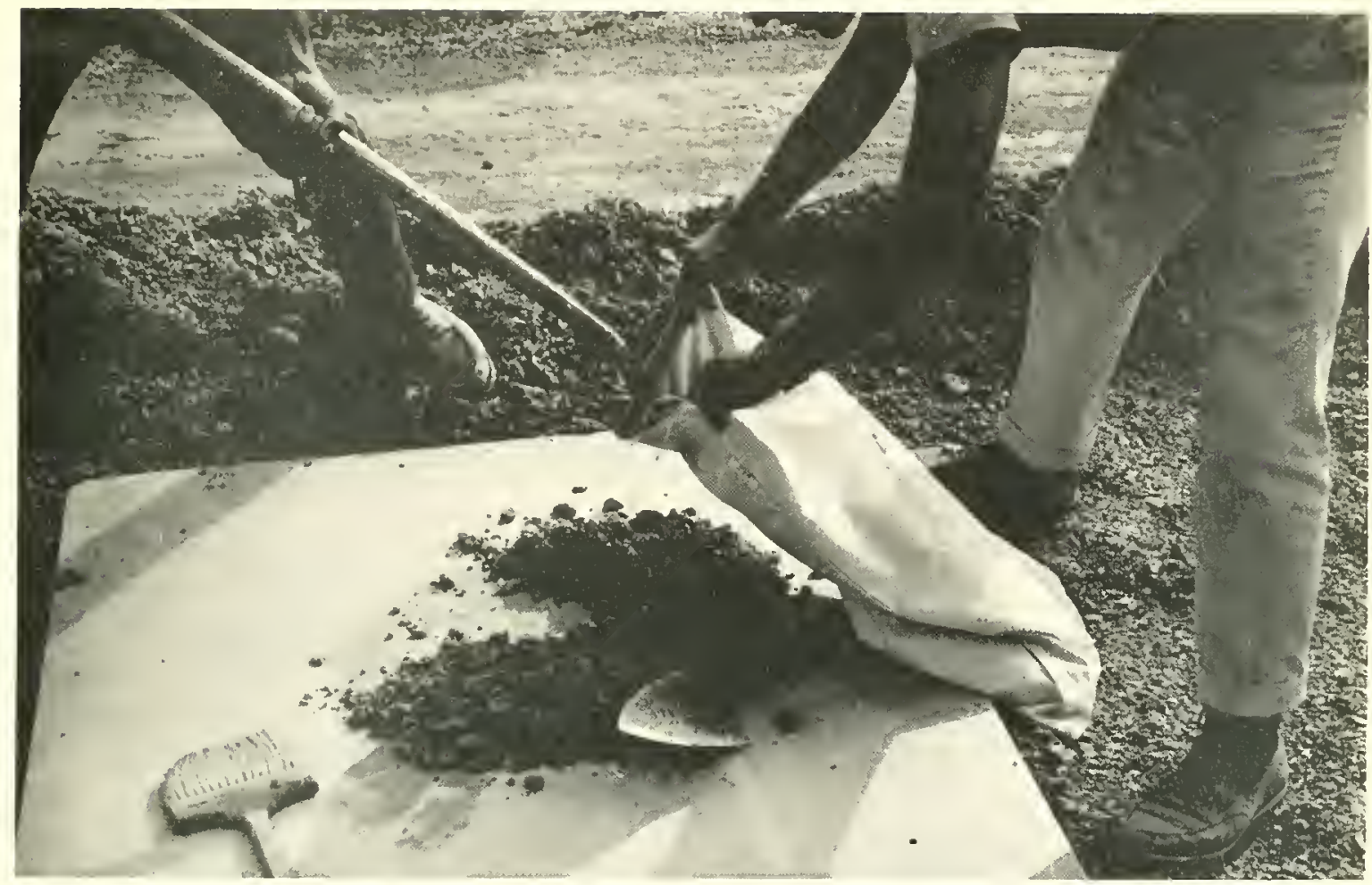

FIGURE 27. INSURING NO MATERIAL IS LOST DURING BAGGING. 


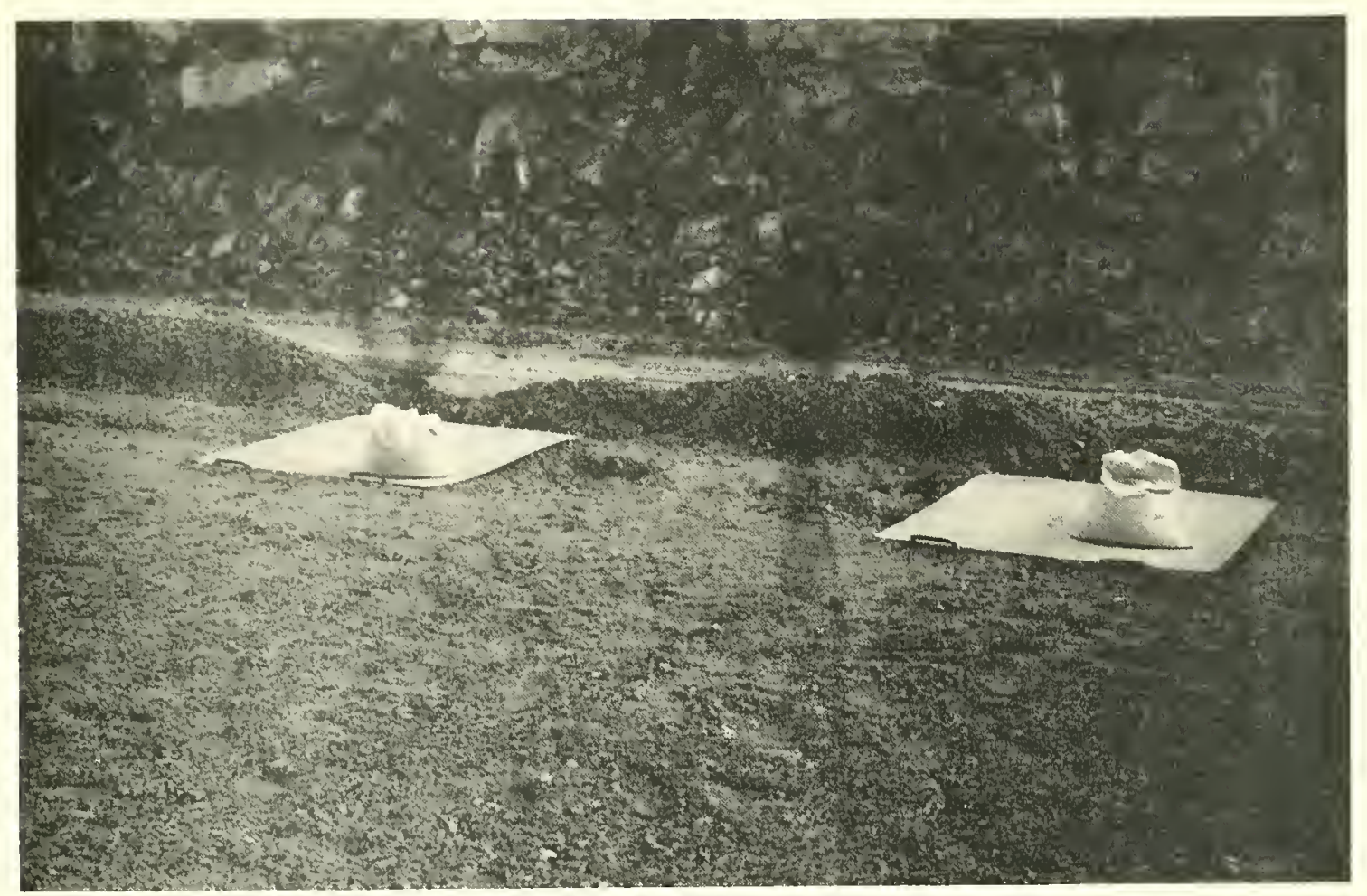

FIGURE 28. SAMPLES AFTER BAGGING PROCEDURE AT JOBSITE IS COMPLETED. 
had to be split on the jobsite because of the mass of material, approximate1y 450 pounds were obtained from each hole (Figures 21, 22, and 23). After the material was split into four quarters, opposite quarters were returned to the hole (Figures 24 and 25 ). The remaining material was remixed and quartered again. Usually, three splitting operations were required before a sample of approximately 50 pounds, a transportable size sample, was obtained. Before bagging the sample, the material was again remixed. Care was taken in the bagging operation to not lose any of the material, especially the fines (Figures 26,27 and 28). A possible handicap of splitting samples on the jobsite is the loss of fine material because of wind. llowever, the samples in this study were sufficiently damp because of the water that had been added to the material in the pugmill; and thus, such losses of fines were negligible.

Samples and duplicates taken after compaction were obtained in the same manner as before compaction samples, except for an initial loosening of the material. New random coordinates for length and width were, of course, obtained, but the process for hole location and boundary conditions rules remained fixed. Since the material was now in a dense state after compaction with a vibratory compactor (Figure 29), a railroad pick was used on the holes to initially loosen the top portion of the material. After the material for the uncompacted and compacted samples had been bagged, they were loaded into a station wagon (Figure 30 ), 


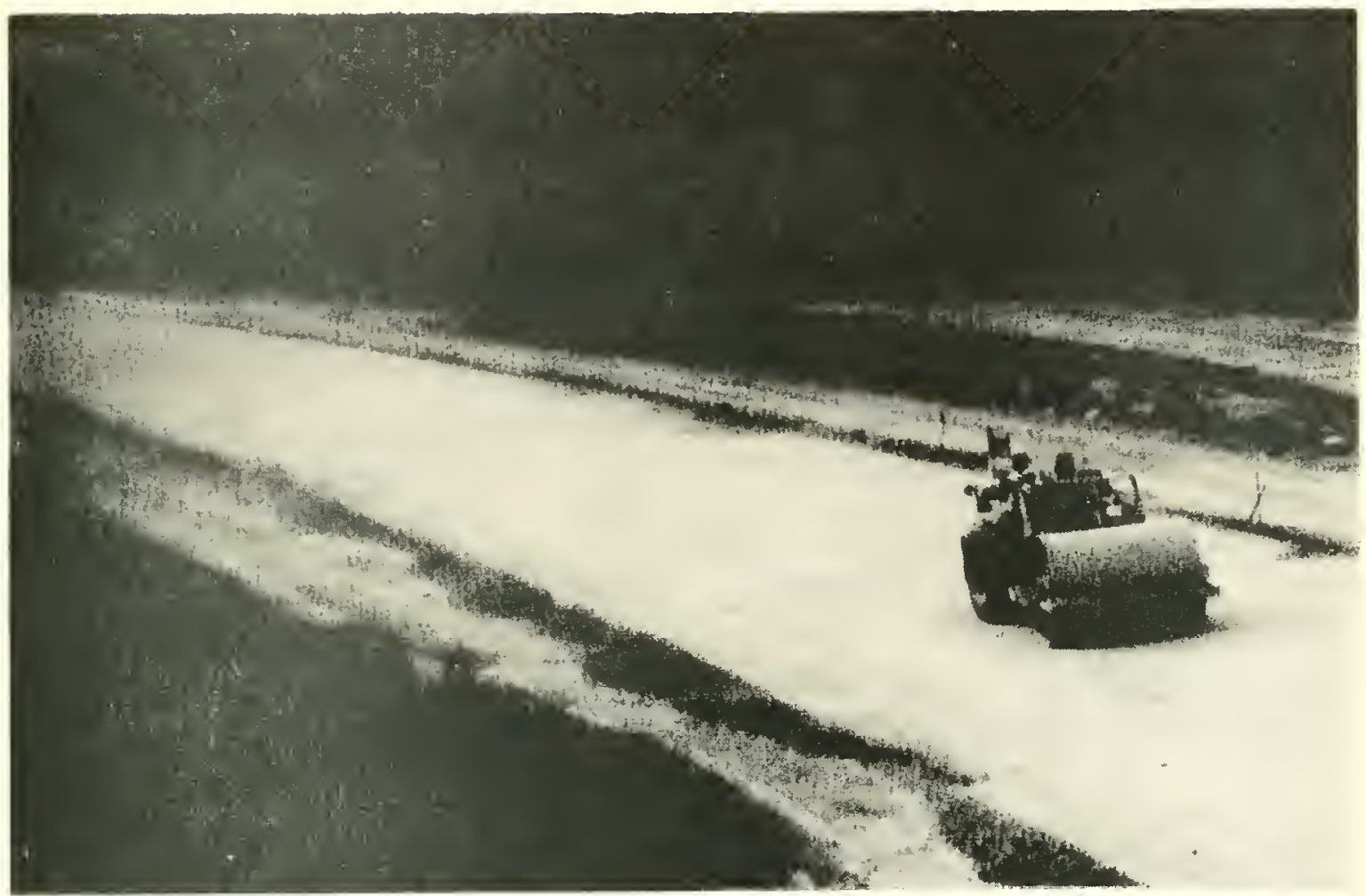

FIGURE 29. VIBRATORY COMPACTOR IN OPERATION. 


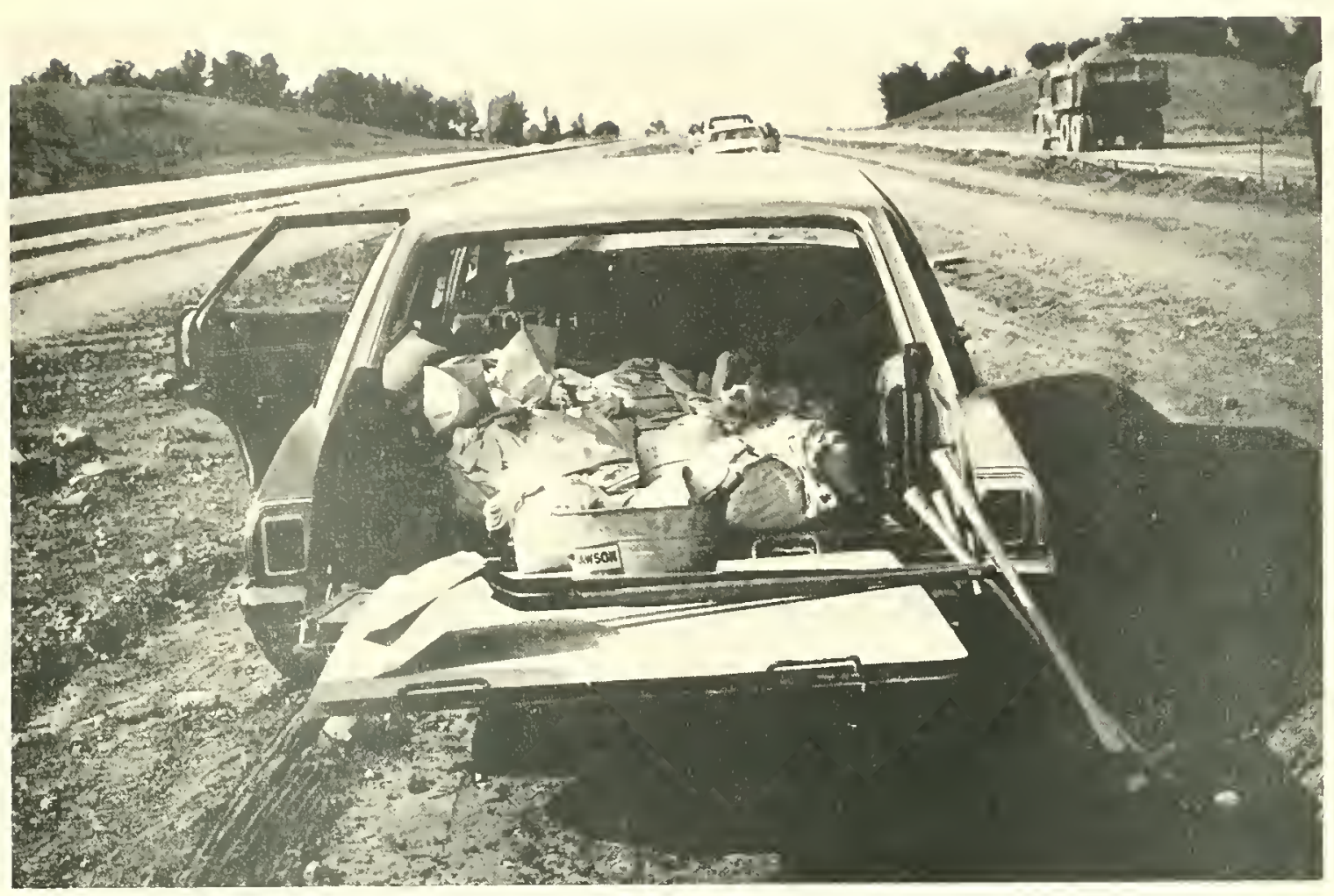

FIGURE 30. SAMPLES READY FOR TRANSPORTATION TO TEMPORARY STORAGE. 
and at the end of each day were transported to covered temporary storage before truck-transported to 1aboratory facilities at Purdue.

\section{Job Size}

Because each sample covered approximately only one hour of production and thus only five hours per full work day, the question arises as to whether the project was of a significant size. The total amount of amaterial hauled to the jobsite for the base course was $54,615.35$ tons. Samples could have been chosen for only 315 minutes out of a possible 600-minute work day. The amount of material which had a chance to be chosen was 28,673 tons which is equivalent to approximately $21,200 \mathrm{yd}^{3}$ of material. This is more than double the minimum requirement of $10,000 \mathrm{yd} .{ }^{3}$ recommended by Bureau of Public Roads for statistical sampling (3). 
STATISTICAL ANALYSIS OF LABORATORY PROCEDURE

Established guidelines for the laboratory sieve analysis of both fine and coarse aggregate have been set forth in AASHO Designations: T11-60 and T27-60. These two methods were combined for the laboratory analysis of most of the samples in this rosearch study. The convenience of using a small sample of the fine material was studied by using AASHO Designation T88-70, Grain-Size Analysis of Soils, and variation of this method. The hydrometer analysis part of the test for very fine material was not used. A11 comparisons were based on a " $t$ " analysis for paired observations (18) testing the assumption, " $\mu_{1}=\mu_{2}$ ".

Since all additional tests were either to be performed by MASHO T88-70 or a method similar to it, AASHO T88-70 was used as the standard. In order that these additional tests could be used in the statistical analysis the initial comparison was between AASHO T88-70 and the AASHO standard test for aggregates $\mathrm{T} 11-60$ and $\mathrm{T} 27-60$. The results of the " $t$ " analysis is given in Table 4 .

AASHO T88-70 and AMSHO T11-60 and T27-60 require obtaining a specified sample size by a sample splitter or quartering method. Nfter obscrving the splitting operation, accuracy of the sample splitter technique was studied. To 
Table 4." $t$ "Test for Paired Observations, T88-70 Sample Splitter Split vs. T11-60 and T27-60

\begin{tabular}{cccc}
$\begin{array}{c}\text { (1) } \\
\text { Size }\end{array}$ & $\begin{array}{c}(2) \\
\text { Calculated } \\
\text { Value }\end{array}$ & $\begin{array}{c}\text { (3) Value } \\
\alpha=40 \%\end{array}$ & $\begin{array}{c}(4) \\
\text { Degrees of } \\
\text { Freedom }\end{array}$ \\
\hline $1^{\prime \prime}$ & -0.023 & .883 & 8 \\
$3 / 4^{\prime \prime}$ & .167 & .883 & 8 \\
$1 / 2^{\prime \prime}$ & .185 & .883 & 8 \\
No. 4 & .197 & .883 & 8 \\
No. 8 & .037 & .883 & 8 \\
No. 30 & .095 & .883 & 8 \\
No. 200 & -0.105 & .883 & 8
\end{tabular}

* If column 3 less than column 2 then statistically critical value 
solve the problem, several samples were initially analyzed by the AASHO T88-70 method using the sample splitter technique. The material used in the analysis was saved and remixed with the bag of material from which it had been obtained. The total sample was next analyzed by the AASHO T88-70 method. The results revealed that the same conclusions would be reached using either analysis arc shown as actual and calculated " $t$ " values in Table 5.

The questions of splitting was further expanded by dividing the material into three size groups by means of a large sieve shaker and then splitting the material on the sample splitter by size groups. After reducing the material to the required sample size, AASHO T88-70 was used for analysis. The results obtained by comparing the usual sample reducing technique prescribed by AASHO T88-70 and the addition of the intermediate sieve split are shown as actual and calculated " $t$ " values in Table 6 . Due to the results obtained, this brief pilot study indicates that all the splitting operations were identical.

After the comparison between AASHO T88-70 and AASHO T1160 and T27-60, a small pilot study was also initiated to attempt to see if using a 150 grams of fine material actually represents the total amount of fines (material passing the No. 4 sieve). This comparison was made by splitting two samples of correct size for analysis from a bag of material. One sample was performed by AASHO T88-70. The second sample used the total amount of fine material but still followed 
Table 5."t"-Test for Paired Observations, T88-70, Sample Splitter Split vs. T88-70 Using Total Amount of Coarse Material

\begin{tabular}{|c|c|c|c|}
\hline $\begin{array}{c}\text { (1) } \\
\text { Sieve } \\
\text { Size } \\
\end{array}$ & $\begin{array}{l}\text { (2) } \\
\text { Calculated } \\
+\quad \text { Value } \\
\end{array}$ & $\begin{array}{c}(3) \\
t \text { Value * } \\
\alpha=40 \%\end{array}$ & $\begin{array}{l}\text { (4) } \\
\text { Degrces of } \\
\text { Ereedom. }\end{array}$ \\
\hline $1^{\prime \prime}$ & -.243 & .941 & 4 \\
\hline $3 / 4^{\prime \prime}$ & -.622 & .941 & 4 \\
\hline $1 / 2^{\prime \prime}$ & -.312 & .941 & 4 \\
\hline No. 4 & -.025 & .941 & 4 \\
\hline No. 8 & .274 & .941 & 4 \\
\hline No. 30 & .342 & .941 & 4 \\
\hline No. 200 & .286 & .941 & 4 \\
\hline
\end{tabular}

*If column 3 is less than column 2 then statistically critical value 
Table 6."t"-Test for Paired Observations T88-70 Sample Splitter Split vs. T88-70 Gilson Split Followed by Sample Splitter Split

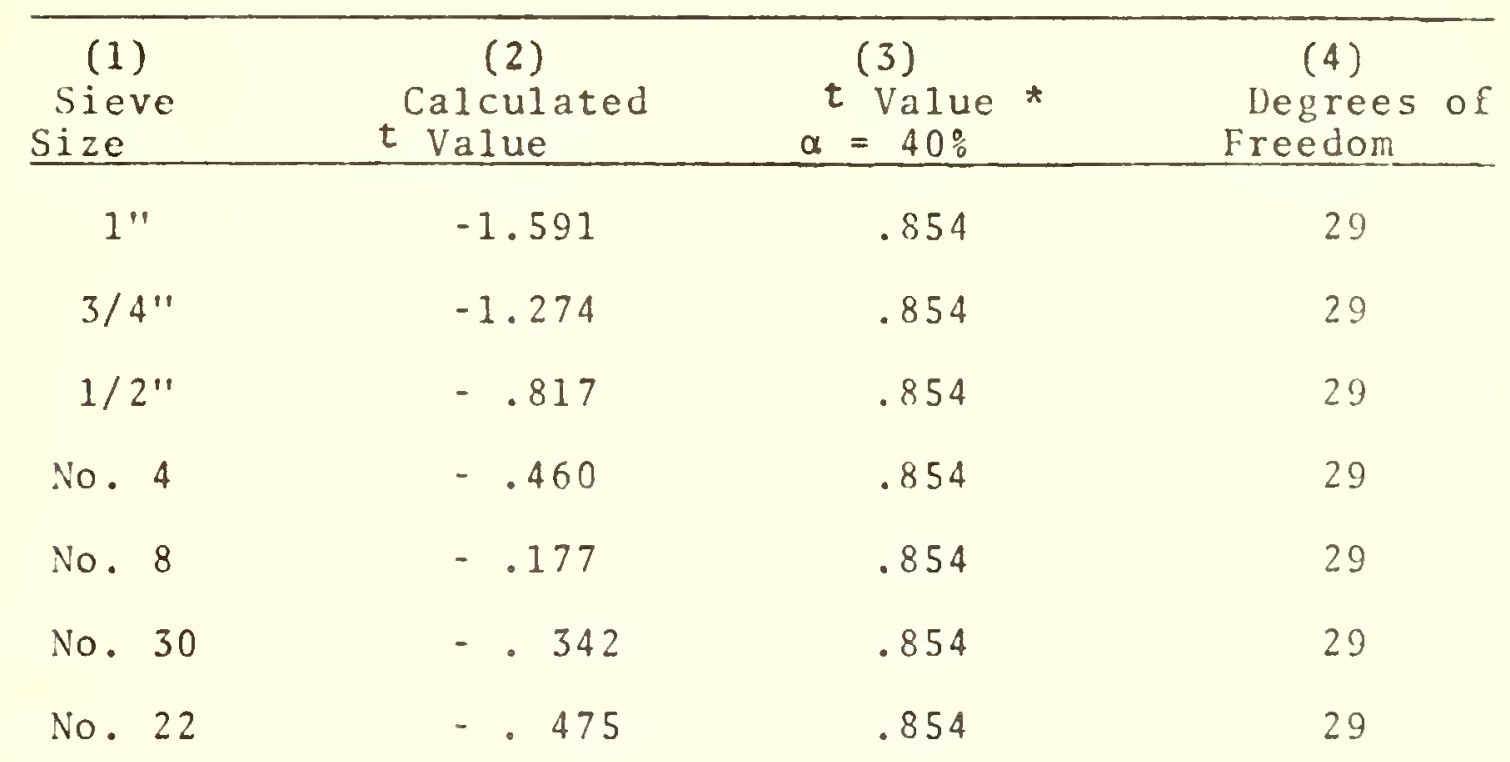

* If column 3 is less than column 2 then statistically critical value 
the process for analysis of $T 88-70$. The results of this analysis proved very consistent and are shown as calculated and actual " $t$ " values in Table 7 .

By reducing the acceptance level to an alpha of forty percent, the chance of accepting a bad sample, the possibility of stating $\mu_{1}=\mu_{2}$ when actually it is not, was decreased considerably. Calculated " $t$ " values in each case were very close to zero which gives the indication that the methods are the same or that the variances are not homogeneous. To insure against non homogeneous variances the Foster-Burr analysis for Equality of Variances was used. Since this is also a requirement for analysis of variance calculations to be used later, all of the data were used and divided into the smallest subgroups possible so one analysis would suffice for both conditions. At the pugmill, the data were categorized according to place and test method. Samples obtained on the jobsite were categorized by before or after compaction, testing method, and sampling position on the roadway.

The sampling positions on the jobsite, as previously mentioned, were randomly selected for a specific batch of material. Furthermore, laboratory testing of the samples followed no specific order. Because of these two conditions samples obtained near the beginning of the project could have been grouped with samples obtained anywhere within the project. Also samples could have been grouped with only consecutive samples. By grouping samples in this manner, 
Table 7." $t$ "-Test for Paired Observations T88-70 Sample Sp1itter vs. T88-70 Sample Splitter Using A11 Fines Minus 150 Grams for liygroscopic Moisture

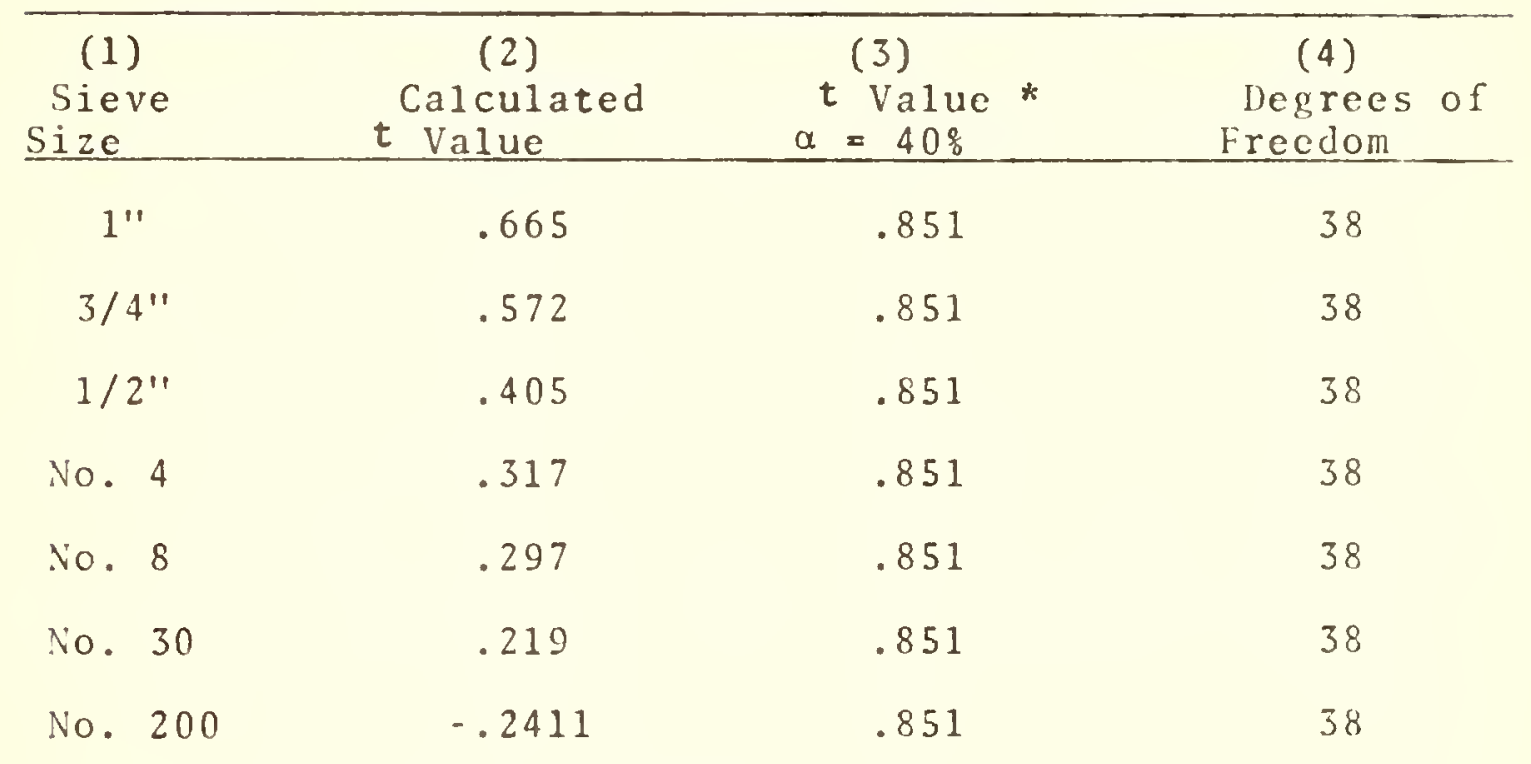

${ }^{*}$ If column 3 is less than column 2 then statistically critical value 
the worst possible condition for proving the variances to be homogeneous resulted.

Table 8 shows the results of the Foster-Burr Analysis for Equality of Variance. The upper range sieve sizes are slightly marginal, but most acceptable according to purdue University's statistical consultants. The analysis, therefore, shows that the variances are homogeneous, the " $t$ " analysis can be accepted, and, furthermore, all samples can be grouped together for further analysis.

The results suggest that AASHO T88-70 yields essentially the same results as methods AASHO T11-60 and AASHO T27-60. 
Table 8. Summary of Foster-Burr Homogeneity of Variance Test (1) (2) (3)

3) (4)

Tabular

Statistic Homogeneity

Sieve No. of O Statistic

Size

Samples a

From Data
$\alpha=$

$\begin{array}{lllll}1 " & 37 & .0470 & .0391 & \text { Marginal } \\ 3 / 4^{\prime \prime} & 37 & .0459 & .0391 & \text { Marginal } \\ 1 / 2^{\prime \prime} & 37 & .0427 & .0391 & \text { Margina1 } \\ \text { No. } 4 & 37 & .0373 & .0391 & \text { Yes } \\ \text { No. } 8 & 37 & .0347 & .0391 & \text { Yes } \\ \text { No. } 30 & 37 & .0360 & .0391 & \text { Yes } \\ \text { No. } 200 & 37 & .0372 & .0391 & \text { Yes }\end{array}$

*Accept hypothesis of homogeneity of variance if values in column (4) exceed values in column (3).

$Q=V\left(v_{1} s_{1}^{4}+\ldots+v_{p} s_{p}^{4}\right) /\left(v_{1} s_{1}^{2}+\ldots+v_{p} s_{p}^{2}\right)^{2}$

$s_{\mathbf{j}}^{2}=$ sample variance

$v_{j}=$ degrees of freedom (sample size - 1)

$\mathrm{P}=$ last sample from parent population

$Q=$ Foster-Burr Statistic 
RESULTS AND DISCUSSION OF RESULTS

\section{Introduction}

The main purpose of this study was to gain knowledge concerning aggregate segregation for Indiana Pugmill mixed No. 53 crushed stone aggregate as it was handled between the producers plant and the insitu compacted highway base. The methods of sampling lent themselves to two major approaches of data analysis. The first of these was a comparison between sampling points: pugmill feeder belt, pugmill output, before compaction, and after compaction. This approach alone, however, is not sufficient to reach definite conclusions concerning the segregation problem. Second, variations occurring within each sampling point must also be studied to insure that their magnitude is not such as to make the problem of segregation between sampling points nominal.

\section{Variations Within Sampling Points}

Experimental Variance

Variation in the material due to testing is one of the three major components of total variation. The other two components are sampling variation and inherent variation. According to previous studies $(10,11,12)$, inherent variation is by far the smallest of the three components and must be obtained by purely mathematical calculations based 
upon particle dimensions. Because of the magnitude of this variance and the fact that it is at best only an estimate, it was not calculated. By omitting the inherent variance, the experimental error (inherent variation plus testing variation) was calculated.

Experimental variation may be simply defined as a measure of operator proficiency and equipment reliability in the laboratory. It approaches a constant between and within sampling points. As a result, samples obtained from several different sampling points were grouped together for the purpose of calculating the variation due to experimental variation. Experimental variation was calculated by the following statistical formula:

$$
V_{T}=\frac{\sum_{i=1}^{n i} \sum_{j=1}^{n j}\left(x_{i j}-x_{i}\right)^{2}}{n i(n j-1)}
$$

where

$$
\begin{aligned}
& \mathrm{V}_{\mathrm{T}}=\text { variance due to testing } \\
& x_{i 1}=\text { initial sample split from a bag of material } \\
& x_{i 2}=\text { second sample split from a bag of material } \\
& x_{i}=\left(x_{i 1}+x_{i 2}\right) / 2.0 \\
& n i=\text { total number of sample bags used for analysis } \\
& n j=2
\end{aligned}
$$

In this study, several different laboratory procedures were used. Experimental variances were calculated for each method except T88-70 with all of the coarse material used in the analysis. Tables $9,10,11$ and 12 show the variances 
Table 9. Experimental Variance

T88-70 (Sample Splitter)

\begin{tabular}{ccc} 
Sieve Size & Variance & $\begin{array}{c}\text { No. of Pairs } \\
\text { Considered }\end{array}$ \\
\hline $1^{\prime \prime}$ & 3.049 & 88 \\
$3 / 4^{\prime \prime}$ & 4.824 & 88 \\
$1 / 2^{\prime \prime}$ & 6.449 & 88 \\
No. 4 & 5.018 & 88 \\
No. 8 & 4.096 & 88 \\
No. 30 & 2.576 & 88 \\
No. 200 & 1.451 & 88
\end{tabular}

Table 10. Experimental Variance

T88-70 (Initial Gilson Split)

\begin{tabular}{ccc}
\hline Sieve Size & Variance & $\begin{array}{c}\text { No. of Pairs } \\
\text { Considered }\end{array}$ \\
\hline $1^{\prime \prime}$ & 3.282 & 30 \\
$3 / 4^{\prime \prime}$ & 4.657 & 30 \\
$1 / 2^{\prime \prime}$ & 6.921 & 30 \\
No. 4 & 3.415 & 30 \\
No. 8 & 3.044 & 30 \\
No. 30 & 1.221 & 30 \\
No. 200 & 1.036 & 30
\end{tabular}


Table 11. Experimental Variance

T88-70 (A11 Fines Minus 150 Grams)

\begin{tabular}{ccc}
\hline Sieve Size & Variance & $\begin{array}{c}\text { No. of Pairs } \\
\text { Considered }\end{array}$ \\
\hline 1" & 2.948 & 34 \\
$3 / 4^{\prime \prime}$ & 4.605 & 34 \\
$1 / 2^{\prime \prime}$ & 3.953 & 34 \\
No. 4 & 2.580 & 34 \\
No. 8 & 1.581 & 34 \\
No. 30 & .718 & 34 \\
No. 200 & .595 & 34
\end{tabular}

Table 12. Experimental Variance

T11-60 and T27-60

\begin{tabular}{ccc}
\hline Sieve Size & Variance & $\begin{array}{c}\text { No. of Pairs } \\
\text { Considered }\end{array}$ \\
\hline $1 "$ & 2.585 & 7 \\
$3 / 4^{\prime \prime}$ & 5.234 & 7 \\
$1 / 2^{\prime \prime}$ & 10.662 & 7 \\
No. 4 & 6.727 & 7 \\
No. 8 & 4.394 & 7 \\
No. 30 & 1.891 & 7 \\
No. 200 & 1.103 & 7
\end{tabular}


obtained for each sieve size for each of the laboratory analysis procedure.

Since all methods of laboratory analysis proved to be identical by " $t$ " analys is for paired observations and homogeneity of variance calcuations, the sample pairs for each of the respective laboratory procedures were combined to obtain an experimental variance that could be compared with total variation at specific points. The experimental variance for this condition is shown in Table 13. Calculations were identical to these used for specific laboratory procedures. Experimental and Sampling Variance

Like testing variation, sampling variation is also a nested variance of the total variance at any specific sampling point. Sampling variation is generally dependent upon operator proficiency, sampling method, and the material state. Sampling methods have been discussed previously, and thus only specific points pertinent to the results will be rementioned.

Sampling variation ideally represents material variation within a defined quantity of material. To obtain such a quantitative value, one would have not only to randomly choose the initial sample but also randomly choose the replicate from a defined quantity of material. Using this type of analysis, point to point variations of a defined material quantity would be removed. 
Table 13. Experimental Variance

All Methods Combined

\begin{tabular}{ccc} 
Sieve Size & Variance & $\begin{array}{c}\text { No. of Pairs } \\
\text { Considered }\end{array}$ \\
\hline $1^{\prime \prime}$ & 3.051 & 159 \\
$3 / 4^{\prime \prime}$ & 4.764 & 159 \\
$1 / 2^{\prime \prime}$ & 6.190 & 159 \\
No. 4 & 4.270 & 159 \\
No. 8 & 3.373 & 159 \\
No. 30 & 1.893 & 159 \\
No. 200 & 1.174 & 159
\end{tabular}


Due to the time limit and accessibility placed upon the field sampling process by the producer, contractor, and sampling positions, a purely statistical sampling variance by definition was unfeasible. Samples taken from the pugmill output were obtained at the beginning of the output flow for the protection of the sampler. Furthermore, sample replicates taken before and after compaction were obtained directly in front of or behind a randomly selected initial sample. This was necessitated by the compaction operation for before compaction sampling. Uniformity was the basis for continuing this sampling process for the compacted sample. As a result, sampling variance is closely allied with variability in technique rather than variability of material within a defined quantity. This is not considered a handicap but a benefit, for a value for operator consistency can be tabulated. The variation within a quantity of material is not directly measurable, but is hypothesized not to be serious due to the number of samples and the relative small size of each batch being considered. This variable associated with technique will be labeled as sampling variance hereafter.

To obtain a meaningful value for sampling variance, each sample obtained from each point would have had to have been split into two parts for laboratory analysis and a testing variance calculated. Furthermore, all samples would have required analysis by the same laboratory technique. This method would have allowed subtracting 
variances by factorial analysis to obtain a quantitative value for sampling. Because of time, finances, and the value lost by not comparing different laboratory techniques, this type of operation was considered unfeasible. As an alternative, a combination of sampling and experimental variance was calculated by:

$$
V_{T S}=\frac{\sum_{i=1}^{n i} \sum_{j=1}^{n j}\left(x_{i j}-x_{i}\right)^{2}}{n i(n j-1)}
$$

where

$$
\begin{aligned}
V_{T S}= & \text { variance due to testing, inherent, and sampling, } \\
x_{i 1}= & \text { initial randomly selected sample } \\
X_{i 2}= & \text { replicate sample of initial randomly } \\
& \text { selected sample } \\
X_{i}= & \left(x_{i 1}+x_{i 2}\right) / 2.0 \\
n i= & \text { number of samples excluding replicates at } \\
& \text { a specific sampling point } \\
n j= & 2
\end{aligned}
$$

Experimental variance was not subtracted from the combination of experimental and sampling variance because of the previous stated reasons. Tables 14,15 , and 16 show the values obtained by these calculations. Easily noted is the difficulty of obtaining samples shown by increasing magnitude of variance, as the material handling process progressed from the aggregate plant to the insitu compacted base state. 
Table 14. Experimental and Sampling Variance, Pugmill

\begin{tabular}{crc}
\hline Sieve Size & Variance & $\begin{array}{c}\text { No. of Pairs } \\
\text { Considered }\end{array}$ \\
\hline 1" & 6.230 & 36 \\
$3 / 4 "$ & 17.043 & 36 \\
$1 / 2 "$ & 26.017 & 36 \\
No. 4 & 19.134 & 36 \\
No. 8 & 8.976 & 36 \\
No. 30 & 2.915 & 36 \\
No. 200 & 1.055 & 36
\end{tabular}

Table 15. Experimental and Sampling Variance, Before Compaction

\begin{tabular}{crr} 
Sieve Size & Variance & $\begin{array}{r}\text { No. of } \\
\text { Conside }\end{array}$ \\
\hline $1 "$ & 3.663 & 36 \\
$3 / 4 "$ & 20.187 & 36 \\
$1 / 2 "$ & 34.765 & 36 \\
No. 4 & 20.715 & 36 \\
No. 8 & 9.677 & 36 \\
No. 30 & 3.593 & 36 \\
No. 200 & 1.417 & 36
\end{tabular}

Table 16. Experimental and Sampling Variance, After Compaction

\begin{tabular}{crr}
\hline Sieve Size & Variance & $\begin{array}{r}\text { No. of Pai } \\
\text { Conside }\end{array}$ \\
\hline $1 " 1 "$ & 4.519 & 36 \\
$3 / 4 "$ & 20.850 & 36 \\
$1 / 2 "$ & 43.341 & 36 \\
No. 4 & 27.903 & 36 \\
No. 8 & 13.036 & 36 \\
No. 30 & 3.907 & 36 \\
No. 200 & 1.567 & 36
\end{tabular}


Uniformity of Material

After appropriate consideration is given to the nested variances of testing and sampling, the remaining difference between them and the total variation can be attributed to uniformity of the material. For the purposes of this research study, uniformity of the material relates directly to the uniformity of the stockpile which is the material source. If the greater part of the total variation at each sampling point can be attributed to experimental and sampling variation, one may conclude that the material is uniform. Furthermore, if the variances are consistent at each sampling point after the error contributed to experimental and sampling is removed, one may conclude that a change in the material can be attributed to segregation.

Total variation was calculated for each sampling position and is displayed in Tables 17 and 18 . Variations were claculated by:

$$
V_{\text {TOT }}=\frac{\sum_{j=1}^{n}\left(x_{i}-x\right)^{2}}{n-1}
$$

where

$$
\begin{aligned}
& \mathrm{V}_{\mathrm{TOT}}=\text { total variation } \\
& \mathrm{X}_{\mathrm{i}} \quad=\text { sample value } \\
& \mathrm{X} \quad=\text { mean of sample values } \\
& \mathrm{n} \quad=\text { number of samples being considered }
\end{aligned}
$$

The variation due to uniformity of production must also be a qualitative measure rather than a quantitative measure in this study because of the sampling and testing 


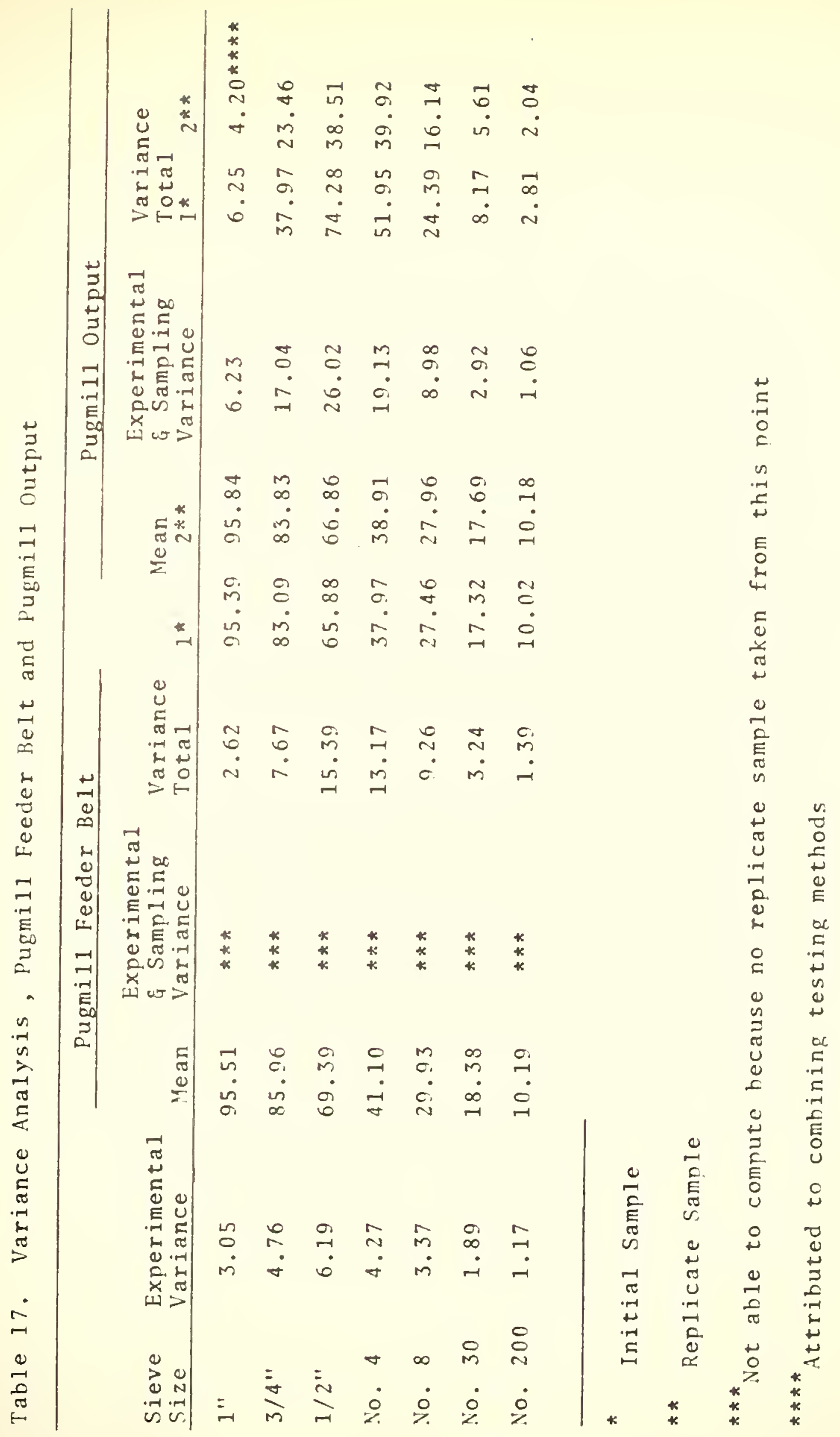




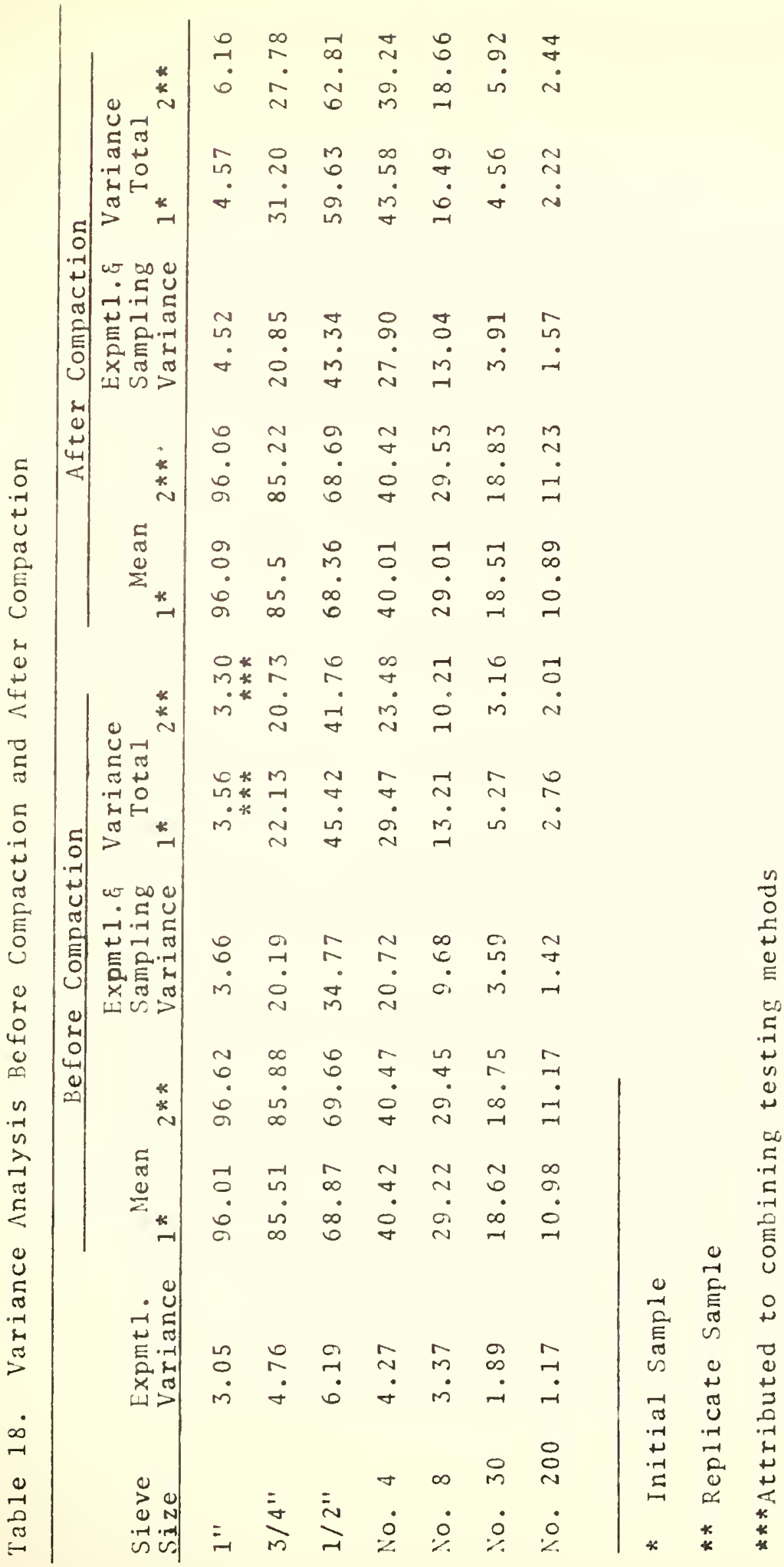


methods previously described. The necessity for a qualitative measure rather than a quantitative measure can easily be explained.

Ideally a factorial analysis of variance would have been used to obtain the quantitative measure of variability of the uniformity. However, since replicate samples at each of the sampling points are not "true" replicates by a strict statistical definition, the mean square for within replicates would be smaller than the actual mean square for within replicates. The mean square for between samples would not change. The result of mean square between samples divided by mean square within replicates could be a critical "F" ratio which would be in error.

To obtain a qualitative measure, the variances for each sampling position were listed (Table 19) and a definite uniformity noticed. To emphasize this uniformity, the coefficients of variation (Table 20) were also calculated for each sampling position and sieve size.

$$
C V=S \cdot D \cdot / \bar{X}
$$

where

$$
\begin{aligned}
& \mathrm{CV}=\text { coefficient of variation } \\
& \text { S.D. }=\text { standard deviation } \\
& \mathrm{X} \quad=\text { sample mean at each sampling point }
\end{aligned}
$$


Table 19. Comparison of Total Variances at Sampling Points

\begin{tabular}{|c|c|c|c|c|c|c|c|}
\hline \multirow{2}{*}{$\begin{array}{l}\text { Sieve } \\
\text { Size }\end{array}$} & \multirow{2}{*}{$\begin{array}{l}\text { Pugmi } 11 \\
\text { Feeder } \\
\text { Be1t }\end{array}$} & \multirow{2}{*}{$\begin{array}{c}\text { Pugmil1 } \\
1^{*}\end{array}$} & \multirow{2}{*}{$\begin{array}{l}\text { Output } \\
2 * *\end{array}$} & & \multicolumn{2}{|c|}{$\begin{array}{c}\text { After } \\
\text { Compaction }\end{array}$} \\
\hline & & & & $1^{*}$ & 2 ** & $1 *$ & $2 * *$ \\
\hline $1 "$ & 2.62 & 6.25 & 4.20 & 3.56 & $3.3 n$ & 4.57 & 6.15 \\
\hline $3 / 4^{\prime \prime}$ & 7.67 & 37.94 & 23.46 & 22.13 & 20.73 & 31.20 & 27.78 \\
\hline $1 / 2^{\prime \prime}$ & 15.39 & 74.28 & 38.51 & 45.42 & 41.76 & 59.63 & 62.81 \\
\hline No. 4 & 13.17 & 51.95 & 39.92 & 29.47 & 23.48 & 42.58 & 39.24 \\
\hline No. 8 & 9.26 & 24.39 & 16.14 & 13.21 & 10.21 & 16.49 & 18.66 \\
\hline No. 30 & 3.24 & 8.17 & 5.16 & 5.27 & 3.16 & 4.56 & 5.9 \\
\hline No. 200 & 1.39 & 2.81 & 2.04 & 2.76 & 2.01 & 2.22 & 2.44 \\
\hline
\end{tabular}

*

Initial Sample

** Replicate Sample 
Table 20. Coefficients of Variation

( 8 )

\begin{tabular}{|c|c|c|c|c|c|c|c|}
\hline \multirow{2}{*}{$\begin{array}{l}\text { Sicve } \\
\text { Size } \\
\end{array}$} & \multirow{2}{*}{$\begin{array}{l}\text { Pugmill } \\
\text { Feeder } \\
\text { Belt }\end{array}$} & \multirow{2}{*}{$\begin{array}{c}\text { Pugmi } 11 \\
1 * \\
\end{array}$} & \multirow{2}{*}{$\begin{array}{l}\text { Output } \\
2^{* *}\end{array}$} & \multicolumn{2}{|c|}{$\begin{array}{c}\text { Before } \\
\text { Compaction }\end{array}$} & \multicolumn{2}{|c|}{$\begin{array}{c}\text { After } \\
\text { Compaction }\end{array}$} \\
\hline & & & & $1 *$ & $2^{* *}$ & $1 *$ & $2 * *$ \\
\hline $1^{\prime \prime}$ & 1.68 & 2.62 & 2.13 & 1.97 & 1.88 & 2.23 & 2.58 \\
\hline $3 / 4^{\prime \prime}$ & 3.22 & 7.41 & 5.78 & 5.50 & 5.30 & 6.56 & 6.18 \\
\hline $1 / 2^{\prime \prime}$ & 5.65 & 13.1 & 9.28 & 9.79 & 9.28 & 11.3 & 11.5 \\
\hline No. 4 & 8.83 & 19.0 & 16.2 & 13.4 & 12.0 & 16.3 & 15.5 \\
\hline No. 8 & 10.2 & 18.0 & 14.4 & 12.4 & 10.9 & 14.0 & 14.6 \\
\hline No. 30 & 9.9 & 16.5 & 13.4 & 12.3 & 9.48 & 11.5 & 12.9 \\
\hline No. 200 & 11.6 & 16.7 & 14.0 & 15.1 & 12.7 & 13.7 & 13.9 \\
\hline Initial & Sample & & & & & & \\
\hline
\end{tabular}


A slight but continuous increase, attributed to sampling, can be noted as the material moves between the handling positions. The samples obtained from the pugmill contradict this theory, but can be explained by lower means at this position and thus not attributed to material uniformity. These means will be discussed in a latter section of this report. The conclusion reached by this examiner is that the variances and coefficients of variation do meet uniformity requirements. This is to conclude any change of the material due to segregation of the aggregate is consistent and not a random chance.

\section{Variation Between Sampling Points}

The statistical analysis of the data to determine results due to segregation was based upon material variation between testing points. This analysis was acoomplished by using standard statistical programs for 1) analysis of variance, 2) homogeneity of variance, and 3) normality of data.

Two criterion must be satisfied before the analysis of variance technique can be applied. First the data within each sampling point must be normally distributed, and second the variance for each sampling point must be homogeneous with the variances of the other sampling points.

Becausc of the laboratory procedure previously described, more than one set of sieve analysis results could occur for any given sample of material. This was 
caused by splitting more than one sample for laboratory analysis from the same bag of material for the purpose of calculating testing variance or for comparison to another laboratory procedure. The initial step for data analysis was reduction of the total number of samples for a given bag of material to only one sample for that given bag. Since all 1aboratory procedures had previously been proven identical, this reduction was accomplished by means of random selection.

Analysis of variance for One Way Design was used to compare the different sampling positions. Four different sampling positions had been used: pugmill feeder belt, pugmill output, before compaction, and after compaction. All positions other than the pugmill feeder belt had a replicate sample. In order to use as much data as possible, the four positions were extended to seven positions:

1) pugmil1 feeder helt, 2) initial sample of pugmill output, 3) replicate sample of pugmill output, 4) initial sample before compaction, 5) replicate sample before compaction, 6) initial sample after compaction, and 7) replicate sample after compaction.

In order to use the analysis of variance, the two previously mentioned criterion had to be met. Homogeneity of variance had already been satisfied by means of a Foster-Burr Analysis. To test for normality, the kolmogorovSmirnov test to check goodness of fit to the normal curve was used. The results of this test are shown in Tables 21 
through 27 . The data were normally distributed at the .05 level of significance. The analysis of variance for one-way design was used to determine if a difference between sampling points was significant. The results of this analysis are shown in Table 28 .

In order to determine the sampling points in which breakdown attributed to segregation occurred, the Newmankedls Sequential Range Test was used for comparison of means. Only those sieve sizes that were critical or marginally critical were used in the test. The results for this tost for the $3 / 4$ inch, No. 8, No. 30, and No. 200 sieve are shown in Tables 29 through 32 .

A significant difference occurred between the pugmil output and the pugmill feeder belt for the $3 / 4$ inch and No. 8 sieves. Since the differences at the pugmill feeder helt were not significant, this difference is not attributed to segregation of the aggregate but to method of sampling. The means for the pugmill output initial and pugmill output replicates are approximately two percent coarser than the other sampling points.

The values for the No. 200 sieve indicate a definitc difference between the material at the aggregatc plant and the jobsite. The material on the pugmill feeder belt and the material output of the pugmill is shown to have comparable gradations. The material on the jobsite also has the same gradation before and after compaction, but not the same gradation of material at the aggregate plant. The 


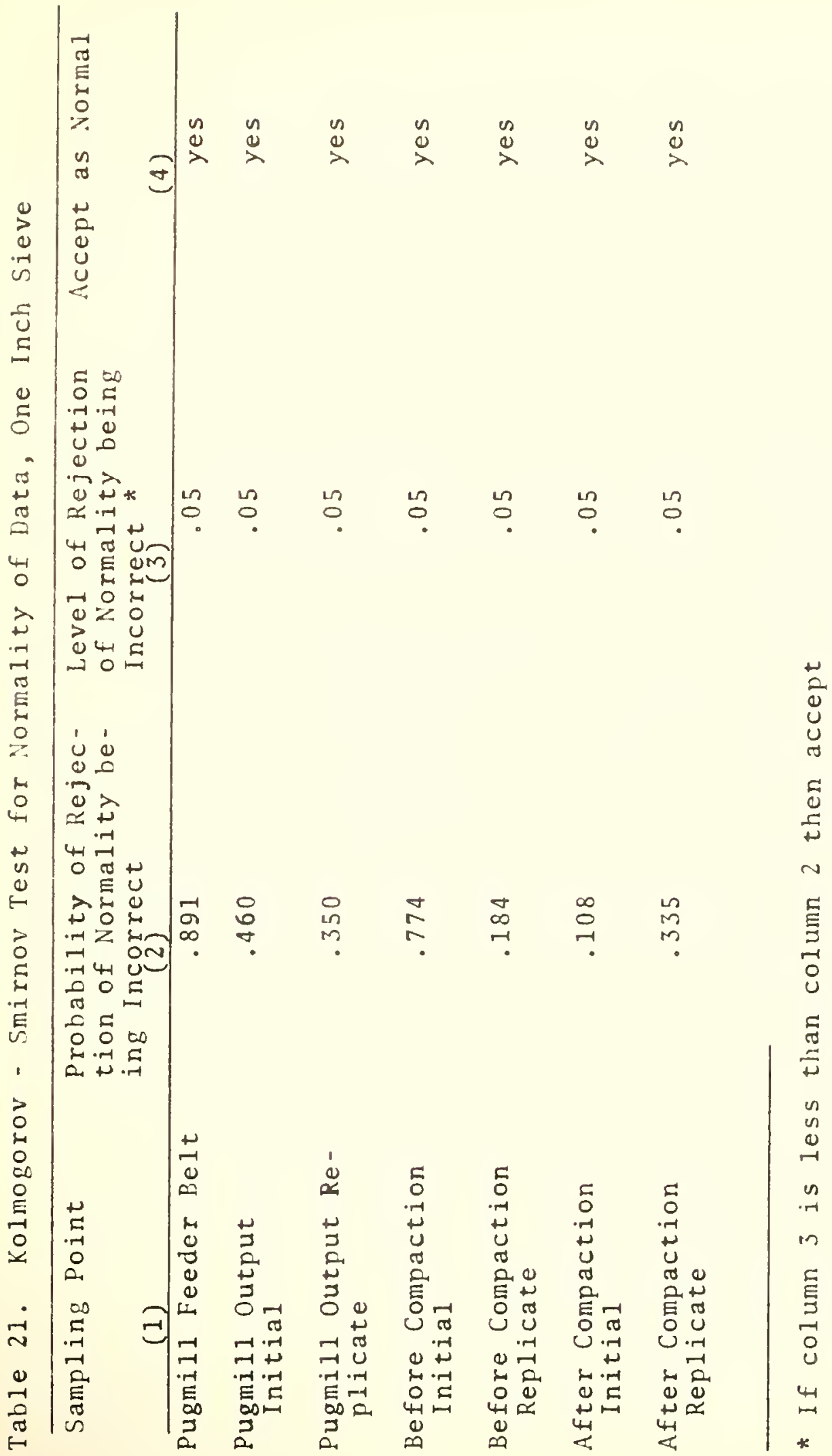




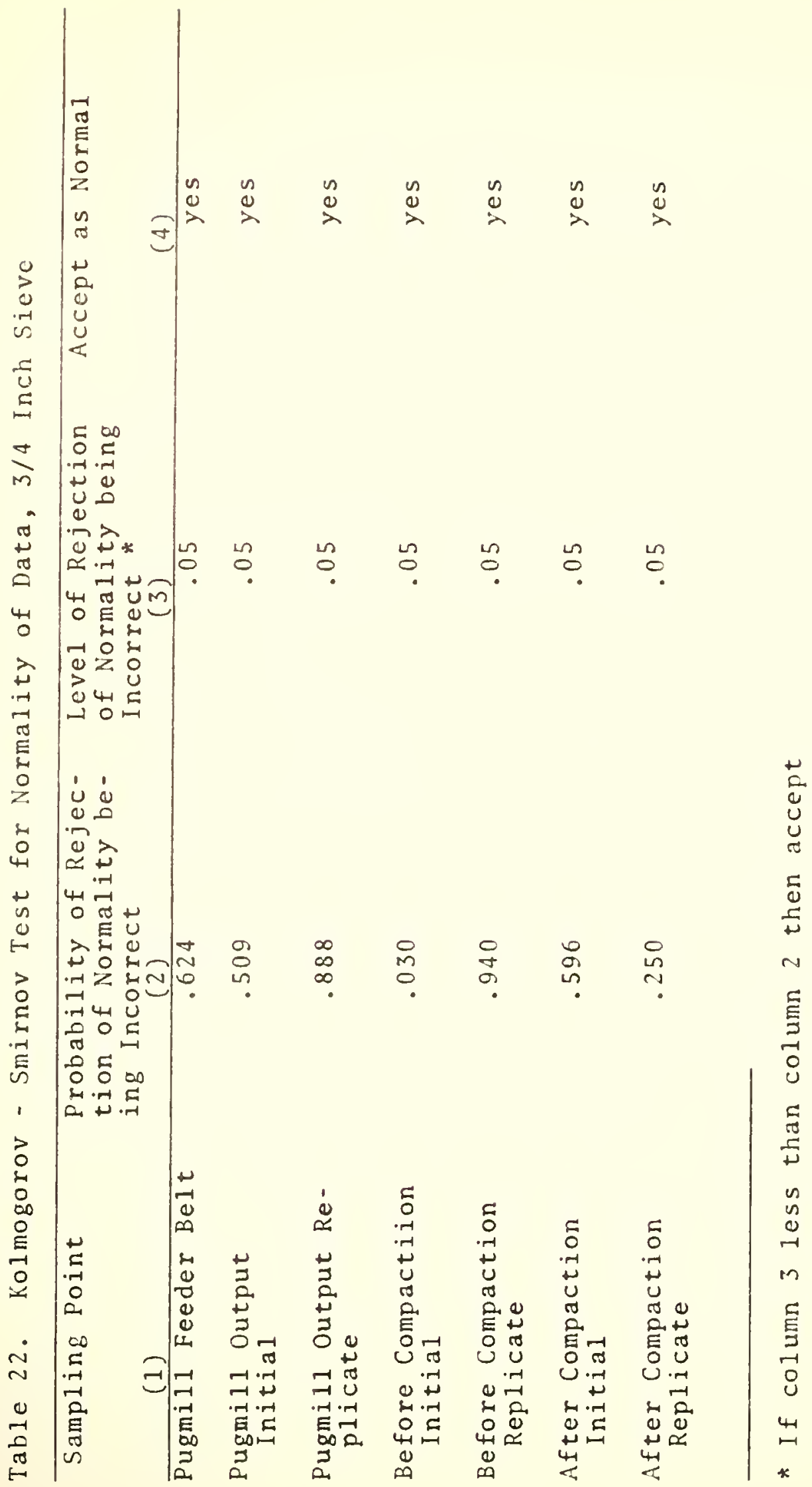




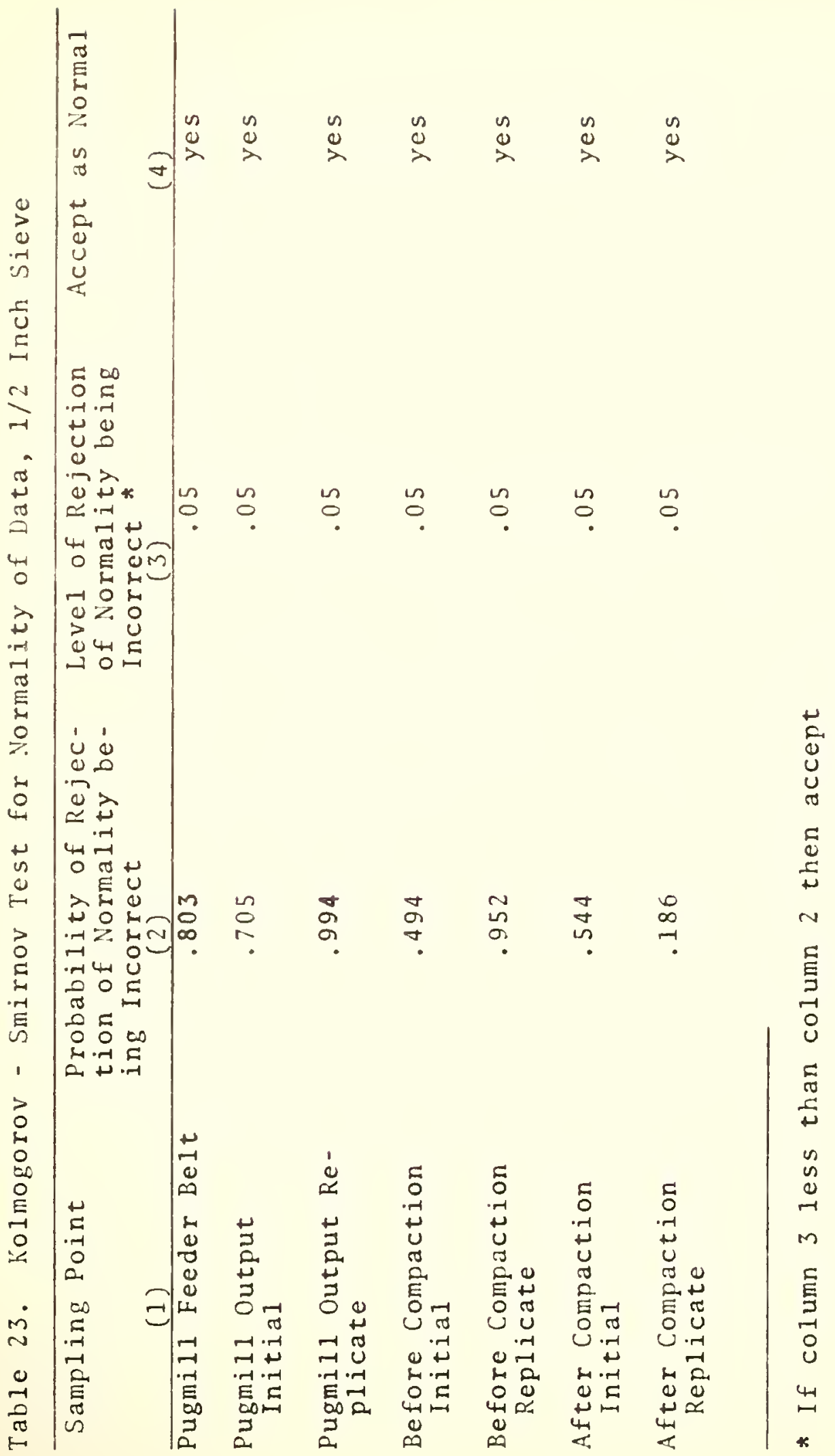









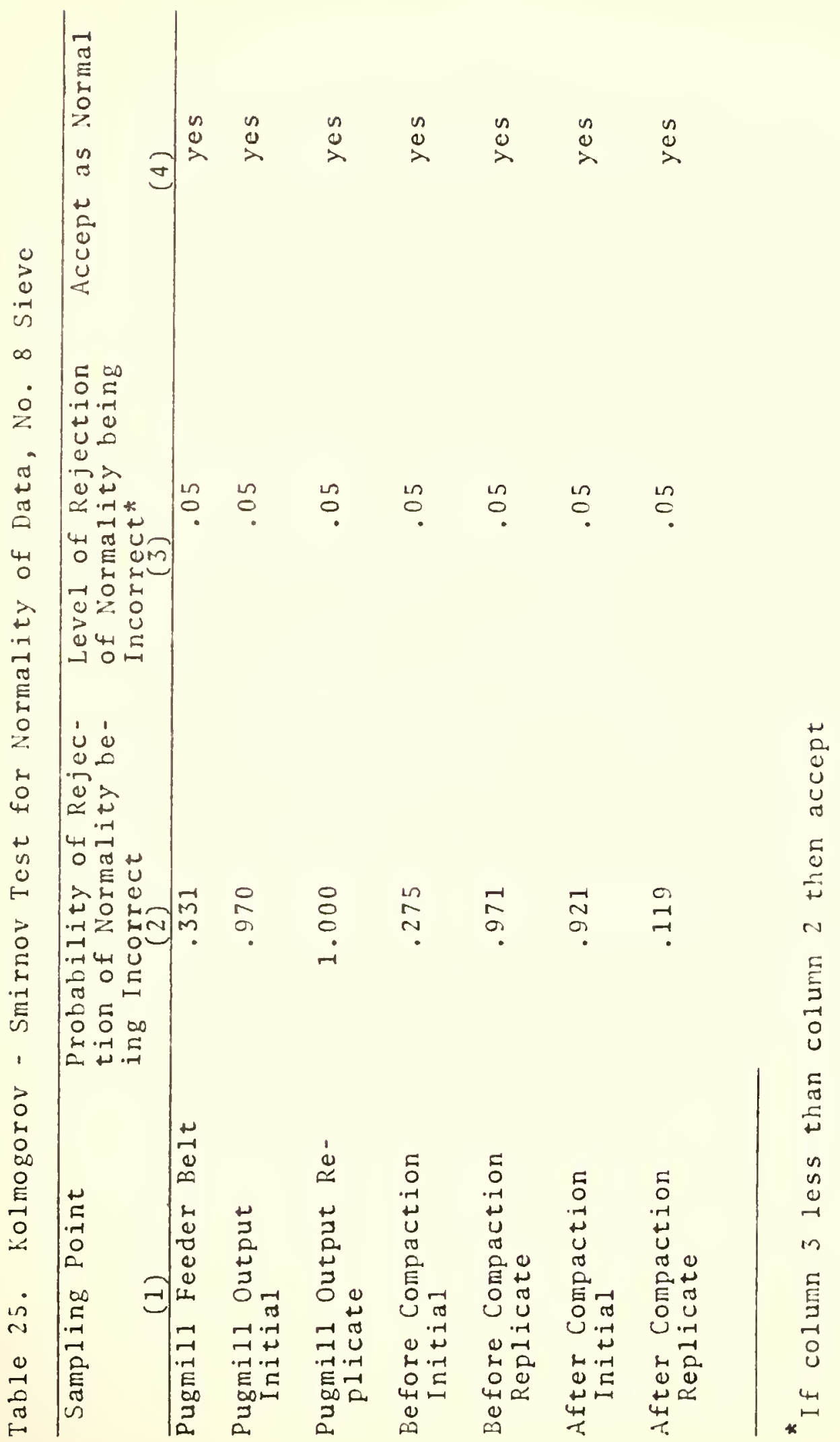




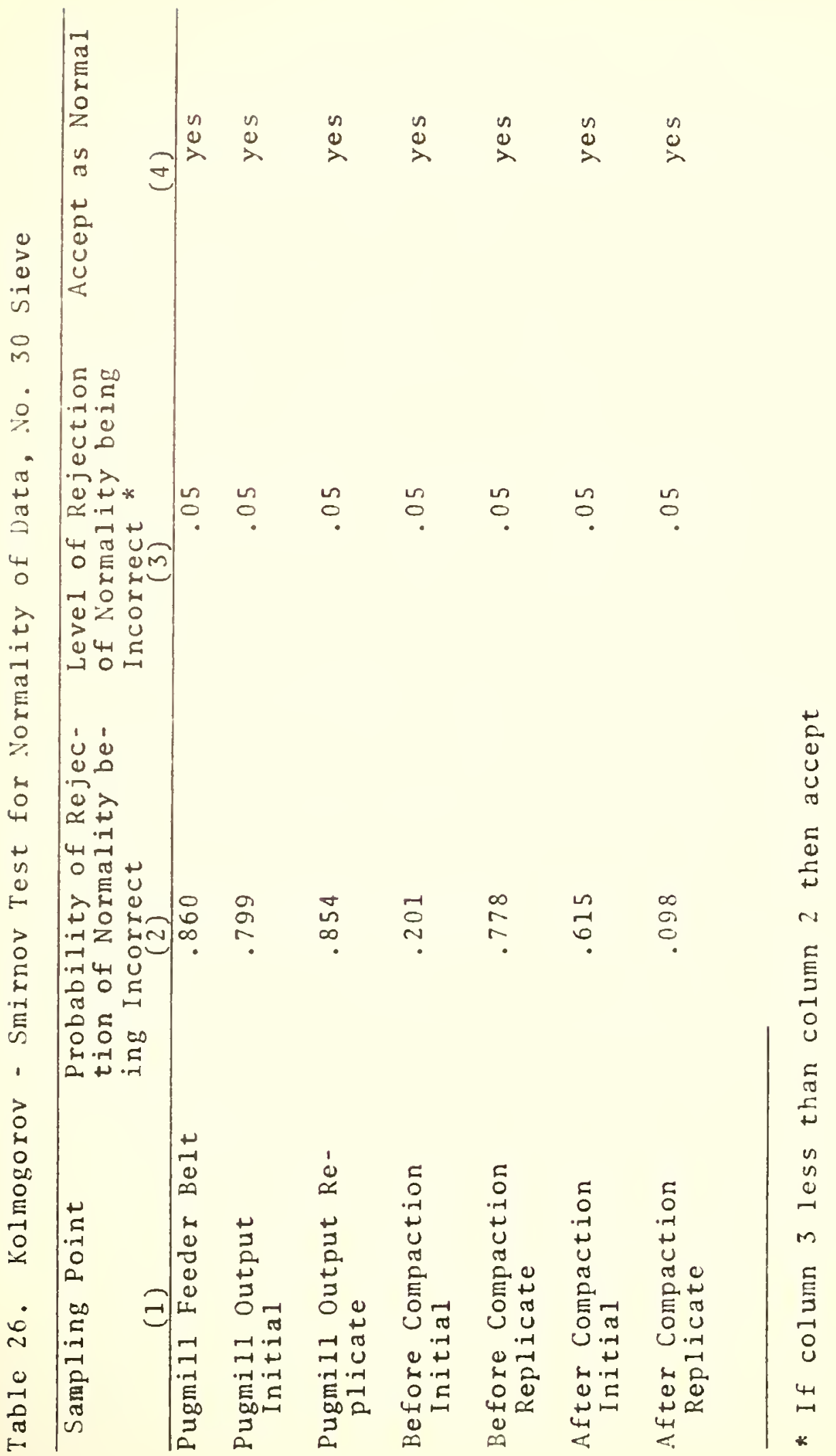




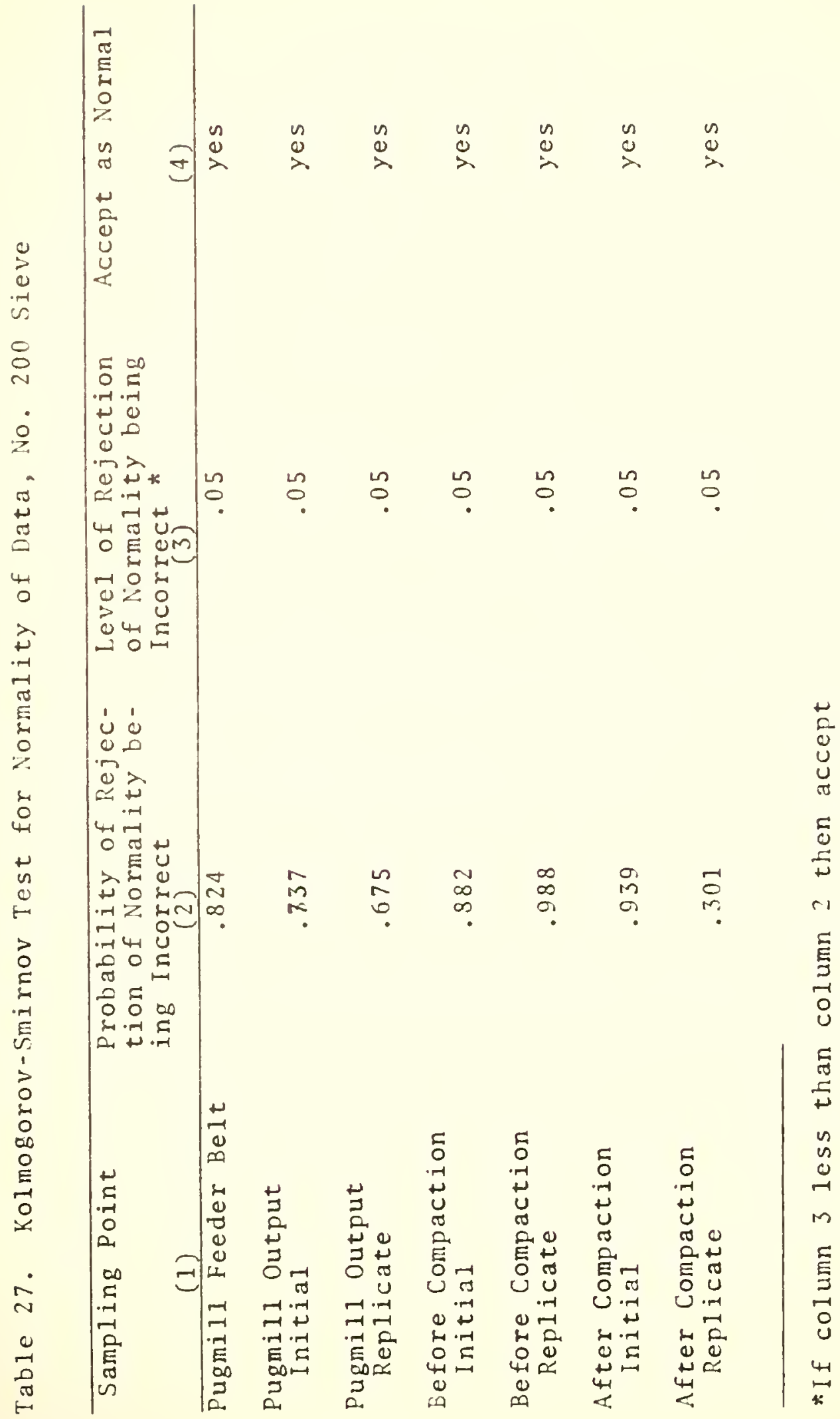


Table 28. Analysis of Variance for One Way Design to Determine Significant Variation Between Sampling Points

\begin{tabular}{|c|c|c|c|c|c|}
\hline \multirow[t]{2}{*}{$\begin{array}{l}\text { Sieve } \\
\text { Size }\end{array}$} & \multicolumn{2}{|c|}{$\begin{array}{l}\text { Calculated } \\
\text { F-Ratio*** }\end{array}$} & \multicolumn{2}{|c|}{$\begin{array}{l}F \text { Ratio } \\
\alpha=.05 \\
\end{array}$} & \multirow[t]{2}{*}{ Critical } \\
\hline & Actual $* *$ & Inverted* & Actual** & Inverted* & \\
\hline $1^{\prime \prime}$ & .649 & 1.543 & 2.13 & $3.60 * * * *$ & No \\
\hline $3 / 4^{\prime \prime}$ & 2.432 & & 2.13 & & Margjnal \\
\hline $1 / 2^{\prime \prime}$ & 1.988 & & 2.13 & & No \\
\hline No. 4 & 1.735 & & 2.13 & & No \\
\hline No. 8 & 2.638 & & 2.13 & & Margina 1 \\
\hline No. 30 & 3.190 & & 2.13 & & Yes \\
\hline No. 200 & 5.979 & & 2.13 & & Yes \\
\hline
\end{tabular}

\footnotetext{
* Degrees of freedom numerator $=6$

Degrees of freedom denominator $=339$

** Degrees of freedom numerator $=339$

Degrees of freedom denominator $=6$

*** F Ratio $=\frac{\text { Between Groups }}{\text { Within Groups }}$

$* * * *$ For F ratios less than 1.00 the inversed F ratio is calculated and compared as standard procedure
} 


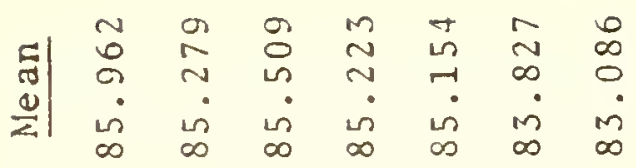

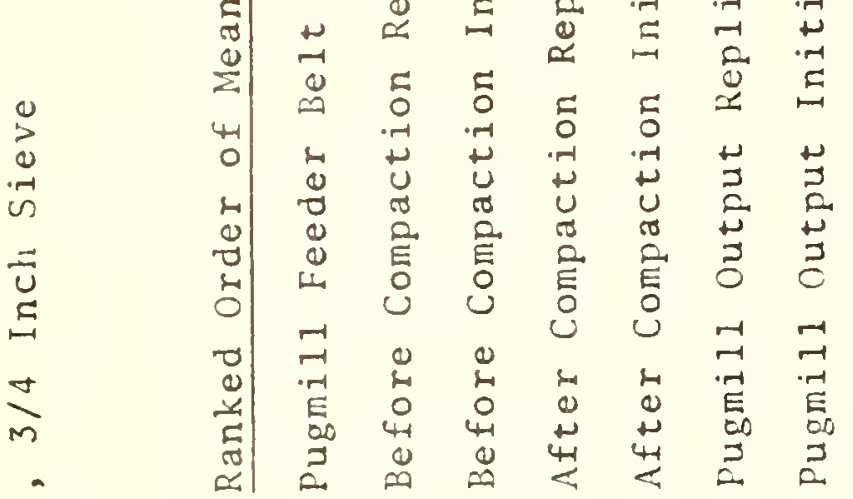

in

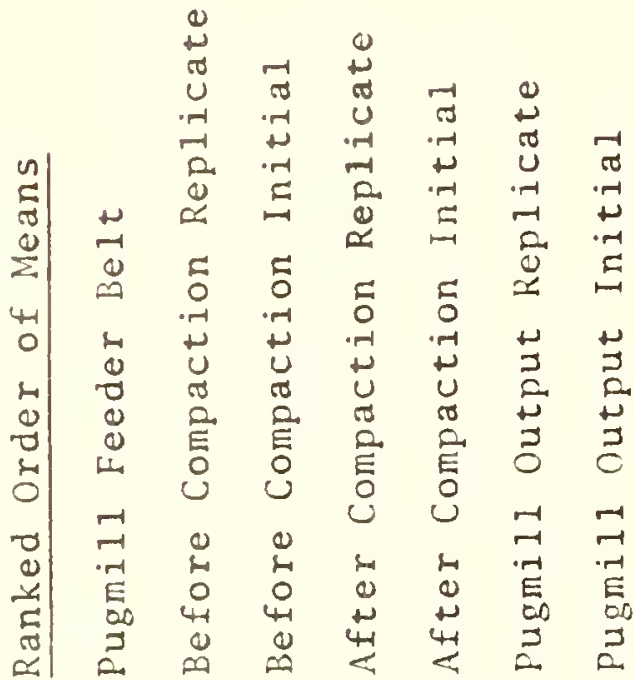

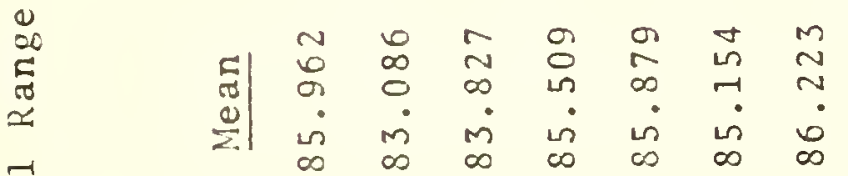

7

-

5

$\stackrel{0}{0}$

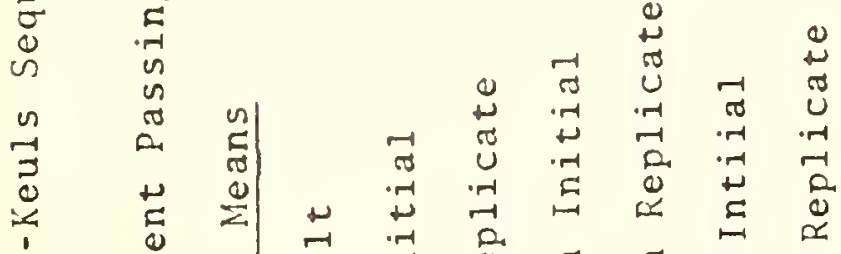

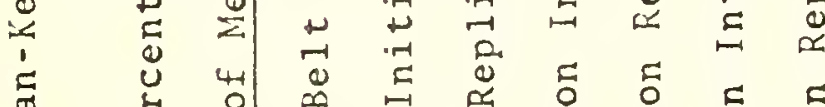

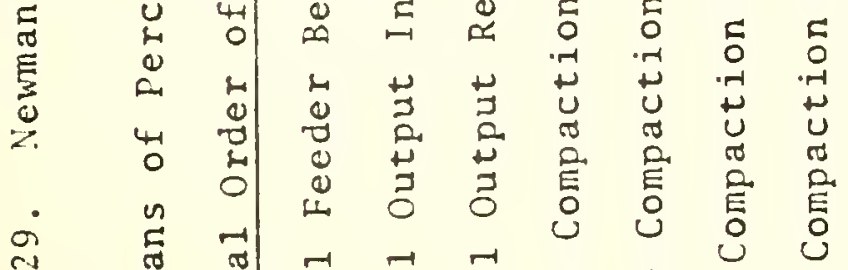

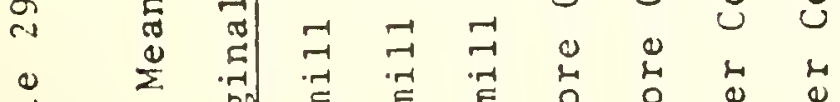

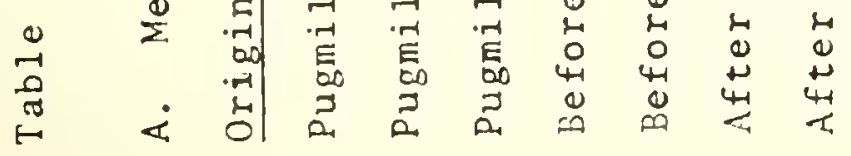




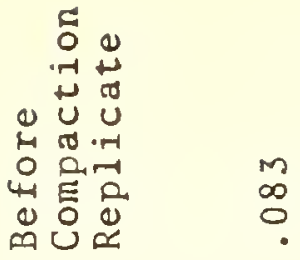

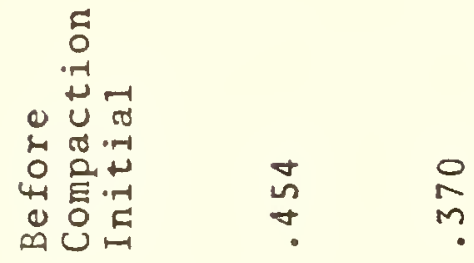

등

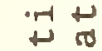
U $\rightarrow$ to $\cdot \pi$

(1) 0,1

世 है

茪

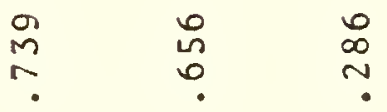

$\frac{\pi}{m}$

$\stackrel{4}{u}$

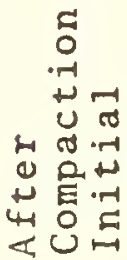

$\stackrel{0}{\infty}$

ถัก

in

0
1
0

疍

$\propto$

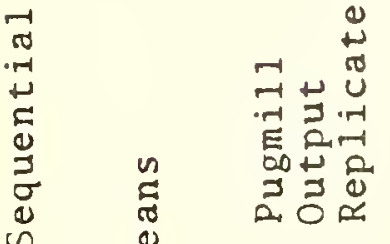

$\begin{array}{lll}N & N & N \\ m & 0 & \infty \\ \pi & n & 0\end{array}$

$\begin{array}{ll}N & n \\ \infty & n \\ 0 & n\end{array}$

$m$

2

$\stackrel{m}{*} m$

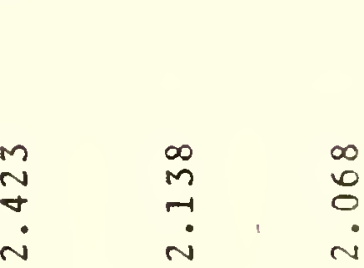

33

จำ

대

تี

Do 07

วิ山心

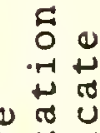

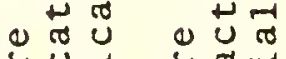

की

4 E०

क्ष

Uू E.

(1)

$\dot{\pi} \dot{\varphi}$

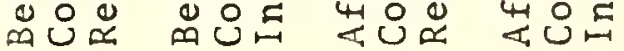

230

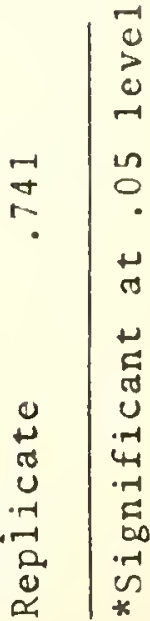




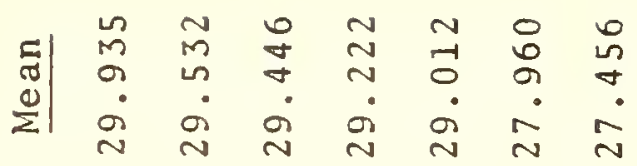

0
0
0
5

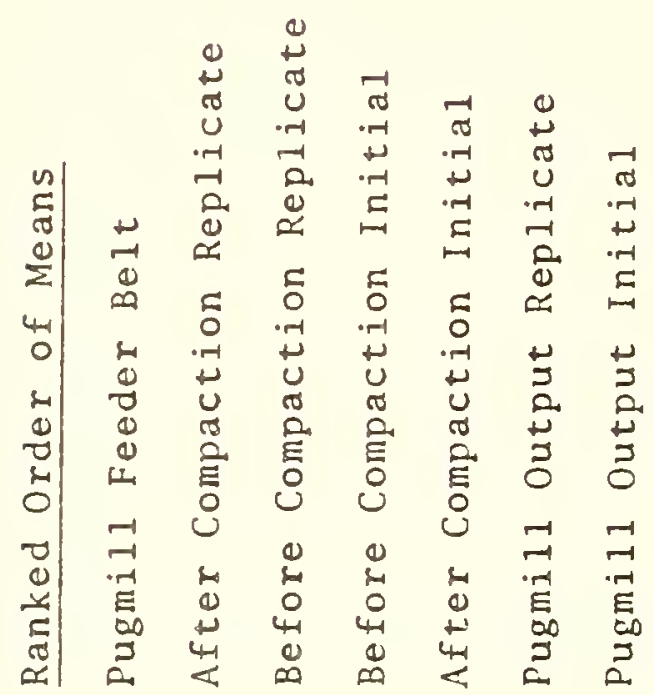

$\infty$

8

in

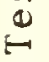

है

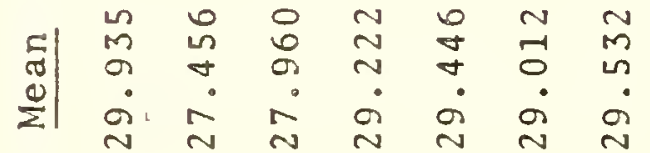



年

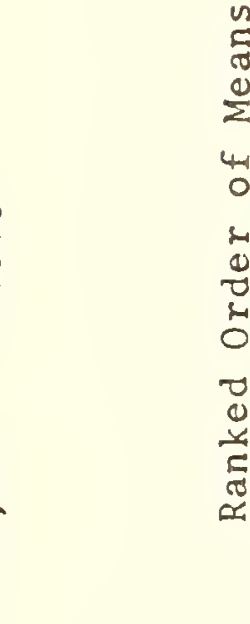



i

$\begin{array}{ll}0 & \frac{1}{2} \\ -10 & <\end{array}$ 


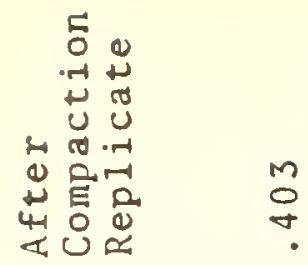


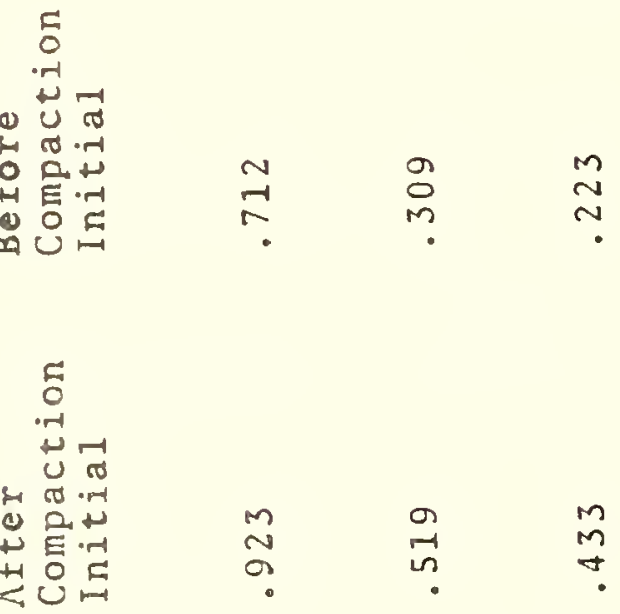

$\stackrel{m}{n}$

an

in

in

$m$

$\stackrel{0}{\sim}$

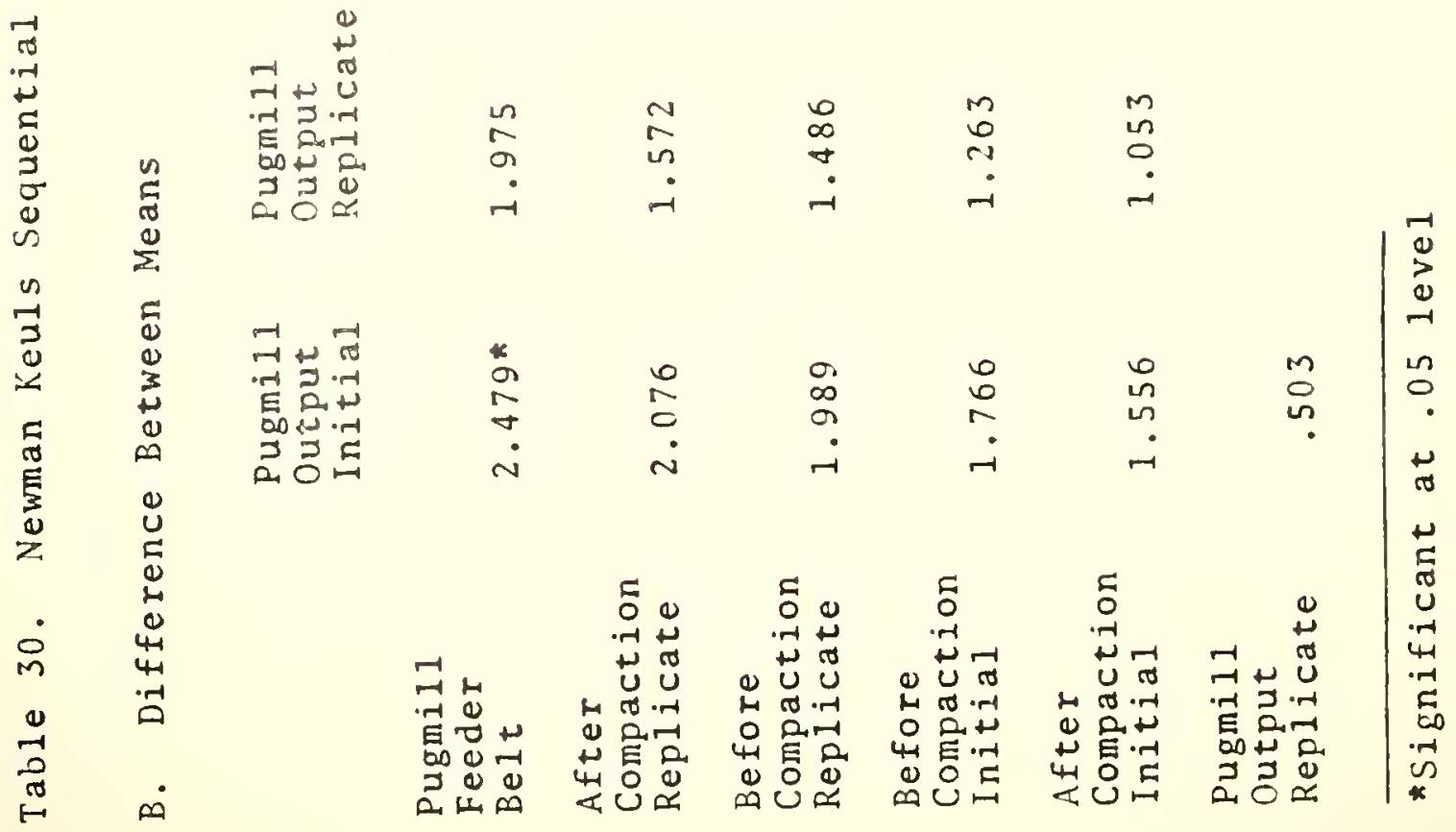




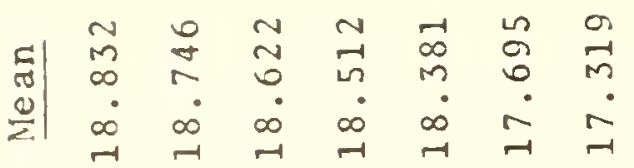

0
0
0
0
0
$m$
0
0
0
0
0

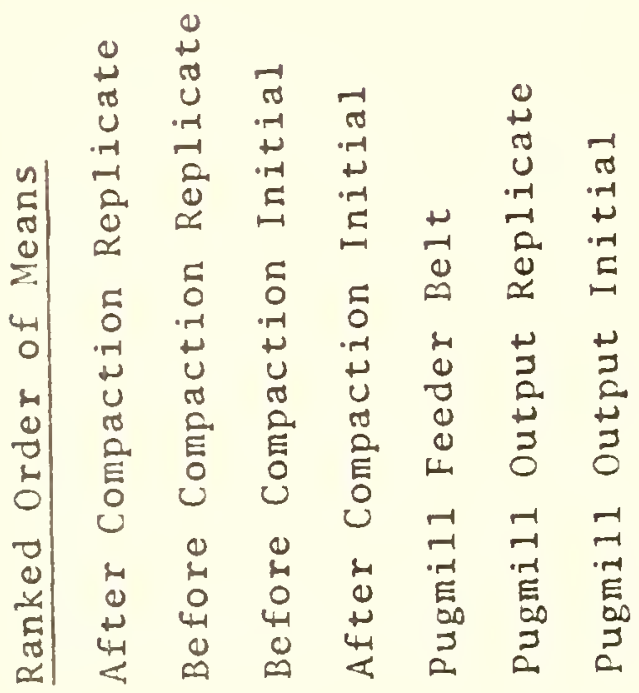

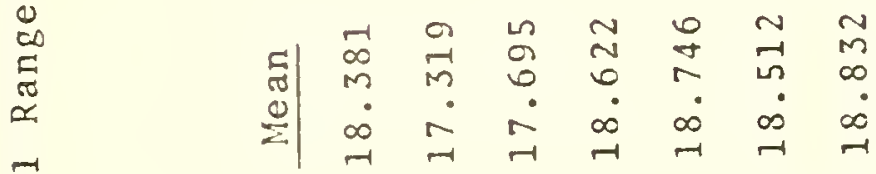

$\pi$

.

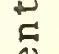

0
0
0
0

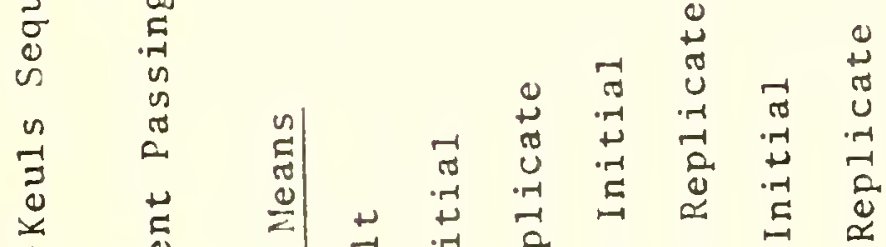

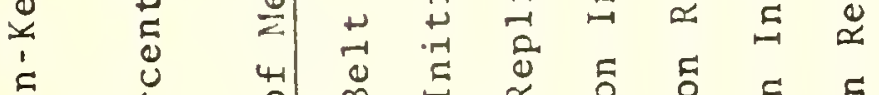

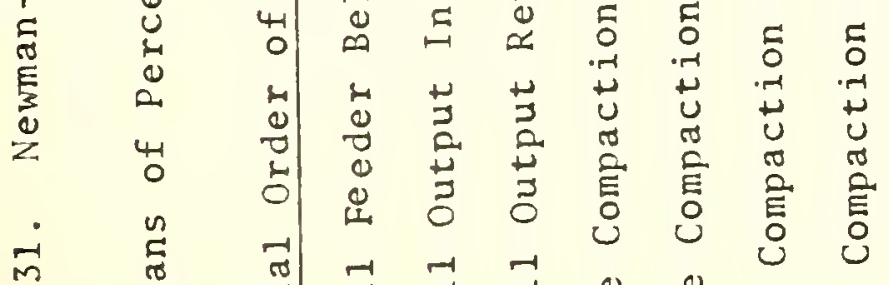

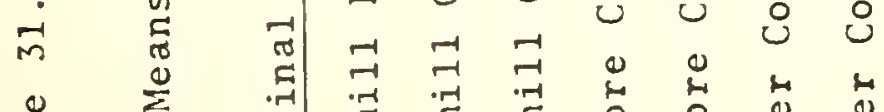

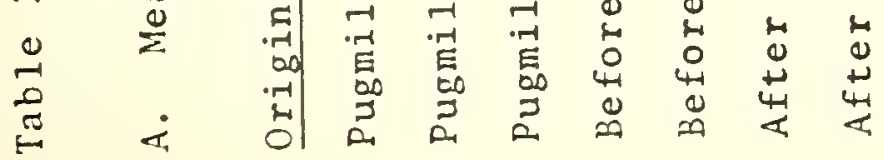




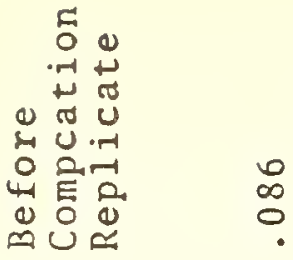

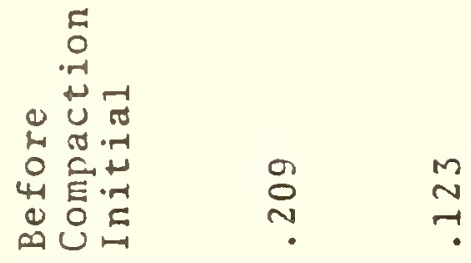
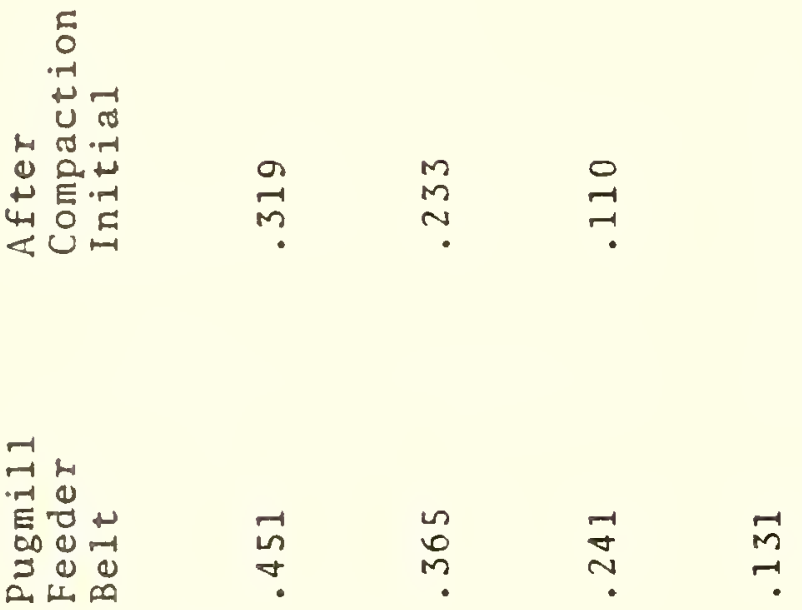

点

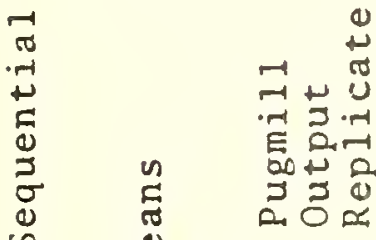

in

$\begin{array}{lll}-1 & \infty & \infty \\ 0 & N & \infty \\ -1 & 0 & \infty\end{array}$

$\infty$

i

*

造

0
0
0

$\stackrel{*}{n}$

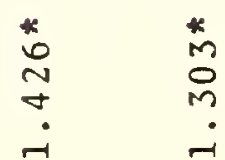

$\stackrel{0}{=}$

$=$

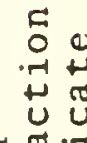

$\pi \cdot \pi$

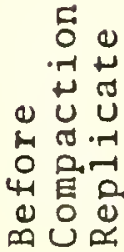

苗员

40000

๘

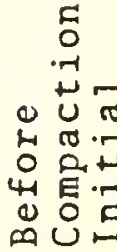

$\frac{5}{0}$

$\sum_{0}^{0}$

$<U \alpha$

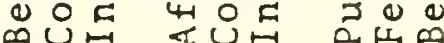

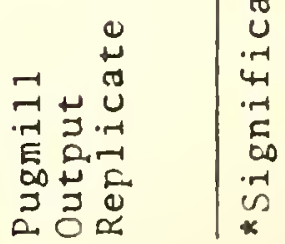




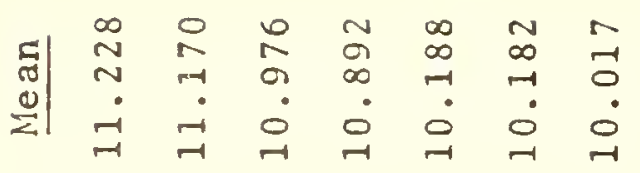

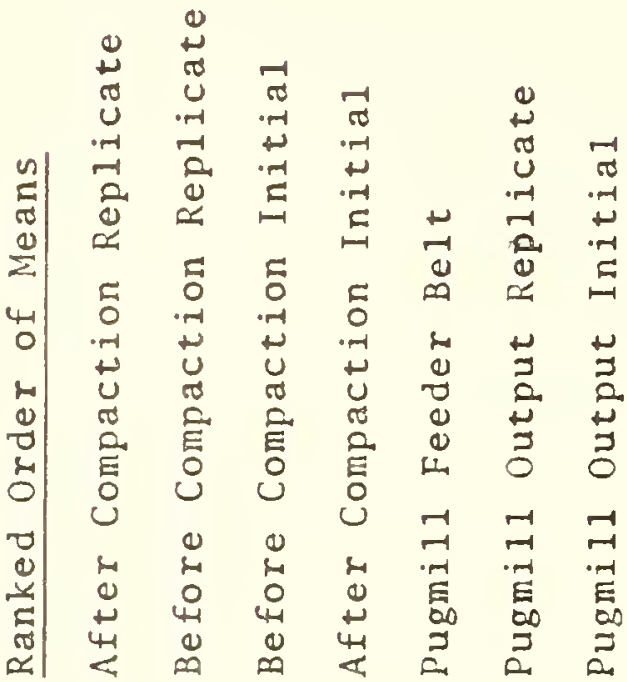

in

O

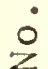

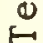

0

車

$\begin{array}{llllllll}\infty & N & N & 0 & 0 & N & \infty \\ 0 & \infty & \infty & 0 & 1 & 0 & N \\ 0 & 0 & -1 & \infty & -1 & \infty & N \\ 0 & 0 & 0 & 0 & -1 & 0 & -1\end{array}$

7

. -1

5

$\Xi \quad \infty$

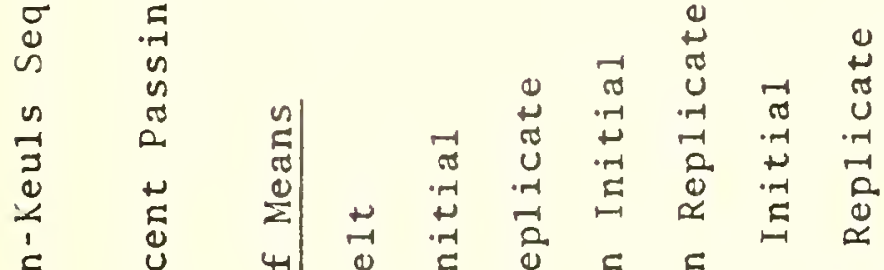

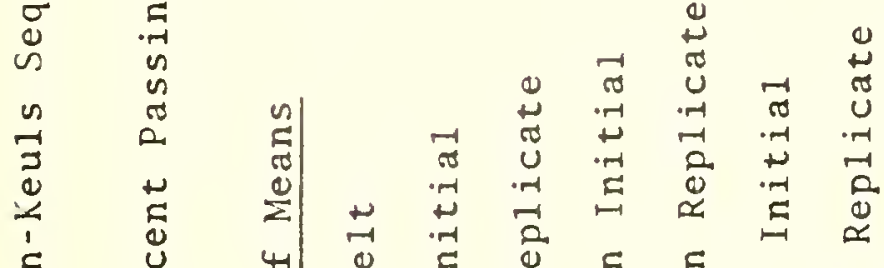

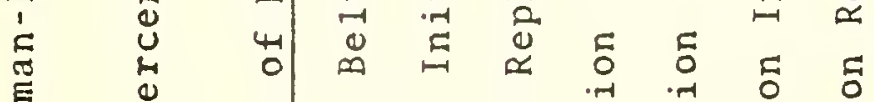

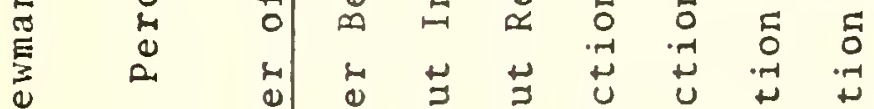

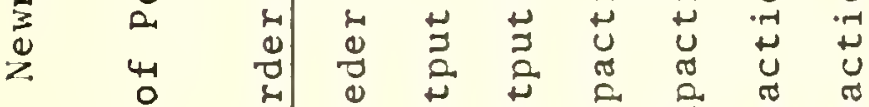

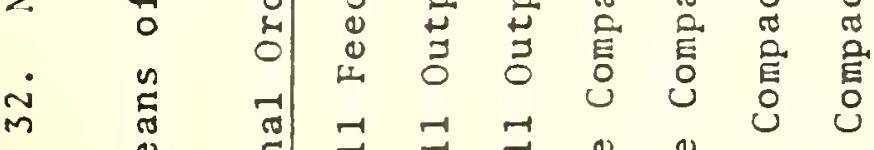

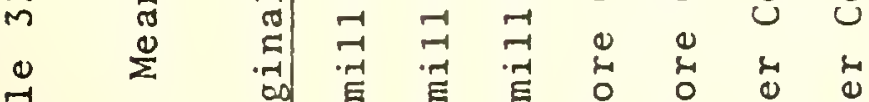

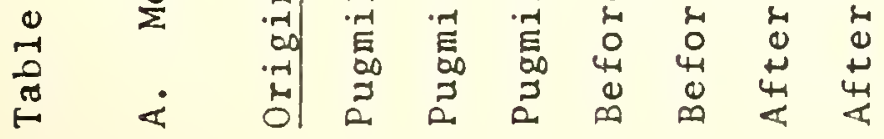




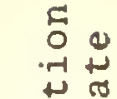

- U U

पू

証宫

$\stackrel{0}{\infty} \cong$

$\stackrel{\infty}{10}$

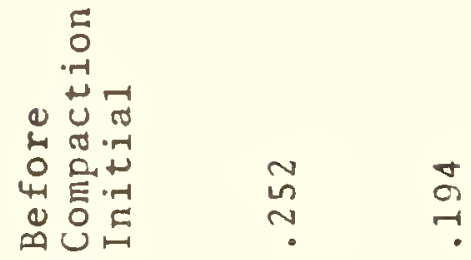

i)

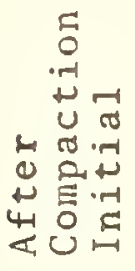

$\begin{array}{lll}0 & \infty & + \\ m & N & 0 \\ i & 0 & \end{array}$

건

-

E

D)

เป็

$\stackrel{*}{*}+\frac{1}{0}$

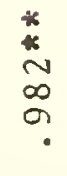

$\begin{array}{ll}* & * \\ \infty & 0 \\ 0 & 0\end{array}$

告

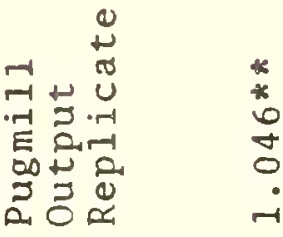
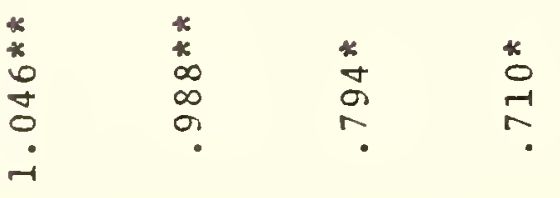

ᄋ

之
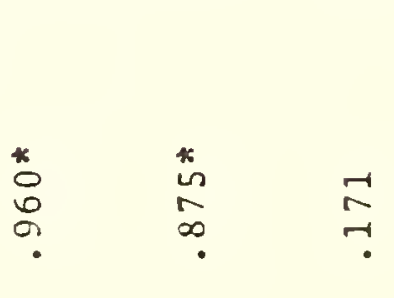

先

ह

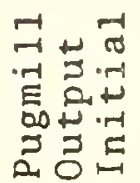

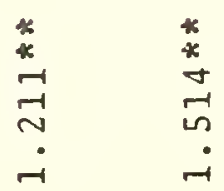

$\stackrel{*}{n}$

$\pi$

$\begin{array}{lll}-1 & -1 \\ 0 & 0 & 0 \\ 0 & 0 & 0\end{array}$

$\stackrel{*}{*} \underset{-1}{*} \quad *$

0
6
$?$

$\rightarrow-$

00

ॠ

$\stackrel{+}{\rightleftarrows}$

ชิ

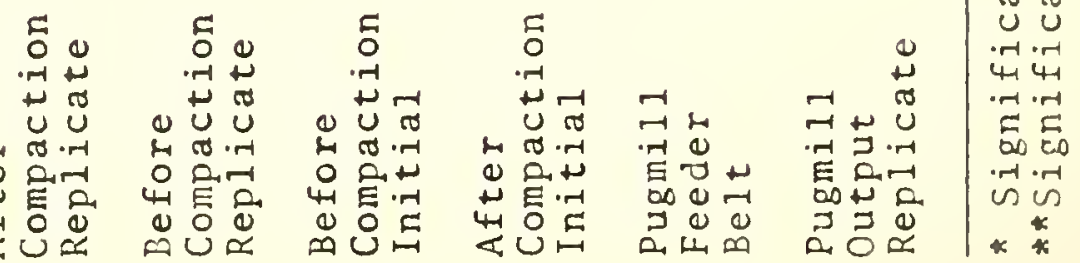


above indicates that segregation of fine material occurs as a result of transportation and spreading.

Since no samples were obtained between the transportation handling process and the spreading process, no specific conclusions can be reached to depict which handling process was responsible for the segregation. However, by observing the results of the other sieve sizes analyzed, the spreading operation would indicate a greater portion of the responsibility than the transportation handling phase. The material in the truck bed is in the form of a cone pile during transportation. As a result, the larger particles should flow to the sides of the truck. If this were the case segregation for the upper sieve values should have resulted. Since the material had water added to it in the pugmill, this flow of larger particles did not occur to a significant degree.

After the trucks arrived at the jobsite, they usually waited before dumping their load of aggregate because of other trucks ahead of them. Days of high temperature would have a definite drying effect upon the aggregate; the smaller particles would be mostly affected by this drying. As noted previously, an auger device is used to distribute the aggregate after it is dumped into the spreader box of the CMI spreader. The finer dry particles could possibly have been segregated by this auger operation. 
The No. 30 sieve appeared to give the first indication of segregation. The material continued to be coarser for the pugmill output and a significant difference between the pugmill output and al1 other sampling points occurred. Even though segregation remained questionable at this point, the means of the test values had developed a consistent order of rank. The material on the jobsite was finer than the material at the producer's plant. The arithmetic means of the sampling points after compaction enclosed the before compaction means which indicated no change in the material after spreading. Since the pugmill sample initial revealed a significant difference with other sampling points and due to the established order of mean rank, the No. 30 sieve can be depicted as a critical transition point for segregation.

\section{Effects of Sampling Positions}

A most difficult task of quality control of highway material is the determination of appropriate sampling positions. As previously discussed in this report, the handling processes of aggregates used in bases have a definite effect upon the final product. Furthermore some sampling positions give a better indication of the final material than others.

The most appropriate sampling point for base material is, of course, after compaction. This is the only position at which the actual gradation of material in use is 
obtained. The difficulty of sampling at this point, however, is a hinderance.

Based on the findings of this report, equally as good samples for aggregate gradation purposes were obtained before compaction as after compaction. Samples could be obtained at this sampling point with much less difficulty and, based on the previous ranking of means, with less variation. This fact is emphasized by reference to the sampling variances which increased as the material neared its final state.

Sampling the free-fall material as it fell from the pugmill bin is not desirable for prediction of the final product. When placing an individual in a truck bed and instructing him to catch a free-fall sample, the aggregate flow must be slightly reduced for his protection. Table 33 shows the means for each sampling position and sieve size. As previously noted, the results of samples obtained from the pugmill bin suggest material were consistently coarser than at other locations.

The results of this study suggest that samples obtained from the pugmill feeder belt give an excellent indication of the material in the compacted state. Scgregation on the No. 200 and possible No, 30 sieve contradict possible sampling at this point for final acceptance; however, for plant control purposes samples obtained here are sufficient and appear superior to other sampling points at the aggregate 
Do

.

U $N N N m m$

$4 \pi \cdot \pi$

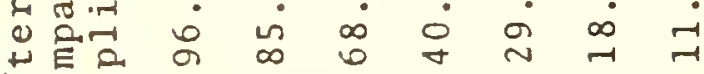

400

$\underset{\substack{n \\ N}}{0}$

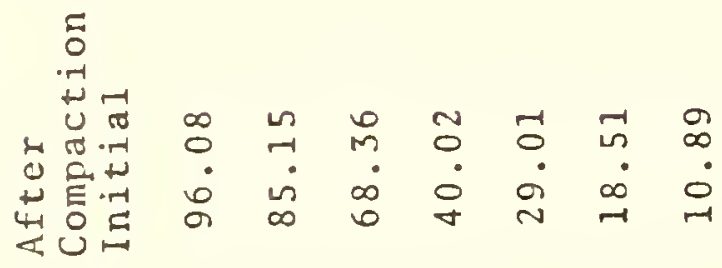

E.

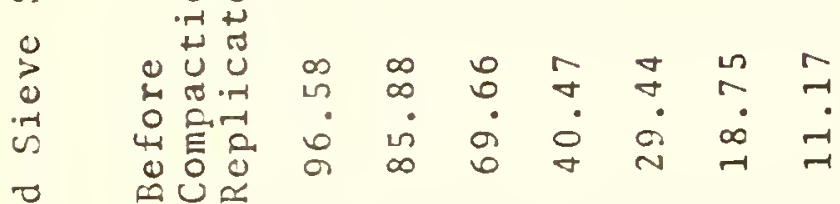

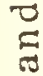

$\stackrel{-\pi}{0} \quad$ 赵

0

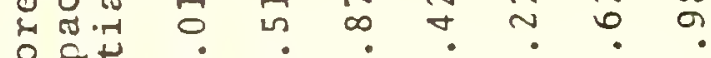

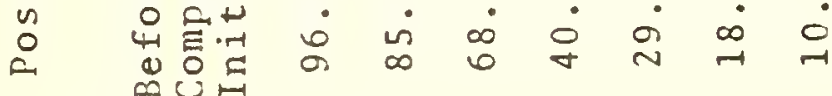

is

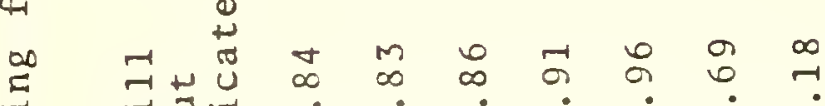
至苛年

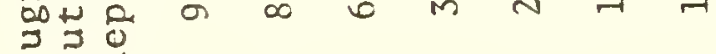

D म 0 ฉ

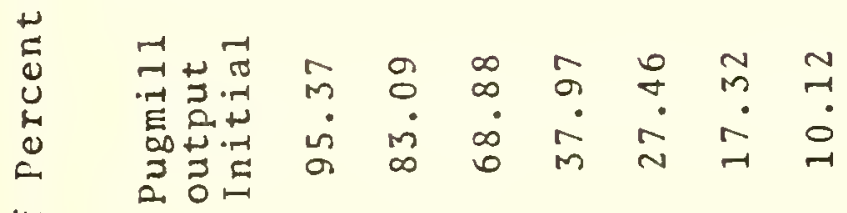

4

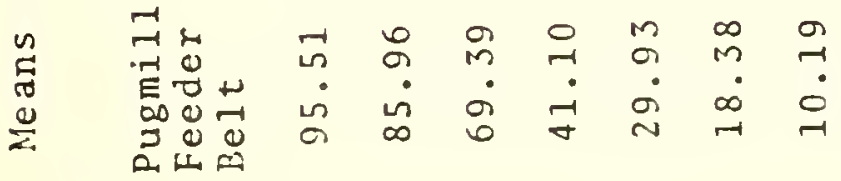

$\dot{m}$

$\frac{0}{2}$

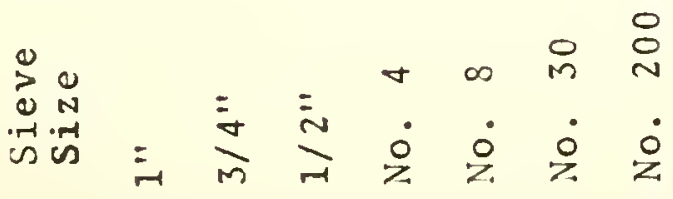


plant. Since no replicate samples were obtained from the belt, variance due to sampling could not be calculated; however the material variation and coefficients of variation were low at this position giving an indication of a low sampling variance. This point emphasizes the desirability of pugmill feeder belt sampling over other commonly used methods at the aggregate plant which often resemble stockpile sampling techniques. 
SUMMARY OF CONCLUSIONS

In this study the gradation variability of Indiana No. 53 pugmill mixed crushed limestone aggregates used in bases was investigated. The data were statistically analyzed for the purpose of determining gradation variability, uniformity within sampling points, and changes in gradation resulting from the handling phases between the aggregate plant stockpile and the in situ compacted base.

Following is a summary of the conclusions drawn from the statistical analysis of this study. These results apply to materials and processes used in the study.

1. Gradation variability within sampling points existed. This within variability can possibly be attributed to initial aggregate stockpile formation.

2. Some variation between sampling points, was noted. This variation, however was quite small and was probably due to material handling between the aggregate plant and before compaction. Changes in grain size distribution was statistically critical only for low sieve sizes, No. 30 and No. 200. Even so, the material changed little from point to point in the production stream. By ranking arithmetic means, an indication of changes in grading on the higher sieve sizes was evident, but not critical. 
3. Sampling points on the roadway before and after compaction indicated no change in the material. pugmill feeder belt samples at the aggregate plant were superior to other plant sampling points for final insitu compacted product prediction. Samples obtained from the pugmill bin output were coarser by approximately two percent. These coarser values were attributed to sampling technique. 


\section{RECOMMENDATIONS FOR FURTHER RESEARCH}

The following remarks are based upon the results presented in this report and observations made during the study.

Sample analysis was conducted by MASHO T11-60 and T27-60, Sieve Analysis of Fine and Coarse Aggregate. Comparisons were made between the standard AASHO method and AASHO T88-70 Grain Size Analysis of Soils. The results of tests using several variations of AASHO T88-70 were also compared to AASHO T11-60 and T27-60. Because of the excellent correlation obtained, further research concerning variations in testing methods is encouraged.

Jobsite sampling points were randomly selected for a defined quantity of material in this study. The effects of obtaining samples at different positions between the beginning and ending of the spread could be a contributing factor to variability of aggregate and should be a topic for future research. Furthermore, sampling positions across the road could contribute to variability of aggregate gradation. These possible causes were not discussed in the research findings due to a lack of consistent points to satisfy statistical conditions. 
Sample points at the producer's plant for this study were on the pugmill feeder belt and at the discharge of the pugmill output bin. Other points should be investigated. Possibilities would be more in depth truck bed sampling than has previously been done, full pugmill bin discharge sampling, and the sampling of a dumped load immediately after it had been loaded by pugmill bin discharge.

A primary purpose of this study was to give an indication of change in aggregate gradation during the material handling process. No attempt was made to evaluate the effect of this change on performance of highways in service. Further research is recommended dealing with the effect of a material gradation change on performance. 
BI BL IOGRAPHY 
1. Aughenbaugh, N. B., Johnson, R. B., Yoder, E. J., Degradation of Base Course Aggregates During Compaction, School of Civil Engineering, Purdue University, May, 1963.

2. Barber and Sawyer, "Highway Subdrainage", Proceedings, Highway Research Board, 1952.

3. Bureau of Public Roads, "The Statistical Approach to Quality Control in Highway Construction", April 1965.

4. Burmister, D. M., "The Grading-Density Relations of Granular Materials", Proc. American Society of Testing and Materials, Vol. 38, Part 2, pp. 587-601 (1938).

5. Chamberlain and Yoder, "Effects of Base Course Gradation on Results of Laboratory Pumping Tests", Proceedings, Highway Research Board, 1958.

6. Deklotz, "Effect of Varying the Quantity and Quality of the Soil Portion of Highway Aggregates on Their Stability", Proceedings, Highway Research Board, 1940.

7. Indiana State lighway Commission "Standard Specifications", 1969 .

8. Majidzadeh, $k$. and Brahma, C. S., "Statistical Analysis of Aggregate Size Distribution", The Ohio State University Department of Civil Engineering and Transportation Research Center, 1969.

9. "Manual for Aggregate Inspectors", Indiana State Highway Commission, March 1969.

10. Miller Warden Associates, "Effects of Different Methods of Stockpile Sampling Interim Report", proceedings, Highway Research Board, 1964.

11. Miller Warden Associates, "Development of Guidelines for Practical and Realistic Construction Specifications. Interim Report", Proceedings, Highway Research Board, 1965.

12. Miller Warden Associates, "Evaluation of Construction Control Procedures, Interim Report", proceedings, Highway Research Board, 1967. 


\section{BIBLIOGRAPIIY (Continued)}

13. Ostle, Bernard, Statistics in Research, Second Edition, The Iowa State University Press, 1963.

14. Ritter, L. J., Jr., Paquette, R. J., Highway Engineering, Third Edition, The Ronald Press Company, 1967 .

15. Taylor, D. W., Soil Mechanics, John Wiley and Sons, Inc., pp. $111-1 \overline{23,1948 .}$

16. Teng, W. C., Foundation Design, Prentice-Ha11, Inc., pp. 3-26, 1962 .

17. Williamson and Yoder, "An Investigation of Compaction Variability for Selected Highway Projects in Indiana", March 1967.

18. Yoder, F. J., "Principles of Pavement Design", John Wiley and Sons, Inc., pp. 283-314, 1959. 
APPENDIX 


\section{APPENDIX}

Truck Sampling Device

The truck sampling device designed for obtaining a free fall sample from the pugmill output is shown in Figure 31. This device was designed to rest on rollers supported by the truck side boards. Two handicaps resulted in the elimiantion of this technique.

First the sampling device was too heavy for the individuals working at the producer's plant to handle safely. Second, the side boards of the trucks on which the device rested were non-uniform. As a result, the device would not be used as designed.

Both of these handicaps could possibly be overcome by mounting rails on the pugmill super structure for the device to rest. The sampling device would then not have to be handled, nor would non-uniform side boards affect its use. Because the device could sample anytime during a truck's loading and sample during full pugmill discharge, samples taken by it could easily meet requirements for random sampling. 

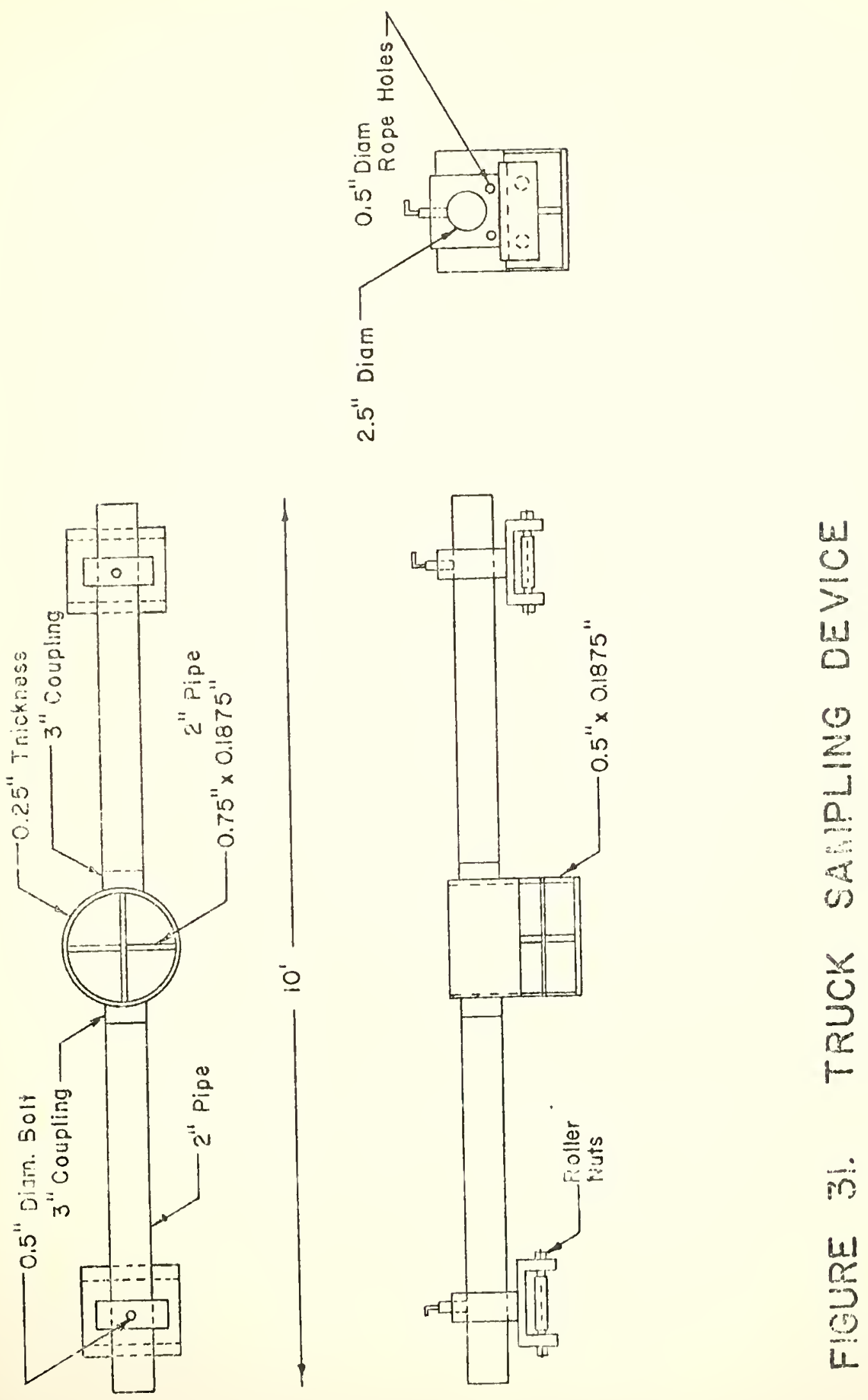

ris

$\frac{41}{95}$ 

